\title{
TROPOSPHERIC CLOUDS IN ANTARCTICA
}

\author{
David H. Bromwich, ${ }^{1,2}$ Julien P. Nicolas, ${ }^{1,2}$ Keith M. Hines, ${ }^{1}$ Jennifer E. Kay, ${ }^{3}$ Erica L. Key, ${ }^{4}$ \\ Matthew A. Lazzara, ${ }^{5}$ Dan Lubin, ${ }^{6}$ Greg M. McFarquhar, ${ }^{7}$ Irina V. Gorodetskaya, ${ }^{8}$ \\ Daniel P. Grosvenor, ${ }^{9,10}$ Thomas Lachlan-Cope, ${ }^{11}$ and Nicole P. M. van Lipzig ${ }^{8}$
}

Received 1 May 2011; revised 18 October 2011; accepted 18 October 2011; published 12 January 2012.

[1] Compared to other regions, little is known about clouds in Antarctica. This arises in part from the challenging deployment of instrumentation in this remote and harsh environment and from the limitations of traditional satellite passive remote sensing over the polar regions. Yet clouds have a critical influence on the ice sheet's radiation budget and its surface mass balance. The extremely low temperatures, absolute humidity levels, and aerosol concentrations found in Antarctica create unique conditions for cloud formation that greatly differ from those encountered in other regions, including the Arctic. During the first decade of the 21 st century, new results from field studies, the advent of cloud observations from spaceborne active sensors, and improvements in cloud parameterizations in numerical models have contributed to significant advances in our understanding of Antarctic clouds. This review covers four main topics: (1) observational methods and instruments, (2) the seasonal and interannual variability of cloud amounts, (3) the microphysical properties of clouds and aerosols, and (4) cloud representation in global and regional numerical models. Aside from a synthesis of the existing literature, novel insights are also presented. A new climatology of clouds over Antarctica and the Southern Ocean is derived from combined measurements of the CloudSat and Cloud-Aerosol Lidar and Infrared Pathfinder Satellite Observation (CALIPSO) satellites. This climatology is used to assess the forecast cloud amounts in 20th century global climate model simulations. While cloud monitoring over Antarctica from space has proved essential to the recent advances, the review concludes by emphasizing the need for additional in situ measurements.

Citation: Bromwich, D. H., et al. (2012), Tropospheric clouds in Antarctica, Rev. Geophys., 50, RG1004, doi:10.1029/2011RG000363.

\section{INTRODUCTION}

[2] Understanding Antarctic clouds and properly representing them in climate models is paramount to ensure the realism of future climate projections in high southern lati-

\footnotetext{
${ }^{1}$ Polar Meteorology Group, Byrd Polar Research Center, Ohio State University, Columbus, Ohio, USA.

${ }^{2}$ Atmospheric Sciences Program, Department of Geography, Ohio State University, Columbus, Ohio, USA.

${ }^{3}$ Climate and Global Dynamics Division, National Center for Atmospheric Research, Boulder, Colorado, USA.

${ }^{4}$ Arctic Division, Office of Polar Programs, National Science Foundation, Arlington, Virginia, USA.

${ }^{5}$ Antarctic Meteorological Research Center, Space Science and Engineering Center, University of Wisconsin-Madison, Madison, Wisconsin, USA.

${ }^{6}$ Scripps Institution of Oceanography, University of California, San Diego, La Jolla, California, USA.

${ }_{7}^{7}$ Department of Atmospheric Sciences, University of Illinois at Urbana-Champaign, Urbana, Illinois, USA.

${ }^{8}$ Department of Earth and Environmental Sciences, K.U. Leuven, Heverlee, Belgium.

${ }^{9}$ Centre for Atmospheric Science, SEAES, University of Manchester, Manchester, UK.

${ }^{10}$ Now at Department of Atmospheric Sciences, University of Washington, Seattle, Washington, USA.

${ }^{11}$ British Antarctic Survey, Cambridge, UK.
}

tudes. As the source of precipitation, clouds are integral to the replenishment of the Antarctic Ice Sheet by snowfall and, thus, to its state of equilibrium and contribution to global mean sea level. Through their shortwave and longwave radiative properties, clouds influence the temperature of the atmosphere. This, in turn, can have direct effects on the cryosphere when temperatures reach the melting point or through changes in the atmospheric moisture content (ClausiusClapeyron law) and their possible impact on snowfall. Similarly, clouds exert important control over the heat and freshwater budgets of the Southern Ocean, a key component of the global ocean circulation and global carbon cycle. Furthermore, modeling studies have shown that changes in cloud properties over Antarctica may impact regions of the globe well beyond high southern latitudes [Lubin et al., 1998].

[3] The first decade of the 21st century has seen the growing realization that clouds play a critical role in the climate system and that much is still unknown about their properties and response to climate change [e.g., Stephens, 2005; Solomon et al., 2007; Dufresne and Bony, 2008]. This statement is particularly true for the Antarctic region given the paucity of cloud observations. Some integrated 
efforts such as the Global Energy and Water Experiment (GEWEX) Cloud System Study (http://gcss-dime.giss.nasa. gov/) have fostered cloud-related research and field programs. While polar clouds have been an integral component of this initiative, the emphasis has been largely placed on the Arctic region, with relatively little effort in the Antarctic.

[4] Although commonly grouped under the same "polar" attribute, the Arctic and Antarctic regions exhibit stark contrasts in their respective geography, climate, and atmosphere and, therefore, also in their cloud characteristics. With its extremely low temperatures and specific humidity and its pristine atmosphere, Antarctica represents a unique environment for cloud formation. Like other aspects of the Antarctic climate, our current knowledge of clouds in this region is mostly tied to the sparse network of staffed stations with, in particular, little insight into clouds over the Antarctic interior. Further, the limitations of cloud observations based upon satellite passive visible-infrared measurements have represented a significant challenge to investigations of clouds in high southern latitudes.

[5] An overview of Antarctic clouds was given by King and Turner [1997] as part of a comprehensive description of the climate of Antarctica. These results were essentially based on (1) limited records of conventional cloud observations from Antarctic stations and (2) early versions of satellite passive cloud retrievals. A recent short review by Lachlan-Cope [2010] has provided additional insight into clouds' microphysical properties (phase, size, and shape of cloud particles).

[6] A new era began, undoubtedly, in the early and mid2000 s with the launch of active cloud sensors mounted on polar-orbiting satellites. These observations have allowed for more reliable cloud detection over the ice sheet and Southern Ocean, a three-dimensional perspective on cloud distribution, and information about cloud microphysical properties with an unprecedented spatial coverage.

[7] The impetus for the present review stems from the International Workshop on Antarctic Clouds, held in July 2010 at the Byrd Polar Research Center of The Ohio State University. The workshop participants recognized that, indeed, substantial progress had been accomplished over the last decade but that many questions remain unanswered. As a result, in anticipation for future research efforts, the present review aims to provide an up-to-date synthesis of our knowledge of clouds in Antarctica. As indicated in the title, the main focus is on clouds within the troposphere, although stratospheric clouds are also briefly discussed in several places.

[8] The paper addresses successively the four following questions.

[9] 1. What instruments and methods are used to observe Antarctic clouds, and what are the main cloud data sets currently available? (section 2).

[10] 2. What is the typical spatial distribution of clouds over Antarctica and the Southern Ocean, and how does it vary seasonally and on longer time scales? (section 3 ).

[11] 3. What is known about the microphysical properties of Antarctic clouds, including those of aerosols serving as condensation nuclei? (section 4).
[12] 4. How, and how well, are Antarctic clouds represented in current climate models? (section 5).

[13] The conclusion (section 6) summarizes the remaining challenges and proposes future research directions. A map of Antarctica (Figure 1) shows the regions and locations referred to throughout the paper. A list of acronyms is given in Table 1.

\section{OBSERVATIONAL METHODS}

[14] To first order, the understanding of Antarctic clouds comes from direct observations. The variety of observed properties can in turn be applied toward empowering numerical and climate models as well as directly improving weather forecasting. Antarctic clouds can be examined from the point of view of the surface as well as from airborne and space-based platforms. Observational studies are beginning to capture the basic characteristics and trends that serve as our basis for understanding Antarctic clouds. These studies are, however, nowhere near as extensive as studies in most other regions. This section offers an overview of the methods that have been and are being used to study Antarctic clouds.

\subsection{Surface-Based Observations}

[15] Observations of cloud fraction, cloud type, and cloud base (or cloud ceiling) are commonly reported at staffed stations around the Antarctic. Summer season provides the densest data coverage, as most stations and research field camps are actively measuring at this time of year. Austral winter sees a reduction in visual cloud observations as summer stations close, and some year-round stations reduce the observing frequency from three to six hourly periods. Visual observations of clouds from the surface are aided, where possible, by measurements from ceilometers (Figure 2). These instruments employ a pulsed diode laser at nearinfrared wavelengths to provide a vertical backscatter profile, from which information about cloud height or vertical visibility can be derived. Cloud observations are coded, per World Meteorological Organization standards [e.g., World Meteorological Organization, 1995] and transmitted to the global telecommunications system for distribution. These observations are, in many cases, primarily made to support logistical operations in the Antarctic, yet they do have the ability to provide basic information about clouds around the Antarctic. These observations have been utilized directly to understand Antarctic clouds [e.g., Kirchgäßner, 2010] as well as to determine when clouds interfere with other surfacebased observations of the upper atmosphere [e.g., McCarthy et al., 2007; Balsamo et al., 1997].

[16] An extensive compilation of conventional cloud observations was first produced by Warren et al. [1986, 1988] on the basis of records from land stations (19711981) and ship reports (1930-1981). This data set has since been updated through 1996 [Hahn and Warren, 2003]. It includes the records from 27 stations poleward of $60^{\circ} \mathrm{S}$, not all of them continuously operated throughout the period. Most of the stations are located on the coast of Antarctica 


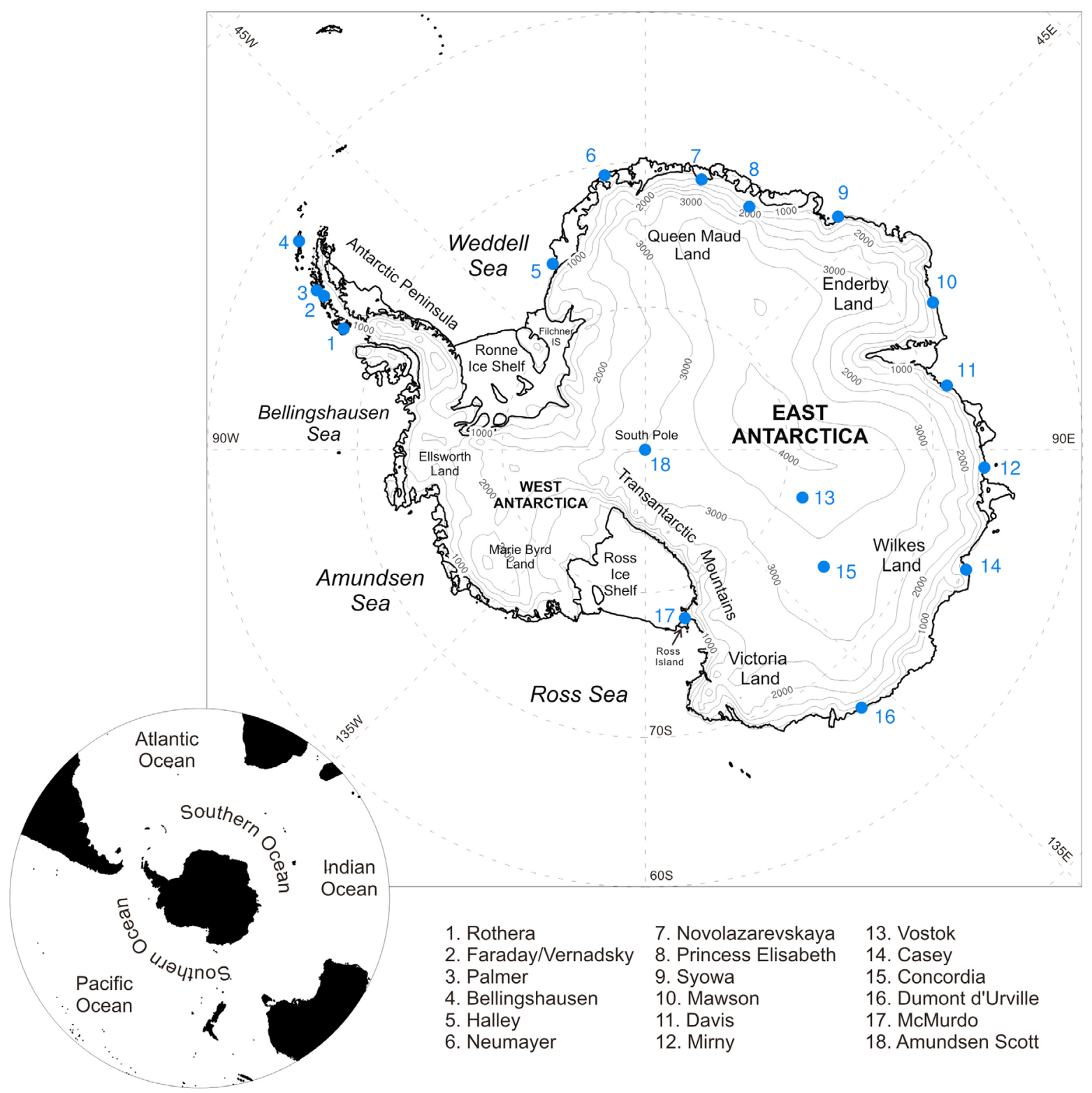

Figure 1. Map of Antarctica with topographic contours at $500 \mathrm{~m}$ intervals. The blue circles show the locations of some of the main staffed stations currently in operation, with their names listed below the map.

(Figure 1), the number of stations varying with time and season. This compilation has provided the first insight into the climatology of Antarctic clouds. However, with such a small sample of sites over such a large area, the observations' broader applicability is limited and underevaluated. Furthermore, visual cloud observations have been shown to underestimate the average cloud amount at night, which is of particular concern in high-latitude regions owing to the absence of sunlight during half of the year [Hahn et al., 1995; Town et al., 2007].

[17] To garner more detailed in situ information about clouds (e.g., phase, particle size, vertical distribution), additional surface-based observations have been made using a variety of remote sensing methods, involving both active and passive instruments. Digital cameras have been tested to observe cloud cover [Souza-Echer et al., 2006]. During the South Pole Atmospheric Radiation and Cloud Lidar Experiment (SPARCLE), direct physical measurements of clouds, including cloud particles, were made from the ground via tethered balloon [Walden et al., 2001; Town et al., 2005]. Ground-based lidars have been utilized, such as the Micro Pulse Lidar (MPL), to study cloud height distributions and cloud thickness [Cacciani et al., 1997; Walden et al., 2001; Shiobara et al., 2003; Mahesh et al., 2005] or cloud microphysical properties [Del Guasta et al., 1993]. Cloud optical depth and transmittance of solar radiation have been determined from downward broadband solar irradiance using pyranometers [Fitzpatrick and Warren, 2004, 2005]. A combination of shortwave (pyranometer), longwave (Eppley pyrgeometer), and net 
TABLE 1. List of Acronyms

\begin{tabular}{|c|c|}
\hline Acronym & Meaning \\
\hline AMPS & Antarctic Mesoscale Prediction System \\
\hline APP-x & AVHRR Polar Pathfinder extended \\
\hline AR4 & IPCC Fourth Assessment Report \\
\hline asl & above sea level \\
\hline AVHRR & advanced very high resolution radiometer \\
\hline AWS & automatic weather station \\
\hline BAS & British Antarctic Survey \\
\hline BSRN & Baseline Surface Radiation Network \\
\hline CALIOP & Cloud Aerosol Lidar with Orthogonal Polarization \\
\hline CALIPSO & $\begin{array}{l}\text { Cloud-Aerosol Lidar and Infrared Pathfinder } \\
\text { Satellite Observations }\end{array}$ \\
\hline CAS & Cloud Aerosol and Spectrometer \\
\hline $\mathrm{CCM}$ & community climate model \\
\hline $\mathrm{CCN}$ & cloud condensation nuclei \\
\hline CIP & Cloud Imaging Probe \\
\hline CIWP & cloud ice water path \\
\hline CLWP & cloud liquid water path \\
\hline $\mathrm{CN}$ & condensation nuclei \\
\hline CPR & cloud profiling radar \\
\hline DMS & dimethyl sulfide \\
\hline FSSP & forward scattering spectrometer probe \\
\hline FTIR & Fourier transform infrared radiometer \\
\hline GCM & global climate model \\
\hline GLAS & Geoscience Laser Altimeter System \\
\hline HM & Hallett-Mossop (process) \\
\hline ICESat & Ice, Cloud, and land Elevation Satellite \\
\hline IN & ice nuclei \\
\hline IPCC & Intergovernmental Panel on Climate Change \\
\hline ISCCP & International Satellite Cloud Climatology Program \\
\hline LES & large eddy simulation \\
\hline MLD & mixed-layer depth \\
\hline MODIS & Moderate Resolution Imaging Spectroradiometer \\
\hline MPL & Micro Pulse Lidar \\
\hline MSA & methanesulfonate \\
\hline NCAR & National Center for Atmospheric Research \\
\hline NOAA & National Oceanic and Atmospheric Administration \\
\hline NWP & numerical weather prediction \\
\hline PAERI & Polar Atmospheric Emitted Radiance Interferometer \\
\hline POAM & Polar Ozone and Aerosol Measurement \\
\hline PolarLAPS & Polar Limited Area Prediction System \\
\hline PSC & polar stratospheric cloud \\
\hline RH & relative humidity \\
\hline RSV & research and supply vessel \\
\hline SAM & Stratospheric Aerosol Measurement \\
\hline SeaWIFS & Sea-viewing Wide Field-of-view Sensor \\
\hline trc & raw cloud transmittance \\
\hline WRF & Weather Research and Forecasting (model) \\
\hline
\end{tabular}

radiation (pyradiometer) time series have been analyzed to determine the influence of clouds on the surface radiation balance [Nardino and Georgiadis, 2003]. Cloud studies are currently underway that merge information from active and passive sensors, for example, ceilometer, infrared pyrometer, and vertically pointing precipitation radar in Queen Maud Land [Gorodetskaya et al., 2010]. The infrared pyrometer measures the downward thermal emission in the 8-13 $\mu \mathrm{m}$ atmospheric window (clouds dominate the signal while the emissions from water vapor and $\mathrm{CO}_{2}$ are minimized). The radiation flux is converted to the equivalent blackbody brightness temperature. The vertical profile of equivalent radar reflectivity from the $24 \mathrm{GHz}$ Doppler radar is used for detection of snowfall depth and intensity [Kneifel et al., 2011].

[18] A Fourier transform infrared (FTIR) spectroradiometer and Polar Atmospheric Emitted Radiance Inter- ferometer (PAERI) have been used to measure cloud optical and radiative properties. These two instruments measure the downward radiation over a set of spectral intervals (e.g., 500-1800 $\mathrm{cm}^{-1}, 800-1200 \mathrm{~cm}^{-1}, 1800-3030 \mathrm{~cm}^{-1}$, etc.). Ultraviolet measurements, historically available at some stations, have supported the use of the FTIR for cloud studies in the Antarctic Peninsula [Lubin, 2004]. The FTIR has also been used at South Pole Station to determine cloud base heights in the Antarctic troposphere using a method originally designed for estimating cloud top heights [Mahesh et al., 2001a]. PAERI, FTIR, radiosonde, and surface pyrgeometer observations have been combined to study fractional cloud cover over South Pole Station [Town et al., 2005, 2007] (see section 3.1.4).

\subsection{Airborne Measurements}

[19] Direct measurements of clouds from aircraft platforms are essential to complement ground-based observations as they provide direct cloud samples (Figure 3). Because of the logistical challenge of operating such aircraft in Antarctica, airborne observations remain relatively limited and have only taken place during the austral summer.

[20] Several campaigns have been undertaken over the Antarctic Peninsula and in the Ross Sea sector of the continent. One program involved sampling low stratus clouds near Ross Island and McMurdo Station, using cloud water collection probe, cloud condensation nucleii spectrometer,

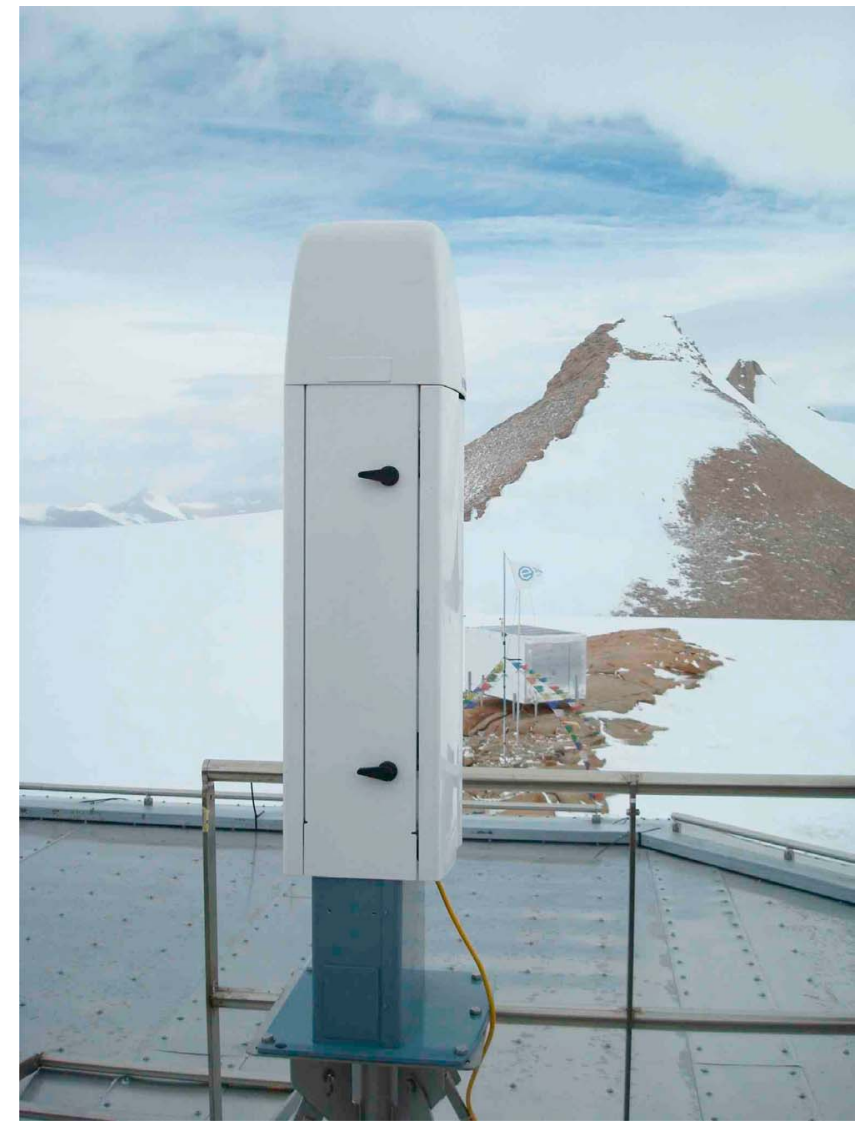

Figure 2. Ceilometer at Princess Elizabeth Station, Antarctica. 


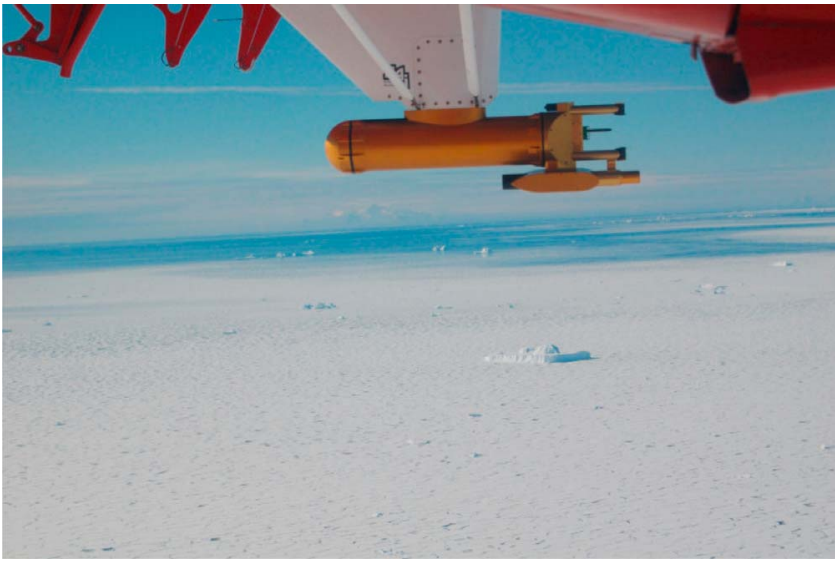

Figure 3. An airborne cloud probe mounted on a British Antarctic Survey aircraft observing clouds over the Antarctic Peninsula.

and forward scattering spectrometer probe (FSSP) instrumentation to collect cloud particles and measure their size and distribution [Saxena, 1983; Saxena and Ruggiero, 1990b]. Samples collected during the flight were examined through electron microscope to determine the cloud condensation and ice nuclei of the cloud particles found in the sample. During January 1986, measurements from a downward-viewing lidar mounted on a supply aircraft were carried out during a series of flights between McMurdo Station and the South Pole, revealing the vertical cloud structure along the flight track [Morley et al. 1989]. Additional recent airborne studies, especially in the Antarctica Peninsula region, have been or are presently being conducted [Lachlan-Cope et al., 2001; Lachlan-Cope, 2010]. Section 4.3.3 gives some details on one of these campaigns.

\subsection{Satellite Remote Sensing}

[21] Meteorological satellites first flew over the Antarctic in 1960, with the launch of Television and Infrared Operational Satellite (TIROS-1), the world's first weather satellite. However, usable and routinely available satellite observations applied to the Antarctic only came over the next decade [Lazzara et al., 2003]. With multiple daily passes over high latitudes, a polar-orbiting platform has been, and remains, the prime satellite type able to offer the best information over the continent itself. Both active and passive remote sensing methods have been employed to investigate Antarctic cloud systems. Some efforts, while global in scale, have included analysis over the Antarctic, while others are focused on the Antarctic itself. An overview of cloud detection from space can be found in the work by Stephens and Kummerow [2007] and Kokhanovsky et al. [2011]. Additional details can be found in the comprehensive review of satellite remote sensing over the polar regions given by Lubin and Massom [2006] and Massom and Lubin [2006].

\subsubsection{Satellite Passive Observations}

[22] Cloud detection algorithms based on passive visibleinfrared (VIS-IR) typically rely on the albedo and thermal contrast between clouds and the background (Earth's surface). In polar regions, these algorithms face three important challenges: (1) the "white on white" problem in the VIS spectral range because of the very similar albedo of cloud top and the snow- or ice-covered surface, (2) the "cold on cold" problem in the IR spectral range enhanced by the frequent and strong surface temperature inversion, and (3) the absence of sunlight during the winter months. An overview of several VIS-IR cloud detection schemes is given by Thomas et al. [2004].

[23] The largest sample of passive VIS-IR observations has been provided by the advanced very high resolution radiometer (AVHRR), flown from 1978 onward on the NOAA satellite series as part of the Polar Operational Environmental Satellite (POES) program. Cloud distribution in the Antarctic from AVHRR data and radiation measurements at the surface have been investigated on the high polar plateau at Dome Fuji Station [e.g., Yamanouchi et al., 1987, 2000]. An operational real-time cloud detection scheme of clouds was developed using observations from AVHRR over Antarctica [Turner et al., 2001] for use on the Antarctic Peninsula. Additional studies have been done over the Antarctic using the AHVRR, including one developed for the automated detection of sea ice, which had the added success of determining high and low clouds in addition to land and sea ice [Williams et al., 2002]. Distributions of mesoscale cyclones have been analyzed from AVHRR over portions of the Antarctic [Carrasco et al., 2003].

[24] AVHRR observations over polar regions, along with observations from geostationary satellites over lower latitudes, have been integrated in the first global analysis of clouds, the International Satellite Cloud Climatology Project (ISCCP) [Schiffer and Rossow, 1983, 1985; Rossow and Schiffer, 1999; Rossow and Duenas, 2004], which currently spans 1983-2009. Important efforts have been made to improve cloud detection over polar regions in the most recent version (D) of ISCCP cloud products [Rossow and Schiffer, 1999; Hatzianastassiou et al., 2001]. However, the ISCCP two-channel cloud detection scheme [Rossow and Garder, 1993] does not take full advantage of the five channels available on AVHRR sensors from 1982 onward (a sixth channel was added in 1998). All available channels from AVHRR have been used to produce the AVHRR Polar Pathfinder (APP) cloud data set, with an extended version (APP-x) currently available [Meier et al., 1997; Key, 2002]. Over the polar regions, APP-x was found to produce cloud fractions approximately $20 \%-30 \%$ higher than ISCCP [Pavolonis and Key, 2003; Thomas et al., 2004] and show better agreement with groundbased observations [Pavolonis and Key, 2003; Wang and Key, 2005]. However, Town et al. [2007] found that both the ISCCP and APP-x cloud masks show relatively little reliability over the East Antarctic plateau.

[25] Since 2000, additional VIS-IR observations have been obtained from the Moderate Resolution Imaging Spectroradiometer (MODIS) installed on the two polarorbiting Aqua and Terra satellites [Ackerman et al., 1998; Frey et al., 2008; Ackerman et al., 2008]. Its cloud masking 
algorithm employs measurements from 14 spectral bands (out of 36 available) with higher spectral resolution than AVHRR. Examples of MODIS cloud products are given in Figure 4. Liu et al. [2004] evaluated an early version of MODIS cloud mask over polar regions and found that
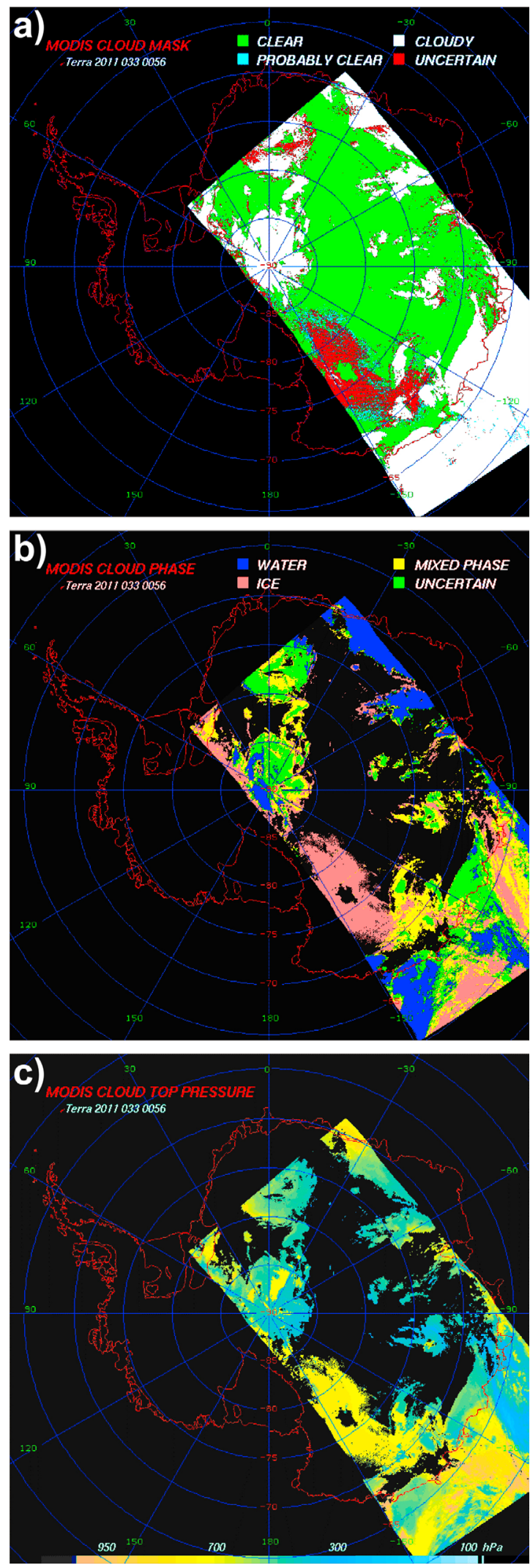

$40 \%$ of the clouds went undetected during the polar night. This nighttime bias as well as cloud detection over bright surfaces has been addressed by subsequent improvements to the cloud detection algorithm [Frey et al., 2008] and again in the early 2011 release of MODIS cloud products (http:// modis-atmos.gsfc.nasa.gov/_docs/Collection_051_Changes_v1. pdf). Yet even in recent versions of MODIS cloud products, cloud detection over sea ice and land ice remains challenging [Ackerman et al., 2008; Frey et al., 2008].

[26] A combination of VIS and IR observations from geostationary and polar orbiting satellites has been merged into a mosaic covering the Antarctic and providing a full cover of the adjacent Southern Ocean (Figure 5) [Lazzara et al., 2003; M. Lazzara and S. Knuth, Arctic and Antarctic satellite composite imagery, submitted to Polar Research, 2011]. While these composites are only available in a limited number of common spectral channels, they offer a synoptic depiction of the cloud systems around the Antarctic and Southern Ocean and have been used for weather forecasting, education, and deriving atmospheric wind vectors [Key et al., 2003; Lazzara et al., 2010].

[27] Cloud detection based on the AVHRR and MODIS sensors largely pertain to tropospheric clouds (up to $\sim 10 \mathrm{~km}$ in polar regions). These sensors are ineffective at detecting the tenuous polar stratospheric clouds (PSCs) that form over Antarctica in the core of winter. Instead, existing PSC climatologies over Antarctica originate mainly from solar occultation observations: those from the Stratospheric Aerosol Measurement (SAM) II onboard Nimbus 7 satellite [Poole and Pitts, 1994], and those from the Polar Ozone and Aerosol Measurement (POAM) II and III onboard the SPOT-3 and SPOT-4 satellites, respectively [Fromm et al., 1997, 2003]. The combined data sets provide more than two decades of PSC observations [Fromm et al., 2003]. The solar occultation technique measures how atmospheric constituents affect the transmission of sunlight through the Earth's atmosphere during the satellite "sunrise" and "sunset." One important caveat of this method is that these data only sample a slowly varying latitude, highest $\left(\sim 85^{\circ} \mathrm{S}\right)$ near the equinoxes and lowest $\left(\sim 65^{\circ} \mathrm{S}\right)$ near the solstices [Fromm et al. 2003]. Observations from spaceborne active instruments have considerably improved the detection of Antarctic PSCs.

\subsubsection{Satellite Active Remote Sensing}

[28] Active remote sensing techniques have largely overcome the limitations of the passive instruments in polar regions. Active instruments (e.g., radar and lidar) measure the properties (backscatter and polarization) of a signal emitted from space and reflected by the atmospheric con-

Figure 4. Sample MODIS Aqua/Terra satellite images from 2 February 2011 over the Antarctic depicting cloud properties: (a) cloud mask, (b) cloud phase, and (c) cloud top pressure. Figure courtesy of the Cooperative Institute for Meteorological Satellite Studies (CIMSS) and the Antarctic Meteorological Research Center, Space Science and Engineering Center, University of Wisconsin-Madison (AMRC/ SSEC/UW-Madison). 


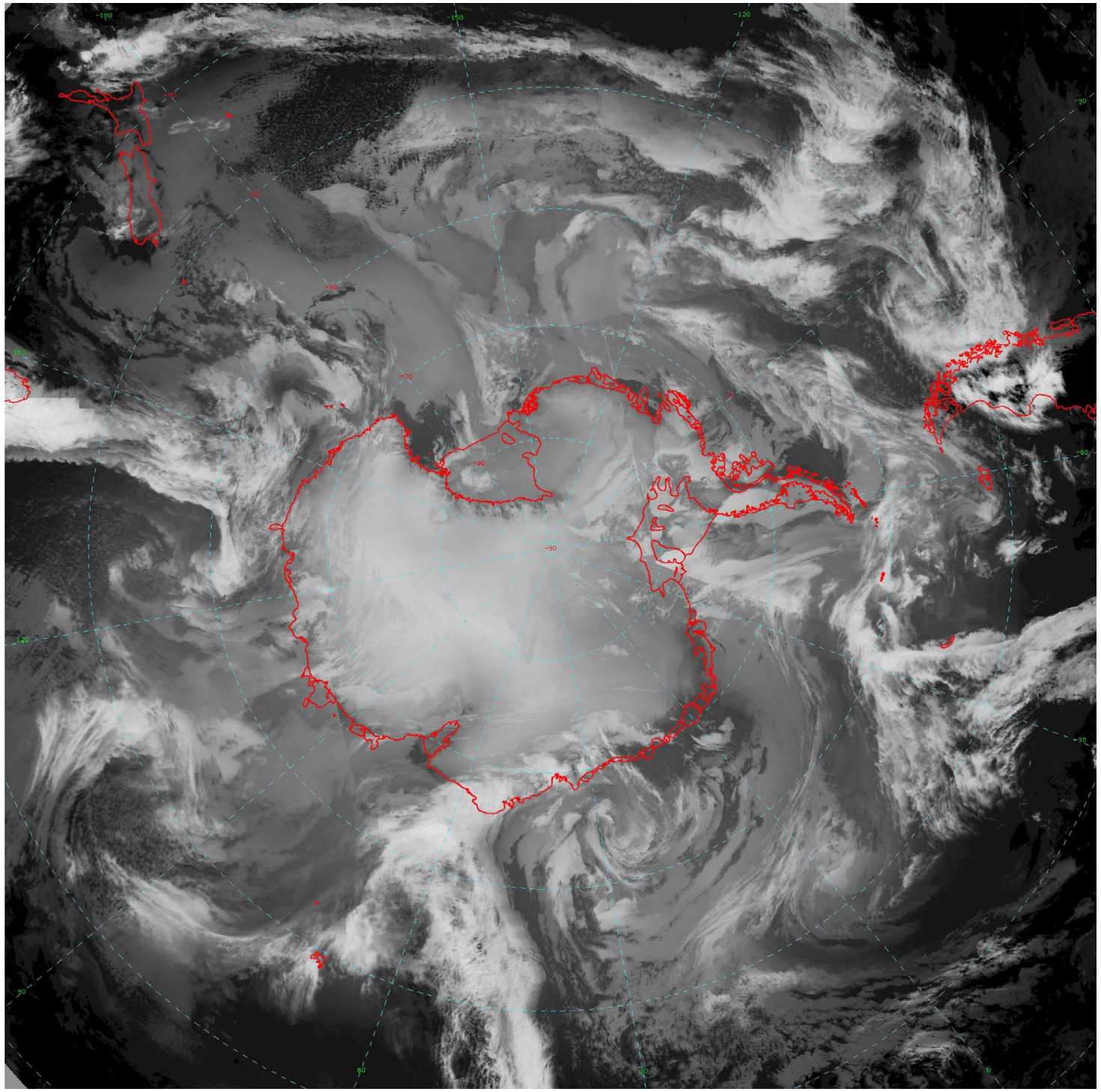

Figure 5. Antarctic infrared satellite composite from 20 January 2011 at 15:00 UTC showing clouds over the Antarctic and adjacent Southern Ocean. Figure courtesy of AMRC/SSEC/UW-Madison.

stituents (e.g., cloud particles) and by the Earth's surface. As such, the measured quantities are not affected by the presence of snow or ice on the surface or the absence of sunlight. This method has provided more accurate observations of clouds, which have often been used to gauge passive cloud observations [e.g., Naud et al., 2005]. One limitation of the active remote sensing technique lies in the narrow footprint of the sensors that allows only a reduced spatial sampling. For this reason, only monthly or seasonal statistics are meaningful.

[29] Cloud observations from active sensors began in January 2003 with the Geoscience Laser Altimeter System (GLAS) installed on NASA's Ice, Cloud, and land Elevation Satellite (ICESat) [Zwally et al., 2002; Stephens et al., 2002; Spinhirne et al., 2005a; Winker et al., 2007]. Operating at 532 and $1064 \mathrm{~nm}$, the GLAS lidar is sensitive to small cloud droplets and ice particles, in particular those from the tenuous layers of stratospheric clouds [Palm et al., 2005;
Spinhirne et al., 2005b; Dessler et al., 2006]. Unfortunately, because of technical deficiencies discovered shortly after the launch [Abshire et al., 2005], the GLAS lidar was operated only intermittently throughout the ICESat mission, which ended in 2010. GLAS data provided the first opportunity to validate satellite passive cloud retrievals with spaceborne active measurements over the polar regions [Mahesh et al., 2004; Ackerman et al., 2008]. Using GLAS observations, Spinhirne et al. [2005b] produced a map of monthly mean cloud frequencies over Antarctica and the Southern Ocean for October 2003.

[30] The second set of spaceborne active remote sensing data comes from the $94 \mathrm{GHz}$ cloud profiling radar (CPR) on the CloudSat satellite and from the Cloud-Aerosol Lidar with Orthogonal Polarization (CALIOP) lidar on the CALIPSO satellite (Figure 6). Both CloudSat and CALIPSO were launched in April 2006 and have been flying in formation within the A-train satellite constellation [Stephens et al., 


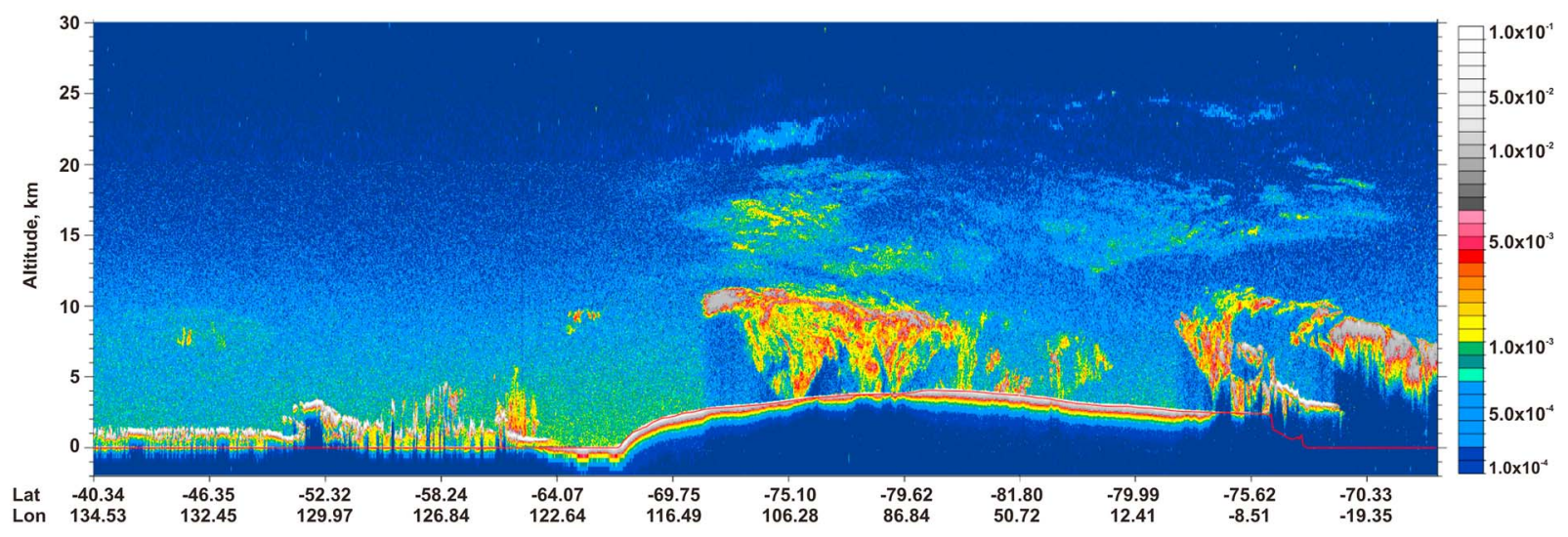

Figure 6. Total attenuated backscatter from CALIOP $532 \mathrm{~nm}$ lidar (in per kilometer per steradian) over Antarctica on 10 July 2008. Figure courtesy of NASA's Atmospheric Science Data Center, available at http://eosweb.larc.nasa.gov/.

2002]. CALIOP operates in similar wavelengths to GLAS but is also sensitive to the polarization of the $532 \mathrm{~nm}$ signal, which plays an important role for the retrieval of cloud microphysical properties [Grenier et al., 2009]. One important downside of the lidar is that its signal becomes attenuated by thick cloud layers. The radar, on the other hand, with a longer wavelength (a few millimeters) is sensitive to larger hydrometeors and can peer through thick clouds but is affected by reflection from the surface, or surface clutter [Grenier et al., 2009; Winker et al., 2010]. In order to take advantage of these complementary views of the atmosphere, joint CloudSat-CALIPSO products have been developed using collocated observations from the two sensors [Mace et al., 2009; Hagihara et al., 2010]. The individual swath cloud products have been used to derive monthly gridded cloud fraction data [Kay et al., 2008; Kay and Gettelman, 2009; Wang et al., 2008; Adhikari et al., 2010; Verlinden et al., 2011].

\subsubsection{Cloud Products and Terminology}

[31] In the literature, several expressions are commonly used to quantify the amount of clouds over a given area. Cloud fraction refers to the fractional area of the sky covered by clouds, as typically reported by surface synoptic observations [e.g., Hahn and Warren, 2003]. On the other hand, satellite cloud retrievals provide, in their most elementary spatial unit (e.g., pixel), only simple binary information; the sky is either "cloudy" or "clear," and the conditions are assumed to be homogeneous over the whole area covered by the pixel. If the spatial resolution of the cloud mask is high enough and the spatial coverage sufficient (as is typically in cloud masks based upon satellite passive VIS-IR measurements), cloud fraction statistics can be derived that can be directly compared with visual cloud observations.

[32] Active remote-sensing instruments, such as spaceborne radars and lidars, are characterized by a narrow field of view that allows only for a relatively low spatial sampling (especially over middle and low latitudes). From these observations, monthly cloud frequencies (or cloud incidences) can be derived from the ratio of the number of cloudy profiles detected by the sensor over a given area, over the total number of profiles. In theory, these cloud frequencies should equal the temporally averaged cloud fractions defined above if the conditions are horizontally homogeneous and the number of observations sufficiently large (see Wyser and Jones [2005] for additional discussion). These conditions are not generally observed in practice. A detailed description of two satellite-based cloud products (MODIS and CloudSatCALIPSO) is given below. These two data sets are among those used in section 3 to describe the climatological distribution of Antarctic clouds. The different "views" of clouds from these products may account for some of the differences seen in the cloud distributions.

[33] The MODIS monthly cloud fractions are based upon the MODIS instrument on Terra (averaged for daytime and nighttime) and correspond to the MODIS Level 3 cloud fraction product [Hubanks et al., 2008]. The MODIS $1 \times$ $1 \mathrm{~km}$ cloud mask estimates the probability for a pixel to be cloudy or clear and includes four categories: "confident cloudy," "probably cloudy," "probably clear," and "confident clear." The MODIS $5 \times 5 \mathrm{~km}$ Level 2 cloud fractions are derived by computing, in each $5 \mathrm{~km}$ box, the fraction of the $1 \mathrm{~km}$ pixels that are either "probably" or "confident" cloudy. The global gridded MODIS Level 3 cloud fractions are then computed as the average cloud fractions of all $5 \times$ $5 \mathrm{~km}$ pixels within $1^{\circ} \times 1^{\circ}$ latitude-longitude grid boxes.

[34] The CloudSat-CALIPSO monthly cloud frequencies are an updated version of the data set produced by Kay et al. [2008] and Kay and Gettelman [2009]. These monthly data are derived from the CloudSat radar cloud mask (2BGEOPROF) and the collocated CALIPSO lidar cloud mask (2B-GEOPROF-LIDAR). As noted in section 2.3.2, the two instruments sense the atmosphere in three dimensions but with different horizontal and vertical resolutions, the "volumes" sensed by the lidar being smaller than those sensed by the radar. In the CloudSat cloud mask, Kay et al. [2008] count the volumes as cloudy when the 2B-GEOPROF data equal 20, 30, or 40 (i.e., cloud detected with increasing level of confidence). As for the CALIPSO cloud mask, the 2B-GEOPROF-LIDAR product provides the fraction, $C_{f}$, of the radar volume that is identified as 
cloudy by the lidar. Kay et al. [2008] define this volume as cloudy for $C_{f}>1 \%$. In comparison, Verlinden et al. [2011] use a threshold value of $50 \%$ to separate between clear and cloudy volumes in the 2B-GEOPROF-LIDAR product. As shown in section 4 , the use of different threshold values likely accounts for differences in cloud amounts. Global gridded monthly cloud frequencies from CloudSat and CALIPSO are produced by computing the ratio of the number of cloudy profiles over the total number of profiles within $2^{\circ} \times 2^{\circ}$ latitude-longitude grid boxes.

\section{SPATIAL AND TEMPORAL VARIABILITY OF ANTARCTIC CLOUD COVER}

[35] This section describes the climatological distribution of clouds over Antarctica and the Southern Ocean and gives some perspectives on its long-term changes. Historically, some insight into the Antarctic cloud climatology has first been gained from cloud observations made at some Antarctic stations, which have been compiled into regional and global cloud data sets [Schwerdtfeger, 1970; Warren et al., 1986, 1988; Hahn and Warren, 2003]. While these observations constitute the longest cloud records, they are unfortunately restricted to a few locations, mostly on the coast of Antarctica. Since the early 1980s, cloud observations with a more complete spatial coverage have been obtained from VIS-IR sensors onboard polar-orbiting satellites. Yet these observations have inherent limitations over cold, ice-covered surfaces. Most recently, the joint CloudSat-CALIPSO data set has provided a more accurate and complete view of clouds. Antarctic cloud climatologies derived from this joint data set have been recently produced [Verlinden et al., 2011]. However, their time span is still limited ( $\leq 4$ years) and the CloudSat-CALIPSO monthly mean cloud fractions may be affected by the low spatial sampling of the radar and lidar instruments over the Southern Ocean (and lower latitudes). Thus, these various data sets have both strengths and limitations. They provide a composite picture of Antarctic cloud climatology in which some inconsistencies are still to be investigated.

\subsection{Antarctic Cloud Climatology}

\subsubsection{General Characteristics of Cloud Distribution}

[36] An overview of the spatial distribution of the mean seasonal total cloud fraction is presented in Figure 7, on the basis of the following data sets and periods: CloudSatCALIPSO (September 2006 to August 2010), ISCCP (December 2000 to November 2009), MODIS (March 2000 to February 2011), and visual observations (1971-1996) from the Hahn and Warren [2003] cloud climatology. The three satellite data sets are also used to compute the zonal-average total cloud fraction as a function of latitude (Figure 8). In Figure 8, the Western and Eastern hemispheres are shown separately to account for the asymmetry of the Antarctic continent (see Figure 1). A description of the different cloud data sets is given in Table 2 .

[37] The four data sets show a maximum in total cloud fraction over the Southern Ocean $\left(50^{\circ} \mathrm{S}-65^{\circ} \mathrm{S}\right)$, decreasing poleward and reaching a minimum over the East Antarctic plateau. The high degree of cloudiness of the Southern Ocean is linked to the abundance of synoptic and mesoscale depressions moving eastward around the Antarctic continent [King and Turner, 1997; Carrasco et al., 2003; Simmonds et al., 2003]. This intense cyclonic activity accounts for the minimum in sea level pressure known as the circumpolar pressure trough, seen in Figure 8. The latitudinal extent of the cloud maximum is broader than previously suggested by southern-hemisphere land station observations [King and Turner, 1997], likely as a result of the paucity of stations between $40^{\circ} \mathrm{S}$ and $60^{\circ} \mathrm{S}$.

[38] Over the ocean, MODIS exhibits the largest cloud amounts, with maxima around $95 \%$ in all seasons. These values are in good agreement with observations from the Antarctic island station, Orcadas $\left(60.7^{\circ} \mathrm{S}, 44.7^{\circ} \mathrm{W}\right)$, with an average cloud fraction of $92.7 \%$ in summer. Over the same latitudes, CloudSat-CALIPSO shows cloud fraction maxima within $80 \%-90 \%$. This difference with respect to MODIS may result from the reduced spatial sampling of the CloudSat-CALIPSO. In the Eastern Hemisphere, CloudSatCALIPSO and MODIS feature a well-defined cloud maximum at $\sim 60^{\circ} \mathrm{S}$, which corresponds to the latitude of greatest cyclone density around East Antarctica [Simmonds et al., 2003].

[39] By reducing the moisture fluxes into the atmospheric boundary layer, the presence of sea ice is associated with a reduction in cloud amounts by $10 \%-20 \%$ compared to the ice-free ocean. This lower degree of cloudiness is consistent with smaller cloud optical depths reported by Fitzpatrick and Warren [2005] within the sea-ice zone. The latter study (restricted to the East Antarctic sector of the Southern Ocean) also shows that clear sky and thin clouds occur, on average, twice as frequently near the Antarctic coast $\left(65^{\circ} \mathrm{S}-\right.$ $\left.70^{\circ} \mathrm{S}\right)$ compared to offshore $\left(55^{\circ} \mathrm{S}-60^{\circ} \mathrm{S}\right)$. Looking at the entire Southern Ocean in Figure 7, the impact of sea ice on cloudiness is particularly manifest over the Weddell and Ross seas.

[40] Several factors contribute to limiting the amount of clouds over Antarctica. Besides the extremely low temperatures and the reduced availability of moisture from surface sublimation, the ice sheet's steep coastal slopes also act as a dynamic barrier (conservation of potential vorticity) to the majority of depressions. Nevertheless, deep tropospheric systems can sometimes penetrate far inland and bring about enhanced cloudiness [Pook and Cowled 1999; Naithani et al. 2002; Massom et al., 2004; Nicolas and Bromwich, 2011]. Furthermore, the large-scale midtropospheric flow in high southern latitudes, with subsidence over Antarctica, is detrimental to cloud formation [James, 1989; Parish and Bromwich, 2007].

[41] Cloudiness decreases more rapidly along the coast of East Antarctica $\left(\sim 65^{\circ} \mathrm{S}\right)$, as a result of steeper coastal topography, higher average elevation, and lower temperatures compared to West Antarctica. The larger cloud amounts found over West Antarctica throughout the year illustrate that the greater ocean influence on the climate of this part of the ice sheet is consistent with greater snow 
DJF
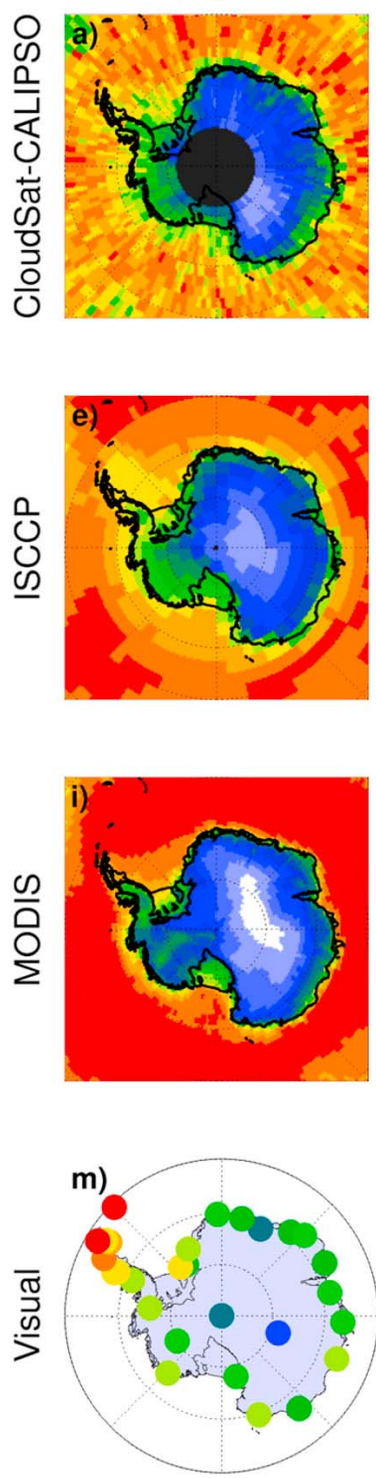

MAM
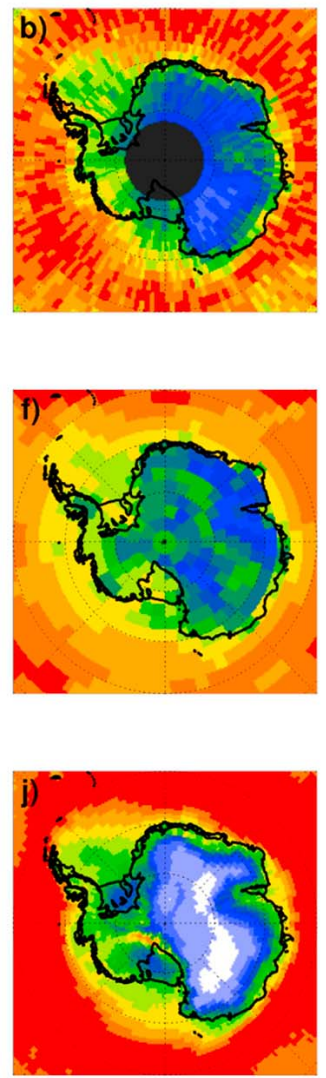

n)

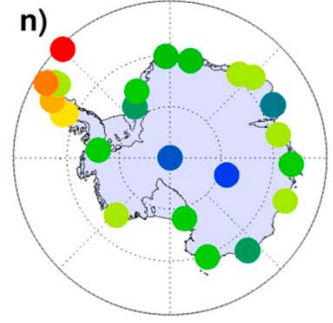

JJA
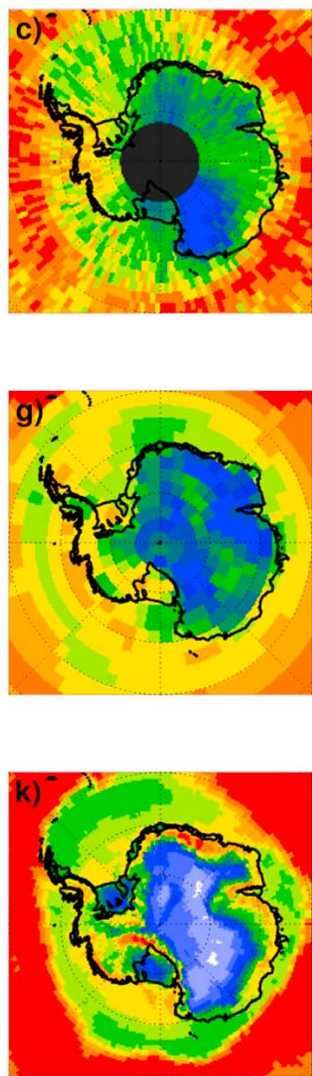

o)

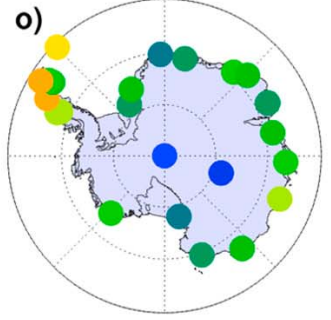

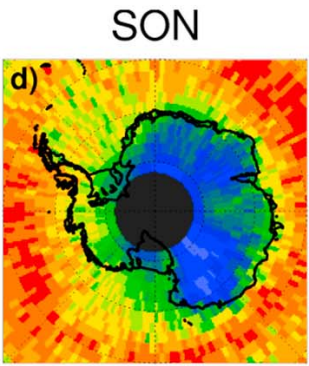
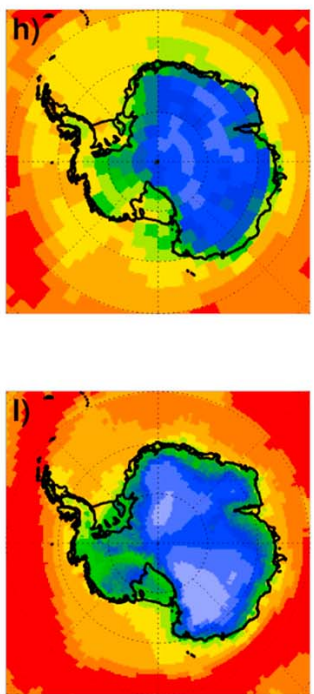

p)

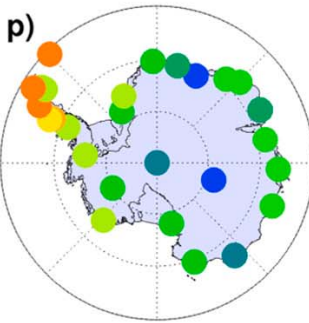

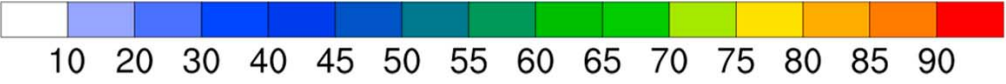

Figure 7. Mean seasonal cloud fraction for (a, e, i, m) summer (December-January-February (DJF)), (b, f, j, n) fall (March-April-May (MAM)), (c, g, k, o) winter (June-July-August (JJA)), and (d, h, l, p) spring (September-October-November (SON)) from the CloudSat-CALIPSO, ISCCP, MODIS, and visual observation monthly cloud data sets described in Table 2. The data span September 2006 to August 2010 for CloudSat-CALIPSO, December 2000 to November 2009 for ISCCP, and March 2000 to February 2011 for MODIS. For the visual observations, the maximum time span is 26 years (1971-1996) but varies among the stations.

accumulation [Bromwich et al., 2004; van de Berg et al., 2006; Arthern et al., 2006]. Repeated intrusions of maritime air have been shown to leave a characteristic tongue of greater cloudiness over central West Antarctica [Nicolas and Bromwich, 2011]. Manifestations of this "marine signature" can be clearly seen in MODIS seasonal cloud maps (Figure $7 \mathrm{k}$ ). Further linkages between the cloud distribution and the atmospheric circulation are discussed in section 3.1.3.

\subsubsection{Seasonal Variations in Total Cloud Fraction}

[42] Over the Southern Ocean equatorward of $60^{\circ} \mathrm{S}$ (the approximate northernmost extent of the sea-ice edge), the total cloud fractions from ISCCP and MODIS show little seasonal variability (Figures 8c-8f). Only CloudSat-CALIPSO shows a minimum in cloudiness occurring in summer $(\sim 5 \%$ lower than in winter). As suggested by Verlinden et al. [2011], this summertime minimum is consistent with the seasonality of the extratropical cyclone activity [see Simmonds et al., 2003]. 
WESTERN HEMISPHERE

(a)

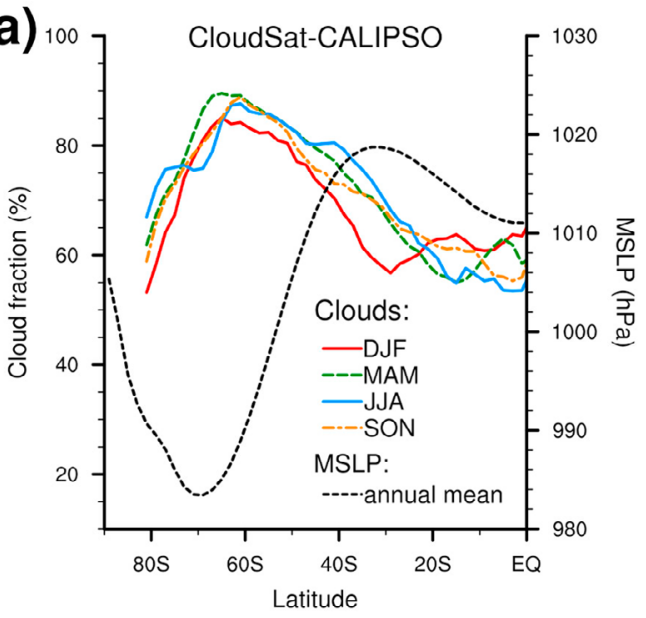

(c)

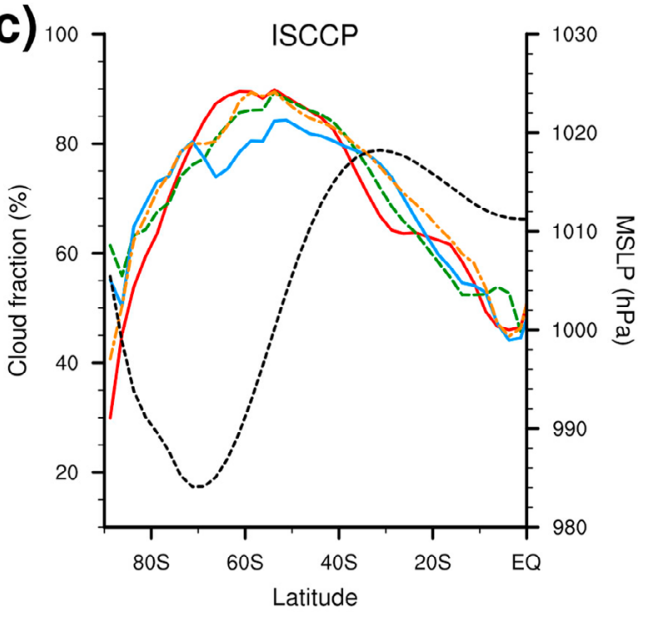

(e)

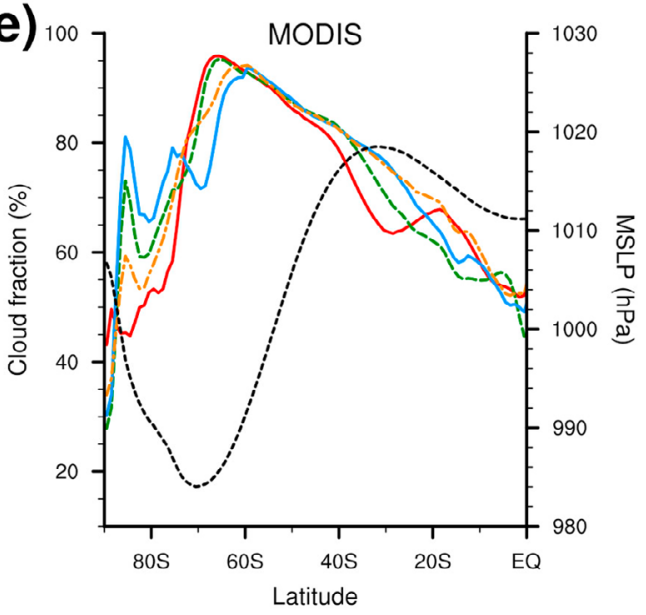

EASTERN HEMISPHERE
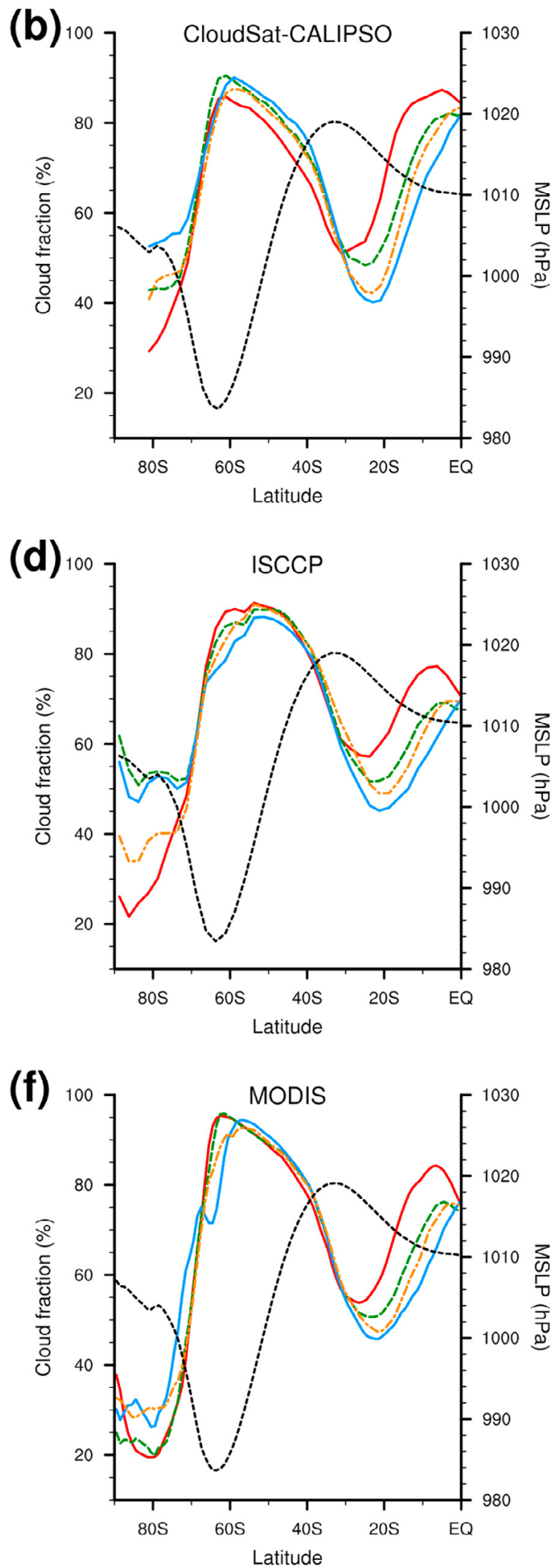

Figure 8. Colored lines are zonal-average mean seasonal cloud fraction in percent from $(a, b)$ CloudSatCALIPSO, (c, d) ISCCP, and (e, f) MODIS as a function of latitude $\left(90^{\circ} \mathrm{S}-0^{\circ}\right)$. The zonal averages are shown for the (left) western longitudes and (right) eastern longitudes. The temporal coverage of each data set is the same as in Figure 7. Black dashed line is the mean annual mean sea level pressure (MSLP) in hectopascals from the ERA-Interim reanalysis averaged over the same longitudes and time periods as the cloud fractions. For MSLP poleward of $\sim 70^{\circ} \mathrm{S}$, one must bear in mind the potential problems posed by the reduction of surface pressure to sea level over high elevated areas. 
TABLE 2. Characteristics of Monthly Cloud Data Sets

\begin{tabular}{|c|c|c|c|c|}
\hline Data Set/Instrument & Characteristics & Time/Space Coverage & Cloud Products & Reference/Documentation \\
\hline \multicolumn{5}{|c|}{ Satellite Passive Method } \\
\hline International Satellite & multisatellite; & July 1983 to & version D2; resolution is & Rossow and Schiffer [1999] \\
\hline Cloud Climatology Project & $\begin{array}{l}\text { NOAA/AVHRR } \\
\text { over polar regions; } \\
5 \text { IR/VIS channels }\end{array}$ & December 2009; global & $2.5^{\circ}$ latitude $\times 2.5^{\circ}$ longitude & \\
\hline MODIS (on Terra) & 36 IR/VIS channels & $\begin{array}{l}\text { February } 2000 \\
\text { to present; global }\end{array}$ & $\begin{array}{l}\text { collection } 5.1 \text {; resolution is } \\
1^{\circ} \text { latitude } \times 1^{\circ} \text { longitude }\end{array}$ & $\begin{array}{c}\text { Ackerman et al. [2008], } \\
\text { Frey et al. [2008] }\end{array}$ \\
\hline \multicolumn{5}{|c|}{ Satellite Active Method } \\
\hline CloudSat Cloud Profiling Radar & $94 \mathrm{GHz} \mathrm{CPR}$ & $\begin{array}{l}\text { June } 2006 \text { to present; } \\
\text { global, no coverage } \\
\text { poleward of } 82^{\circ}\end{array}$ & $\begin{array}{l}\text { monthly gridded cloud product } \\
\text { derived from } 2 \mathrm{~B} \text { GEOPROF and } \\
\text { 2B GEOPROF-LIDAR version R04; } \\
\text { resolution is } 2^{\circ} \text { latitude } \times 2^{\circ} \text { longitude }\end{array}$ & $\begin{array}{c}\text { Kay et al. [2008], } \\
\text { Kay and Gettelman [2009] }\end{array}$ \\
\hline CALIPSO/CALIOP lidar & $\begin{array}{l}\text { dual frequency, } \\
532 \text { and } 1064 \mathrm{~nm} \text {; } \\
\text { orthogonal } \\
\text { polarization }\end{array}$ & $\begin{array}{l}\text { June } 2006 \text { to present; } \\
\text { global, no coverage } \\
\text { poleward of } 82^{\circ}\end{array}$ & $\begin{array}{l}\text { monthly gridded cloud } \\
\text { product derived from } \\
\text { 2B GEOPROF and } \\
\text { 2B GEOPROF-LIDAR } \\
\text { version R04; resolution is } \\
2^{\circ} \text { latitude } \times 2^{\circ} \text { longitude }\end{array}$ & $\begin{array}{c}\text { Kay et al. [2008], } \\
\text { Kay and Gettelman [2009] }\end{array}$ \\
\hline $\begin{array}{l}\text { Cloud climatology for } \\
\text { land stations worldwide }\end{array}$ & & $\begin{array}{r}\text { Visual Meth } \\
1971-1996 ; 27 \text { stations } \\
\text { south of } 60^{\circ} \mathrm{S}\end{array}$ & & Hahn and Warren [2003] \\
\hline
\end{tabular}

Over the ocean south of $60^{\circ} \mathrm{S}$, the total cloud fraction exhibits a maximum in summer and minimum in winter, consistent with the negative impact of sea-ice on surface moisture fluxes.

[43] Over the Antarctic continent, CloudSat-CALIPSO shows zonal-average total cloud fractions reaching a maximum of $50 \%$ in winter and a minimum of $30 \%$ in summer, with intermediate values in the transitional seasons. Despite the known challenges of cloud detection based upon passive VIS-IR measurements, it is noteworthy that ISCCP shows good agreement with CloudSat-CALIPSO over both East and West Antarctica. However, these two data sets exhibit differences in the spatial distribution. This may be linked to the fact that ISCCP cloud fractions correlate poorly with pyrgeometer observations at South Pole [Town et al., 2007] (see section 3.1.4). MODIS estimates do not exceed 30\% throughout the year, a result that likely denotes the lower skill of its cloud masking algorithm over the cold ice sheet surface.

[44] The cloud regime at coastal Antarctic stations derived from visual cloud observations is generally aligned with that of the seasonally ice-covered ocean, characterized by a summer maximum and winter minimum. However, sitespecific conditions (topography and prevailing wind direction) account for departures from this pattern. For example, the cloud minimum occurs in winter at Faraday, Halley, Neumayer, and McMurdo; in summer at Syowa; and in both summer and winter at Davis [van den Broeke, 2000; Bailey and Lynch, 2000b; Turner and Pendlebury, 2004; Fogt and Bromwich, 2008; Kirchgäßner, 2010].

[45] Van den Broeke [2000] found that cloudiness at some Antarctic stations (Faraday and Halley) is influenced by the semiannual oscillation, the twice-yearly contraction and expansion of the circumpolar pressure trough, yielding a double cloud maximum in February through March and October, respectively. On the Antarctic plateau, visual cloud observations at South Pole suggest a minimum in winter but are affected by the absence of sunlight [Hahn et al., 1995; Town et al., 2007]. In comparison, Vostok, the only other station in the Antarctic interior included in the Hahn and Warren [2003] data set, exhibits a winter maximum and summer minimum, consistent with CloudSat-CALIPSO and ISCCP.

\subsubsection{Vertical Distribution}

[46] The 4 year CloudSat-CALIPSO record is used to produce zonal transects of the vertical profile of cloud fraction along latitudes $61^{\circ} \mathrm{S}, 71^{\circ} \mathrm{S}, 77^{\circ} \mathrm{S}$, and $81^{\circ} \mathrm{S}$ (Figure 9). A somewhat similar figure is found in the work by Verlinden et al. [2011]. Some differences between the Verlinden et al. study and Figure 9 are highlighted in the next paragraphs. These discrepancies likely arise because of the different threshold values used to define cloudy volumes (see section 2.3.3). The differing sampling periods (3 years in the Verlinden et al. study versus 4 years in Figure 9) are assumed to have a more secondary effect.

[47] Over the Southern Ocean, the greatest cloud fractions $(>50 \%$ ) occur in the lower troposphere, below $\sim 3 \mathrm{~km}$ above sea level (asl) (cloud fractions of $>50 \%$ are seen in Figure 9, whereas in the work by Verlinden et al. [2011], these values range $25 \%-30 \%$ ). This abundance of low-level clouds denotes the presence of quasi-permanent stratus layers. As shown by Verlinden et al. [2011], these clouds are confined within the atmospheric boundary layer, below a maximum of static stability. The reduction in low-level cloudiness induced by the presence of sea ice can be clearly seen by comparing Figures 9c and 9d (western longitudes). Verlinden et al. [2011] report a second maximum in the upper troposphere $(6-8 \mathrm{~km})$, greatest in winter and more tightly linked to the cyclonic activity. This upper tropospheric maximum is absent from Figures 9a-9c and only weakly apparent in Figure 9d. 

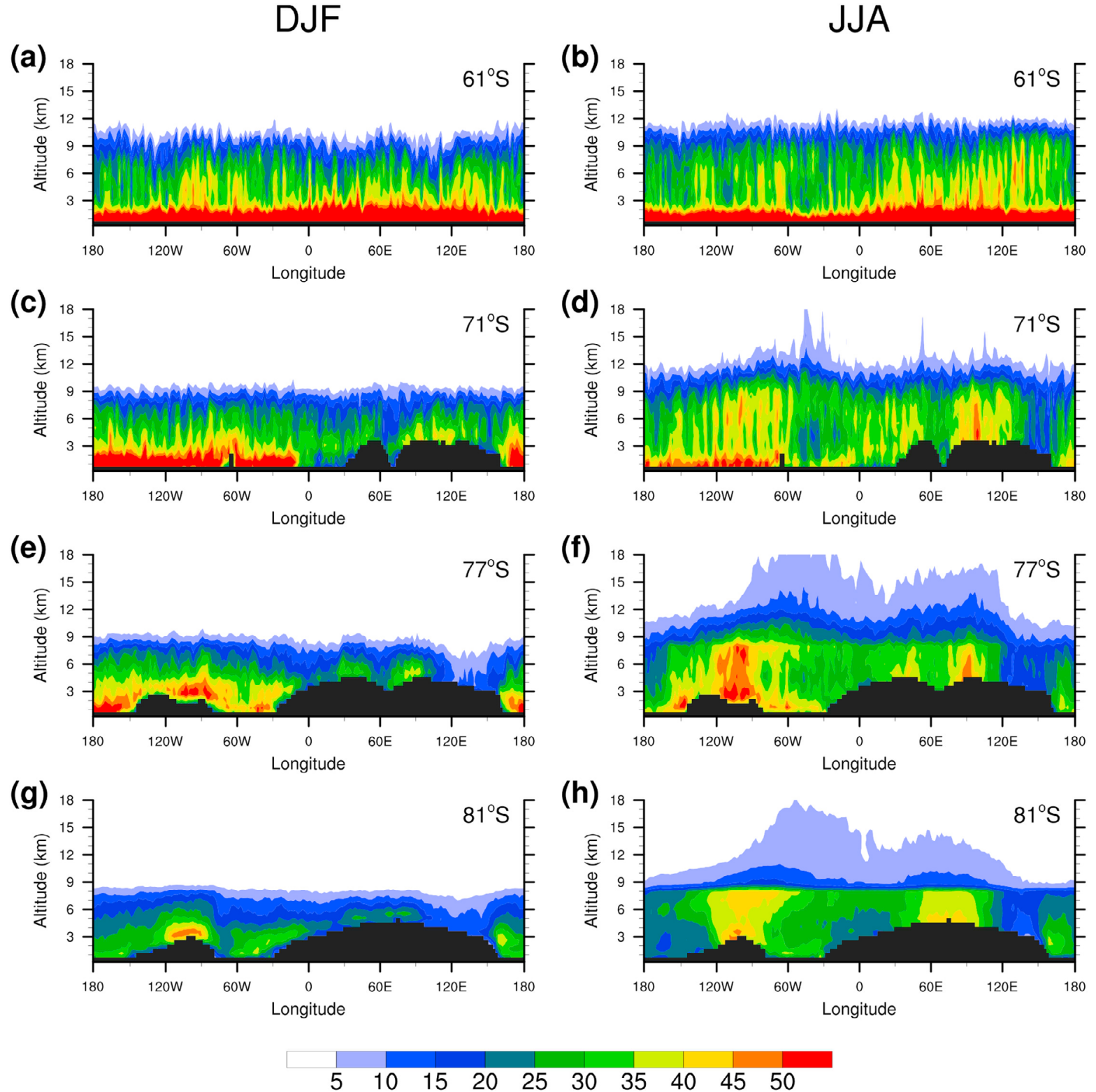

Figure 9. Vertical distribution of the mean seasonal cloud fraction from CloudSat-CALIPSO in (a, c, e, g) summer (DJF) and (b, d, f, h) winter (JJA) as a function of longitude. The profiles are shown (from top to bottom) for latitudes $61^{\circ} \mathrm{S}, 71^{\circ} \mathrm{S}, 77^{\circ} \mathrm{S}$, and $81^{\circ} \mathrm{S}$.

[48] As one approaches the continent, the vertical distribution of clouds becomes less zonally symmetric owing to the presence of the ice sheet but also to the atmospheric circulation. Southerly winds produce an outflow of dry and cold continental polar air, whereas northerly winds tend to bring relatively warm and moist air masses. The meridional transport of moisture at $70^{\circ} \mathrm{S}$ has been shown to be greatest in the West Antarctic sector, both as a result of the mean and eddy components of the tropospheric flow [Genthon and Krinner, 1998; Tietäväinen and Vihma, 2008; Bromwich and Wang, 2008]. In Figures $9 \mathrm{e}-9 \mathrm{~h}$, this region exhibits the greatest cloud amounts throughout the troposphere, particularly in the $90^{\circ} \mathrm{W}-120^{\circ} \mathrm{W}$ sector. This sector of West Antarctica also corresponds to the eastern side (onshore flow) of the quasipermanent upper level center of low pressure located over the Ross Ice Shelf [e.g., Bromwich and Wang, 2008]. The sig- nature of the moisture tongue over central West Antarctica, described by Nicolas and Bromwich [2011] and discussed in section 3.1.1, can be clearly seen in Figures $9 \mathrm{~g}$ and $9 \mathrm{~h}$. In contrast, the western branch of the low $\left(120^{\circ} \mathrm{E}-160^{\circ} \mathrm{E}\right)$ coincides with reduced cloud fractions. In addition to the horizontal atmospheric circulation, Verlinden et al. [2011] show some correspondence between positive wind vertical velocity and regions of enhanced cloudiness, for example, over the western side of the Antarctic Peninsula. Verlinden et al. further show that the $120^{\circ} \mathrm{E}-160^{\circ} \mathrm{E}$ is characterized by strong downward motion over Antarctica, consistent with the low cloud amounts previously mentioned.

[49] One of the notable characteristics of the winter cloud profiles is the greater occurrence of clouds in the upper tropospheric and stratospheric layers (Figures 9d, 9f, and 9h). This phenomenon is consistent with the seasonality of polar 


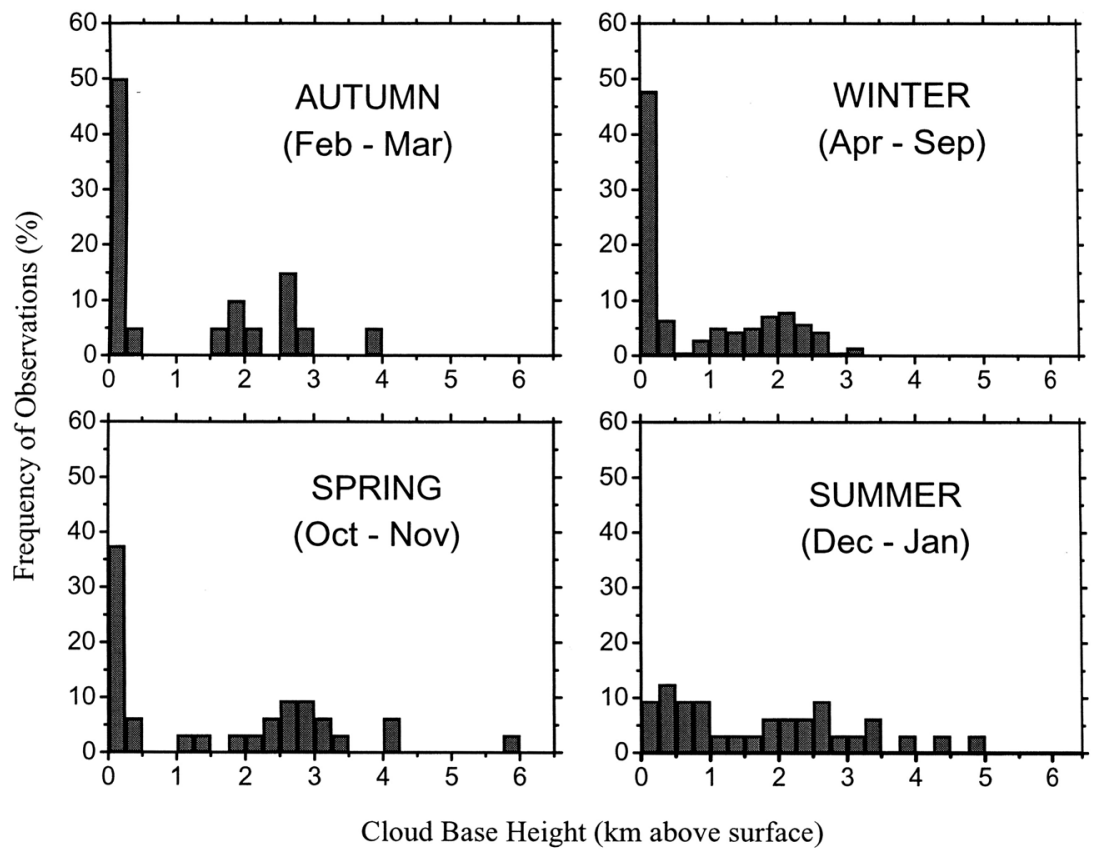

Figure 10. Cloud base heights at South Pole throughout 1991, retrieved from surface-based FTIR spectroradiometer data using a $\mathrm{CO}_{2}$-slicing technique. From Mahesh et al. [2001a].

stratospheric clouds (see Figure 13 and section 3.3). Several factors may contribute to this greater upper level cloudiness. More intense cyclonic activity in winter [Simmonds et al., 2003] favors intrusions of maritime air onto the Antarctic interior. The extremely low temperatures inside the polar vortex allow for cloud formation despite the low levels of specific humidity. Furthermore, the thermal troposphere over Antarctica is more weakly defined in winter (lower static stability) than in summer [Gettelman et al., 2011], which is favorable to the penetration of tropospheric air masses into the lower stratosphere [e.g., Wang et al., 2008].

[50] At $81^{\circ} \mathrm{S}$ and, to a lesser extent, $77^{\circ} \mathrm{S}$ (Figures $9 \mathrm{~h}$ and $9 \mathrm{f}$ ), CloudSat and CALIPSO suggest a sharp decrease in cloud fraction at approximately $8 \mathrm{~km}$ asl, also found by Verlinden et al. [2011]. It is unclear, however, whether this feature is real or not. Indeed, this discontinuity coincides with a change in the horizontal and vertical resolutions of the CALIPSO data at $8.2 \mathrm{~km}$ [Winker et al., 2009] and a drop in the sensitivity of the lidar [Winker et al., 2010]. Moreover, the sharpness of this boundary seems to decrease homogeneously with latitude (Figure 9h versus Figure 9f), and the apparent drop off in cloudiness is not associated with a strong temperature gradient [Gettelman et al., 2011].

\subsubsection{Cloud Cover at South Pole}

[51] The U.S. station, Amundsen-Scott South Pole Station, is one of only two sites on the East Antarctic Polar Plateau with a long-term record of visual cloud observations. CloudSat and CALIPSO do not provide observations poleward of $82^{\circ} \mathrm{S}$; therefore, our knowledge of the cloud climatology over this area primarily relies on a series of groundbased cloud investigations [e.g., Stone, 1993; Mahesh et al., 2001a, 2001b, 2005; Town et al., 2005, 2007].
[52] Town et al. [2007] compared the cloud amounts at South Pole from different sources (visual observations, pyrgeometer, ISCCP, and APP-x) and concluded on the superiority of pyrgeometer measurements. The study confirmed the presence of a low bias (20\%) in visual observations during winter caused by the absence of sunlight, larger than previously estimated by Hahn et al. [1995]. Town et al. [2007] also found that ISCCP cloud amounts agree well with pyrgeometer data during winter but substantially underestimate the cloud amounts during summer (by $30 \%$ ). However, the time series from the two data sets are uncorrelated in winter (they are weakly correlated in summer). The analysis of pyrgeometer observations from 1993 to 2004 by Town et al. [2007] revealed only a slight seasonal variability in cloud cover, with a minimum in summer (45\%-50\%) and values around 55\%-65\% during the other months. Mahesh et al. [2005] analyze groundbased lidar measurements carried out at South Pole between January 2000 and July 2004 and report that clouds were detected on average $40 \%$ of the time, with no apparent seasonality.

[53] Stone [1993] used radiosondes to study clouds over the South Pole during winter. Using change points in the vertical net flux profiles from these sondes, Stone [1993] found cloud bases coincident with the top of the surface inversion (400 $\mathrm{m}$ above the surface). Cloud geometrical thickness was extensive, with tops between 2000 and $6000 \mathrm{~m}$ above the surface. A distribution in cloud base heights, based on FTIR measurements from 1992 [Mahesh et al., 2001a], is shown in Figure 10. In all seasons for this particular year, there is a primary mode near the surface, somewhat consistent with Stone [1993], but suggesting cloud bases more within the inversion than right at the top. A second mode (peak at 2-3 km) also appears. Elastic backscatter lidar observations 

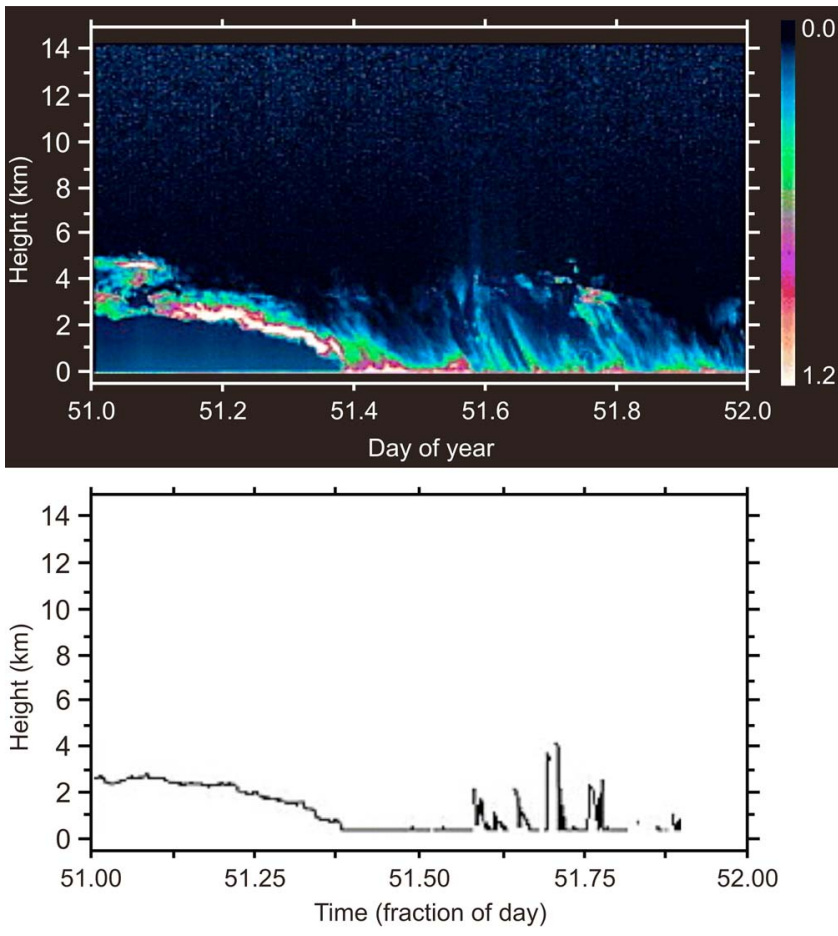

Figure 11. (top) NASA micropulse lidar network (MPLNET) relative backscatter data from South Pole on 20 February 2000, in $10^{-5} \mathrm{~m}^{-1} \mathrm{sr}^{-1}$. (bottom) Cloud base heights retrieved from the lidar backscatter data for each profile, using a value of $0.2 \times 10^{-5} \mathrm{~m}^{-1} \mathrm{sr}^{-1}$ as the threshold of cloud detection. From Mahesh et al. [2005].

at the South Pole from 2000 to 2004 [Mahesh et al., 2005] do not show the specific bimodal distribution as in the 1992 FTIR retrievals. However, individual daily time series of the lidar backscatter suggest frequent occurrence of settling ice crystals in the midtroposphere that may ultimately be responsible for the bimodal distribution appearing in the surface-based passive retrievals (Figure 11).

\subsection{Long-Term Trends in Antarctic Clouds}

[54] Given the known uncertainties associated with cloud observations over high southern latitudes, it is not surprising that little is known about the long-term changes in cloud amounts in this region. For this purpose, an additional problem lies in the presence of potential spurious changes in the satellite-based cloud data sets, caused by radiance calibration issues between satellites [Klein and Hartmann, 1993]. This concern has been addressed in the latest version of ISCCP products [Rossow and Schiffer, 1999]. Evan et al. [2007] still warn against the use of ISCCP for longterm trend analysis. However, the major discontinuities are related to changes in the viewing geometry between geostationary satellites over lower latitudes and, thus, are less of an issue over the polar regions.

\subsubsection{Continental-Scale Trends}

[55] Few studies have looked at the linear trends in total cloud fraction over Antarctica using satellite passive VIS-IR observations. Comiso and Stock [2001] analyzed APP-x monthly cloud anomalies from 1982 through 1999 and found a negative trend of $-0.50 \pm 0.06 \% \mathrm{yr}^{-1}$ on average over Antarctica for elevations $>2000 \mathrm{~m}$. These results are consistent with those reported by Wylie et al. [2005], on the basis of observations from the High-Resolution Infrared Sounder (HIRS). Wylie et al. [2005] compared the HIRS-based average cloud amounts during 1993-2001 and 1985-1992 and found the largest changes on Earth occurring over East Antarctica, with a decrease of $>5 \%$ between the two periods. Comiso and Stock [2001] argue that such a decrease would be consistent with the concomitant slight cooling of the continent during the same period reported by Comiso [2000].

[56] The time series of the mean seasonal cloud amounts over Antarctica from ISCCP are shown in Figure 12. Bearing in mind the caveats relative to this data set, the fall (March, April, and May) and winter (June, July, and August) seasons exhibit negative and statistically significant trends $(-1.46 \pm$ $0.50 \%$ and $-1.68 \pm 0.61 \%$ ), with insignificant trends in the other seasons. The negative trends suggest some overall agreement with the results from Comiso and Stock [2001] and Wylie et al. [2005]. It is noteworthy that none of the seasonal trends from ISCCP are significantly different from zero during 1982-1999, which differs from the conclusions from Comiso and Stock [2001]. However, the ISCCP results do not distinguish between elevation ranges.

[57] For lack of data sets extending back prior to the 1980s, one may turn to the changes in Antarctic surface mass balance, which are, to some extent, affected by changes in clouds as the source of precipitation. The absence of significant change in Antarctic snowfall between 1957 and 2004 reported by Monaghan et al. [2006] seems to indicate similarly nonsignificant change in the average cloud amount over the continent. The main limitations to such inference are that clouds do not necessarily precipitate and that a significant proportion of precipitation over the Plateau falls under clearsky conditions [Bromwich, 1988; Walden et al., 2003; Fujita and Abe, 2006].

\subsubsection{Trends at Some Antarctic Stations}

[58] In spite of their sparse distribution, visual observations provide the longest records of cloud amount in Antarctica,

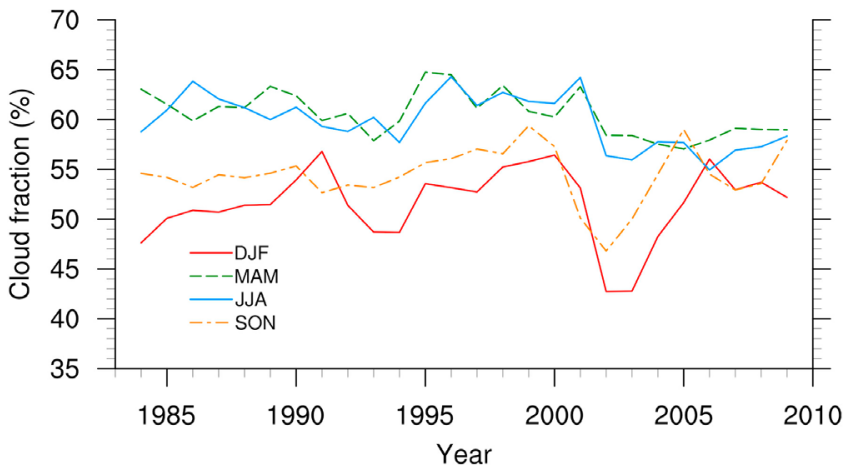

Figure 12. Time series of the mean seasonal cloud fraction from ISCCP spatially averaged (area-weighted) over Antarctica from November 1983 to May 2008. The number in parentheses next to the season name corresponds to the linear trend in cloud fraction in percent per decade and its standard error. 
0

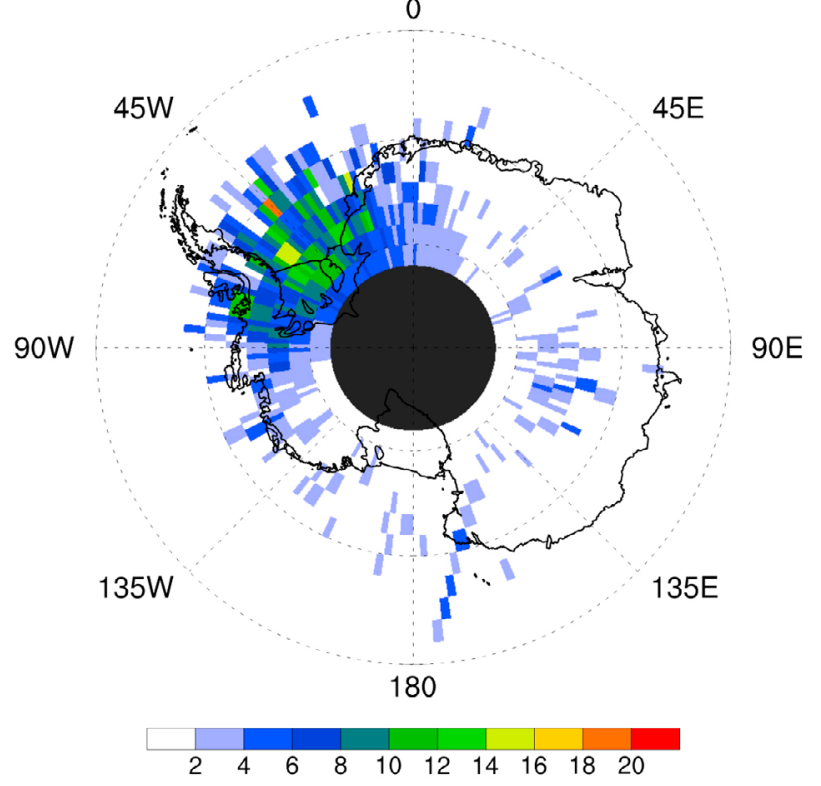

Figure 13. Monthly mean August cloud fraction in percent over Antarctica at $18 \mathrm{~km}$ asl between 2006 and 2010 from CloudSat-CALIPSO retrievals.

some of them starting with the 1957-1958 International Geophysical Year or earlier. Again, caution is required when deriving long-term trends from these data because of artifacts caused by changes in observers and observing practices [e.g., Hahn et al., 1995; Dai et al., 2006; Town et al., 2007].

[59] At Vernadsky/Faraday (western Antarctic Peninsula), Kirchgäßner [2010] reports a significant increase in total cloud cover between 1960 and 2005, with stronger increase in winter. The authors suggest possible linkage with the decreasing sea ice cover in the Bellingshausen Sea [e.g., Stammerjohn et al., 2008]. Enhanced cloudiness at Vernadsky/Faraday is also consistent with the weakening of the semiannual oscillation observed since the 1970s [van den Broeke, 2000]. At Syowa, on the coast of East Antarctica $\left(40^{\circ} \mathrm{E}\right)$, Yamanouchi and Shudou [2007] found a statistically significant increase in the mean annual cloud amount, which is also reflected in all months. At South Pole, Town et al. [2007] found a significant positive trend during 1954-2007 for sunlit months but argue that the results are likely affected by changing observing practices. For a shorter period (1993-2004), the same authors report no significant trends from pyrgeometer observations.

\subsection{Antarctic Stratospheric Clouds}

[60] As mentioned in section 2.3.2, the availability of spaceborne lidar observations from the GLAS and CALIOP lidars has greatly improved the monitoring of PSCs over Antarctica. Using CALIPSO observations from the 2006 winter, Pitts et al. [2007] evaluated the reliability of the solar occultation-based PSC climatologies by producing "virtual solar occulation" data that mimic the sampling of the SAM II. They showed that the occultation-based climatologies poorly represent the Antarctic region as a whole.

[61] In order for the PSCs to form despite the extremely low moisture content, temperatures in the lower stratosphere must fall below $-80^{\circ} \mathrm{C}$. These conditions typically occur within the polar vortex over Antarctica during austral winter. On regional scales, the formation of PSCs has been associated with the occurrence of mountain waves [e.g., Cariolle et al., 1989; Eckermann et al., 2006]. This phenomenon accounts for the relative abundance of PSCs near the Antarctic Peninsula seen both in the SAM II climatology from 1978 to 1989 [Poole and Pitts, 1994] and in the CALIPSO data from the 2006 austral winter [Pitts et al., 2007; Noel et al., 2008; Wang et al., 2008]. It is also apparent in the mean August cloud fraction from CloudSat-CALIPSO shown in Figure 13. Wang et al. [2008] further showed that PSCs may form in connection with deep tropospheric cloud systems as a result of adiabatic and radiative cooling in the lower stratosphere.

[62] Little information exists about the long-term changes in PSCs over Antarctica. Fromm et al. [2003] found minima in 1983 and 1992, the first year following two major volcanic eruptions (El Chichón and Pinatubo). As noted by Lachlan-Cope et al. [2009], temperature changes during the transitional months between winter and the preceding/ following seasons are most consequential for PSCs. Using the temperature fields for June through August 1979-2001 from the ERA-40 reanalysis together with observed estimates of the average water content for the Antarctic winter troposphere, Lachlan-Cope et al. [2009] found that the probability for PSCs to form had increased during this period, a result consistent with the midtropospheric warming in high southern latitudes reported by Turner et al. [2006].

\section{MICROPHYSICAL PROPERTIES OF ANTARCTIC CLOUDS}

\subsection{The Aerosol Regime}

[63] The Antarctic is often regarded as a "pristine" or "clean air" environment. While the Antarctic shows markedly less influence of anthropogenic aerosol than many other regions, it is by no means entirely free of most major aerosol types, and distant anthropogenic sources have been found. The most pristine aspect of Antarctica may be that its extensive continental region has essentially no local aerosol sources and serves as a sink for aerosols. In addition, Antarctic coastal regions show much lower aerosol concentrations than most other maritime regions [Hogan, 1986]. The description of Antarctic aerosols presented hereafter builds upon two comprehensive reviews of early research [Shaw, 1988; Ito, 1989] as well as more recent studies.

\subsubsection{Composition and Seasonal Variability of Antarctic Aerosols}

[64] There is a regular seasonal cycle in aerosol concentrations over the Antarctic Plateau, varying from $10 \mathrm{~cm}^{-3}$ during winter to levels near those of central oceans of 100 $200 \mathrm{~cm}^{-3}$ during summer [Shaw, 1988; Harder et al., 2000]. The largest component by mass is generally sulfate $\left(70 \%{ }^{-}\right.$ $90 \%$ ). However, during winter, the submicron particles are composed of aged sulfate particles and sea salt, as opposed to sulfuric acid particles during summer. At coastal locations such as Ross Island and Syowa Station, the same seasonal cycle appears, but with winter minima on the order of 50 
$100 \mathrm{~cm}^{-3}$ and summer maxima as large as $700 \mathrm{~cm}^{-3}$. This seasonal cycle pertains mainly to the Aitken particles, which have average diameters on the order of $0.01 \mu \mathrm{m}$ and are largely inactive optically. The correlation of this seasonal cycle with available sunlight suggests a formation mechanism involving photochemical oxidation of sulfur compounds. The coarse-mode, or Mie particles (size range typically $0.1-2 \mu \mathrm{m}$ ), show a different seasonal cycle, with minimum concentrations in autumn and maximum concentrations in spring [Ito, 1989]. Bodhaine et al. [1986] and Hogan and Barnard [1978] have suggested that low-lying frontal systems generate warm air intrusions that enhance both moisture and concentrations of Mie particles over the Antarctic Plateau.

[65] Recent research has further clarified the seasonal variation in aerosol composition. The fractional abundance of sulfates and methanesulfonate (MSA) correlates strongly with the availability of sunlight, while heavy metallic ions $(\mathrm{Pb}, \mathrm{Sn}, \mathrm{Zr}, \mathrm{Pb}, \mathrm{Ti}, \mathrm{Mn}, \mathrm{Fe}$, and $\mathrm{Ga})$ and sea salts show maxima both in autumn and winter. This behavior is seen in measurements from Syowa [Hara et al., 1996], Mawson [Savoie et al., 1993], Neumayer [Wagenbach et al., 1988], and Maitri [Deshpande and Kamra, 2004].

[66] The seasonal cycle described above sometimes manifests differently at Palmer Station, an island maritime location [Saxena and Ruggiero, 1990a]. Here, aerosol concentrations are typically $1000 \mathrm{~cm}^{-3}$ year-round but can reach maxima of $4000 \mathrm{~cm}^{-3}$ during August. Sulfur remains the largest Aitken elemental constituent at Palmer Station, and in the fine particle mode the non-sea-salt sulfates correlate well with marine primary productivity [Correia et al., 1998]. However, Saxena and Ruggiero [1990a] also find important mass contributions from chlorine and aluminum (both $24 \%$, primarily in the Mie particles). The former indicates the influence of sea salt, while the latter occurs mainly during northeasterly winds carrying crustal material from exposed rock areas on the Antarctic Peninsula. Savoie et al. [1993] find summertime maxima in MSA concentrations $\left(>200 \mathrm{ng} \mathrm{m}^{-3}\right)$ and non-sea-salt sulfates $\left(>400 \mathrm{ng} \mathrm{m}^{-3}\right)$ at Palmer Station, values twice as large as recorded at Mawson. Correia et al. [1998] find coarse-mode sea salt and soil dust with little obvious seasonal variation, similar to Saxena and Ruggiero [1990a], but also notice enhanced heavy metal $(\mathrm{Ni}$ and $\mathrm{Pb})$ concentrations consistent with long-range transport of anthropogenic pollutants. In the Southern Ocean [McInnes et al., 1997], sea salt appears to be a relatively small contribution to the aerosol particle number density ( $4 \%-7 \%)$, but comprises the largest fraction $(86 \%-100 \%)$ of the coarse-mode particles (mean diameter $>1.5 \mu \mathrm{m})$.

\subsubsection{Biogenic Sources of Antarctic Aerosols}

[67] It was recognized early on [e.g., Shaw, 1988] that the large fraction of sulfate ( $95 \%$ of condensation nuclei) implies a marine biogenic origin for most Antarctic aerosol. The sulfate aerosol ultimately originates from the emission of dimethyl sulfide (DMS) from marine microorgansims into the marine boundary layer, after which a series of oxidation reactions produces sulfuric acid particles. This suggests the potential for biogeochemical feedbacks between the atmosphere (clouds and radiation) and changing marine primary productivity in response to changing sea ice and open water fractions in a warming ocean.

[68] Over remote oceans, biogenic DMS is the largest contributor of photochemically active sulfur to the atmosphere [Andreae and Crutzen, 1997]. The non-sea-salt sulfates and MSA that eventually result, having particle size range $0.1-1 \mu \mathrm{m}$, are hygroscopic and thus have the ability to form cloud condensation nuclei (CCN). This is the basis for the CLAW hypothesis of Charlson et al. [1987] (named after the authors' initials). Vallina et al. [2006] carried out a study of CCN variability over the entire Southern Ocean, using MODIS retrievals of aerosol properties (total aerosol optical depth, fraction of aerosol optical depth in the finemode particles, and effective particle radius) and Seaviewing Wide Field-of-view Sensor (SeaWiFS) retrievals of ocean surface chlorophyll concentration. The seasonality in DMS, resulting from marine primary production, is linked to both the availability of sunlight and the seasonal variation in the ocean mixed layer depth (MLD). During summer, the Southern Ocean MLD is shallow $(30 \mathrm{~m})$, such that phytoplankton growth is iron-limited. During the rest of the year, a much deeper mixed layer (400 $\mathrm{m}$ during winter) results in light-limited phytoplankton growth. Using SeaWiFS chlorophyll as a valid proxy for DMS, Vallina et al. [2006] report a deterministic relationship between DMS and CCN and show convincingly that this is not an artifact of independent seasonal variation in the chlorophyll and aerosol properties.

[69] The biogenic origin of Antarctic aerosols is seen directly in the chemistry of stratus clouds over the Ross Ice Shelf. Cloud water collected by LC-130 aircraft [Saxena, 1983] shows three clear indicators of biogenic influence. First, laboratory infrared absorption spectra are consistent with proteinaceous matter. Second, there are high concentrations of ionically bonded potassium chloride salt, as opposed to sodium chloride. Third, after samples of cloud water were exposed to sunlight and laboratory room temperature for four weeks, algal growth was noticed. CCN in these clouds were active at $1 \%$ supersaturation.

[70] Biogenic contributions to $\mathrm{CCN}$-active Antarctic aerosol are not always entirely local. Alcenar et al. [2010] identified primary productivity in the southern Argentinian shelf region as the main source of aerosol at King George Island, at the northern end of the Antarctic Peninsula.

\subsubsection{Long-Range Sources of Antarctic Aerosols}

[71] Recent research has revealed long-range transport pathways in several Antarctic sectors, such that the Antarctic aerosol regime is not entirely isolated. A 30 year time history of lead deposition in shallow Antarctic snow [Barbante et al., 1998] shows that Australian fossil fuel burning is a source of lead-enriched aerosol intrusion into the Pacific Antarctic sector, while the same source from South America affects the Atlantic Antarctic sector. Analysis of dust in ice cores obtained at James Ross Island, just east of the Antarctic Peninsula, reveal a doubling of aluminosilicate concentration over the 20th century, consistent 
with increasing desertification in both Patagonia and northern Argentina [McConnell et al., 2007]. Aerosol of Brazilian origin has been sampled during austral winter at Troll Research Station $\left(72.0^{\circ} \mathrm{S}, 2.5^{\circ} \mathrm{E}\right)$ in Queen Maud Land, as evidenced by lognormal size distribution modes with median particle diameters $0.105 \mu \mathrm{m}$ and $0.36 \mu \mathrm{m}$, which are characteristic of biomass burning [Fiebig et al., 2009]. Similarly, Hara et al. [2010] find that haze episodes at Syowa Station, during which visibility can drop to $10 \mathrm{~km}$ for periods of $30 \mathrm{~h}$, are caused by biomass burning aerosol from South America transported to the Antarctic coast via the eastward approach of cyclones.

[72] Despite these recent findings, the large-scale impact of anthropogenic aerosol appears to be minimal at present. Satellite-based Total Ozone Mapping Spectrometer investigation of ultraviolet-absorbing aerosol (e.g., black carbon from soot and smoke) throughout the Southern Ocean by Herman et al. [1997] found no detectable abundance at any time of year.

[73] When these long-range constituents are absent, the dominance of the fine-particle mode and the low number concentrations in general yield summertime aerosol optical depths (wavelength $500 \mathrm{~nm}$ ) on the order of 0.03 [Chaubey et al., 2011]. Nevertheless, even the local effects of circumpolar cyclonic storms can increase the concentration of coarse-mode particles (sizes up to $2 \mu \mathrm{m}$ and more optically active) by an order of magnitude [Pant et al., 2010].

\subsubsection{Aerosols in the Antarctic Troposphere}

[74] Aerosol sampled at the Antarctic surface may not be representative of tropospheric aerosol aloft. Using a tethered balloon, Rankin and Wolff [2002] measured enhanced sea salt aerosol $300 \mathrm{~m}$ above the surface of the Brunt Ice Shelf. This type of aerosol enhancement, in moist air a few hundred meters above the surface, is also seen over the Antarctic Plateau [Shaw, 1988]. Aircraft measurements over Syowa revealed Aitken mode particle concentrations at altitudes 2 and $4 \mathrm{~km}$ that are nearly twice as large as those at the surface [Ito, 1989]. Aircraft measurement of Aitken mode particle concentrations over Ross Island [Saxena, 1983] show a factor of four decrease from the surface to $300 \mathrm{~m}\left(600-150 \mathrm{~cm}^{-3}\right)$, followed by linear increase from 300 to $1200 \mathrm{~cm}^{-3}$ between altitudes 300 and $3000 \mathrm{~m}$. The enhanced concentrations very close to the surface indicate that the open ocean is a prevalent source, while the increase with height above $300 \mathrm{~m}$ suggests a strong role for gas-toparticle conversion.

\subsubsection{Cloud Condensation Nuclei}

[75] Hygroscopic properties of Antarctic submicron aerosols are highly conducive to $\mathrm{CCN}$ formation. At Aboa Station $\left(73.1^{\circ} \mathrm{S}, 13.4^{\circ} \mathrm{W}\right)$ in Queen Maud Land, $130 \mathrm{~km}$ from the open ocean, Asmi et al. [2010] found summertime hygroscopic growth factors on the order of 1.75 for particles $90 \mathrm{~nm}$ in diameter. Interestingly, hygroscopicity in the moist marine air masses, bearing recently formed biogenic particles, is slightly lower than that in continental air masses. This is due to the prevalence of aged marine organic particles and smaller MSA volume fraction in air masses reaching the station from continental directions. Non-MSA organics make up $20 \%-30 \%$ of the submicron aerosol mass during summer.

[76] Dissipating stratus clouds on the Antarctic Peninsula occasionally show bursts of CCN [Saxena, 1996]. This occurs when strong winds and vigorous near-surface vertical mixing gives rise to local cloud formation, after which the winds become calm and the cloud base drops to the ground under the prevailing inversion. As the cloud slowly dissipates, sudden $\mathrm{CCN}$ enhancements can last up to $15 \mathrm{~h}$. In these events, CCN concentration can increase by a factor of four at $0.25 \%$ supersaturation and by a factor of seven at $1.25 \%$ supersaturation.

\subsubsection{Ice-Forming Nuclei}

[77] At tropospheric pressures, homogeneous nucleation becomes significant mainly for temperatures in the range $-35^{\circ} \mathrm{C}--40^{\circ} \mathrm{C}$ and below. Therefore, heterogeneous nucleation is responsible for most natural cloud ice water [Szyrmer and Zawadzki, 1997]. There are seven different possible modes of ice crystal nucleation: (1) homogeneous nucleation, (2) deposition nucleation, (3) immersion/condensation freezing, (4) contact freezing, (5) contact freezing "inside out," (6) evaporation freezing, and (7) electrofreezing [DeMott et al., 2010]. Identification of these processes in real clouds is often complicated by the very low concentrations of ice nuclei (IN) in clouds with temperatures on the order of $-10^{\circ} \mathrm{C}, 7-9$ orders of magnitude smaller than total aerosol particle concentration. Generally speaking, natural mineral aerosol is the important source of IN for colder temperatures (below $-12^{\circ} \mathrm{C}--15^{\circ} \mathrm{C}$ ). At warmer temperatures, IN from biological sources become increasingly important [Szyrmer and Zawadzki, 1997].

[78] IN of biological (primarily bacterial) origin are found worldwide in snowfall [Christner et al., 2008] but show the lowest concentrations in polar regions. At northern midlatitudes, Christner et al. [2008] found IN concentrations in melted snow samples in the range $110-120 \mathrm{~L}^{-1}$ of snowmelt. From Wheaton Glacier in the Yukon, IN concentration was on the order of $10 \mathrm{~L}^{-1}$ of snow, and from Ross Island, IN concentration was even lower at $4 \mathrm{~L}^{-1}$ of snow. Junge and Swanson [2008] investigated the ice nucleating potential of bacterial isolates common in Arctic and Antarctic sea ice and found that they only induce nucleation by immersion freezing at temperatures in the range $-40^{\circ} \mathrm{C}--43^{\circ} \mathrm{C}$. Their result does not rule out ice nucleation in the contact or condensation mode. However, this result, along with the findings of Christner et al. [2008], suggests that long-range transport of biogenic material may play a role in Antarctic warm cloud ice nucleation.

[79] The earliest work on Antarctic IN revealed highly prevalent IN at colder temperatures. From a ground-based study at McMurdo station, Bigg and Hopwood [1963] found mean IN concentrations below $1 \mathrm{~L}^{-1}$ (of air) at $-18^{\circ} \mathrm{C}$. However, IN concentrations increased steadily and rapidly with decreasing temperature to $>10 \mathrm{~L}^{-1}$ at $-20^{\circ} \mathrm{C}$ and $\sim 100 \mathrm{~L}^{-1}$ at $-26^{\circ} \mathrm{C}$. These smooth increases are not typical of midlatitudes and suggest a degree of homogeneity in the Antarctic troposphere that may be conducive to fundamental studies of IN. At temperatures below $-18^{\circ} \mathrm{C}$, the Antarctic 
IN concentrations exceeded similar measurements from southern midlatitude sites, while the reverse was true for warmer temperatures. These early measurements did not reveal the chemical composition of the IN but did suggest effective particle diameters in the range 0.02 to $0.2 \mu \mathrm{m}$.

[80] Aerosol sampled at Palmer Station by Saxena and Weintraub [1988] revealed at least five separate IN distribution spectra in concentration versus temperature. One of these is similar to Bigg and Hopwood [1963], but four others show IN concentrations between 40 and $10,000 \mathrm{~m}^{-3}$ for temperatures warmer than $-12^{\circ} \mathrm{C}$. Here, the IN concentrations were estimated by determining the temperatures at which the aerosol droplets freeze. Elemental analysis identified a prominent role for potassium, silicon, and zinc in ice nucleation. Clearly, much more work is needed to elucidate the roles of mineral versus biological IN in Antarctic clouds. Saxena [1983] suggests that condensation freezing may be the dominant mechanism in the case of local biogenic aerosol.

\subsection{Observed Cloud Properties}

\subsubsection{Phase and Size}

[81] Because of Antarctica's remoteness and challenging environment, in situ observations of cloud particle phase and size from research aircraft are rare (an example of recent such observations over the Antarctic Peninsula is described in section 4.3.3). These properties have been mostly remotely sensed using surface-based passive radiometry and spectroscopy [Stone, 1993; Mahesh et al., 2001b]; surfacebased lidars [Smiley and Morley, 1981; Del Guasta et al., 1993]; and, since 2006, the radar and lidar from the CloudSat and CALIPSO missions [Grenier et al., 2009; Hu et al., 2009; Adhikari et al., 2010; Yoshida et al., 2010; Winker et al., 2010].

[82] Lidar-based retrievals of cloud phase typically rely on measurements of the depolarization ratio, that is, the intensity ratio between the planes of polarization parallel and orthogonal to that of the polarized source. In its most simple formulation, the discrimination method assumes minimal depolarization from water droplets (because of their spherical shape) and large depolarization from the irregularly shaped ice crystals [e.g., Sassen, 1991; Hu, 2007]. As noted early on by Smiley and Morley [1981], such assumption is complicated (among other things) by the presence of oriented ice crystals, which are weakly polarizing and thus often result in weak correlation between depolarization and phase [e.g., Hu, 2007; Hu et al., 2007]. This problem has been a focus of improvement in the latest release (version 3 ) of the cloud phase products from CALIPSO [Hu et al., 2009] (available at http://www-calipso.larc.nasa.gov/products/). These observations have provided a global view (equatorward of $82^{\circ}$ ) of cloud phase [e.g., Winker et al., 2010], but the classifications still lack rigorous validation over Antarctica.

[83] Estimates of cloud effective particle size from broadband or spectral radiometric data have usually been based on an a priori assumption about phase: a choice of liquid water or ice is made for the radiative transfer model calculations. Stone [1993] found that the radiometersonde net flux profiles dur- ing winter were consistent with ice particles having effective radius, $r_{e}$, in the range $4-16 \mu \mathrm{m}$. Mahesh et al. [2001b] developed a retrieval method assuming ice phase for their 1992 FTIR data and found a similar size range for clouds during winter; however, in all other seasons many cloudy spectra yield $r_{e}>25 \mu \mathrm{m}$ with their retrieval method. A similar result was obtained by Lubin and Harper [1996] using AVHRR data and an ice cloud radiative transfer model, although with smaller overall $r_{e}$ (5-6 $\mu \mathrm{m}$ during winter and 12-14 $\mu \mathrm{m}$ during summer). Modeling springtime Antarctic Peninsula stratus as liquid water clouds, Lubin [1994] found most $r_{e}$ in the range 9-10 $\mu \mathrm{m}$, which is consistent with highlatitude marine stratus clouds not impacted by anthropogenic aerosol [Lubin and Vogelmann, 2006; Garrett and Zhao, 2006]. In aircraft observations of sub-Antarctic stratus clouds over the Southern Ocean during November and December 1995 [Boers and Krummel, 1998], $8 \mu \mathrm{m} \leq r_{e} \leq$ $10 \mu \mathrm{m}$ was the most common size range of liquid water droplets, followed by a second mode at $13-14 \mu \mathrm{m}$.

[84] These a priori assumptions about a single phase may be inappropriate for future research. Berque et al. [2011] developed an AVHRR retrieval method for the Antarctic Plateau using transects of pixels rather than direct radiative transfer retrieval on individual pixels. Preliminary results show that either liquid water or ice may be the predominant phase at temperatures as low as $-31.7^{\circ} \mathrm{C}$. Analysis of FTIR measurements from Palmer Station during spring 1991 show a predominance of liquid water spectral signatures for clouds with bases below 3000 feet $(\sim 900 \mathrm{~m})$; for higher clouds there are some infrared emission signatures consistent with liquid water clouds having small $r_{e}$, but also clouds with distinct ice-phase signatures [Lubin, 2004].

[85] Methods for discriminating between different classes of cloud particle sizes have used the different detection sensitivities of active remote-sensing instruments, such as the $94 \mathrm{GHz}$ CloudSat radar and the dual-frequency $(532 \mathrm{~nm}$ and $1064 \mathrm{~nm}$ ) CALIOP lidar [Grenier et al., 2009; Adhikari et al., 2010; Winker et al., 2010]. One such example is given in Figure 14, where the total cloud fractions from CloudSatCALIPSO (used in section 3) are separated into the contributions from the radar and from the lidar. Figure 14 reveals a clear seasonal cycle in the lidar signal over the East Antarctic interior (Figure 14a), with a winter (August) maximum of 35\%-40\% and a summer minimum of $\sim 10 \%$. This suggests greater abundance of smaller cloud particles in winter, consistent with the occurrence of clouds in the stratospheric layers. In comparison, the radar contribution exhibits relatively little seasonal variability. To some extent, the same remarks also apply to West Antarctica (Figure 14b), only with a less regular lidar signal and greater cloud fractions from the radar. Admittedly, these observations of the cloud particle size remain qualitative. The study by Grenier et al. [2009] suggests that absolute estimates of $r_{e}$ from CloudSat-CALIPSO are possible, but no comprehensive investigations of this property over Antarctica have been published to date.

\subsubsection{Optical Depth}

[86] Cloud visible optical depth in Antarctica has most often been estimated by iterating on radiative transfer model 
(a) East Antarctica

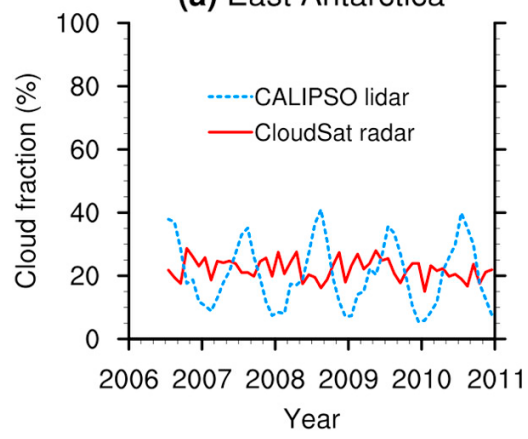

(b) West Antarctica

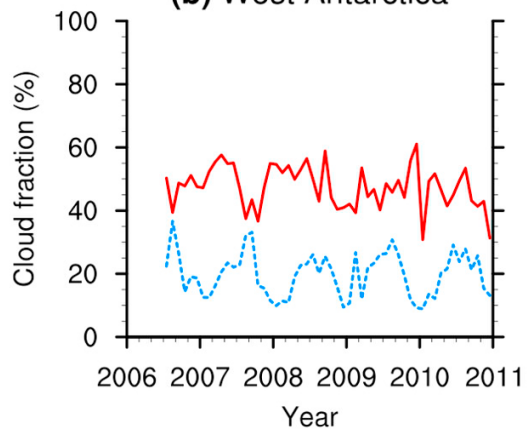

(c)

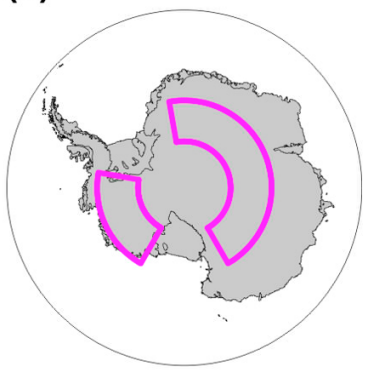

Figure 14. Monthly mean cloud fractions from CloudSat-CALIPSO spatially averaged over (a) the East Antarctic interior and (b) West Antarctica. The total cloud fraction from CloudSat-CALIPSO is decomposed into the contributions from the CloudSat radar (solid red) and the CALIPSO lidar (dashed blue).

(c) The map shows the contours of the East Antarctic $\left(75^{\circ} \mathrm{S}-82^{\circ} \mathrm{S}, 10^{\circ} \mathrm{W}-150^{\circ} \mathrm{E}\right)$ and West Antarctic $\left(75^{\circ} \mathrm{S}-82^{\circ} \mathrm{S}, 80^{\circ} \mathrm{W}-150^{\circ} \mathrm{W}\right)$ regions considered here.

calculations to match measured downwelling shortwave spectral irradiance at the surface. This can be problematic when the surface albedo is very high because of prevailing snow and ice cover, as multiple reflections of photons between the surface and the cloud base diminishes the sensitivity in surface irradiance to cloud opacity [Nichol et al., 2003]. For example, over a surface albedo of 0.95 , typical of clean Antarctic snow at ultraviolet A (UVA, 315-400 nm) and visible wavelengths, a cloud optical depth of 10 will only reduce the surface downwelling irradiance by $5 \%$ compared with clear skies, and a cloud optical depth of 100 is required to cause a $40 \%$ reduction compared with clear skies, for solar zenith angle $60^{\circ}$ [Bernhard et al., 2006]. To estimate cloud optical depth over Antarctic surfaces, high measurement accuracy and precision are required, along with accurate knowledge of the surface albedo.

[87] Stamnes et al. [1990] estimated cloud optical depth at McMurdo Station in the range 10-20 throughout the sunlit part of the year, using UVA spectroradiometer measurements [Bernhard et al., 2006], although several estimates were as large as 40-50. These large values may actually be artifacts of non-plane-parallel radiation transfer. Large excursions in estimated cloud optical depth are a common occurrence when simulating real clouds with a plane-parallel radiative transfer model, then attempting to match the simulations with observations. Lubin and Frederick [1991] obtained similar estimates of cloud optical depth at Palmer Station during spring 1988, with ranges of 8-19 for low overcast, 6-12 for high overcast, and 17-24 for storm and snowfall conditions. During spring 1991 at Palmer Station, Ricchiazzi et al. [1995] find larger stratiform cloud optical depths, mostly in the range 20-50. During summer 2000 at Palmer Station, optical depths of stratus and stratocumulus were similar to those during spring 1988 [Lubin et al., 2002], although stratus fractus of bad weather can show optical depths in the range 40-90 (again, these high values may be artifacts of horizontal cloud inhomogeneity). Fitzpatrick and Warren [2004] caution that radiometrically derived cloud optical depths as described above are best regarded as "effective" optical depths rather than as precise manifestations of instantaneous microphysics.
[88] At South Pole, low cloud total water content and high surface albedo combine to yield small attenuation of surface shortwave irradiance by clouds. Bernhard et al. [2004] found UVA attenuations, relative to clear skies, on the order of $5 \%$ on average, with no measured attenuation greater than $23 \%$. Cloud optical depth estimated from the spectral UVA measurements was between 0 and 1 for $71 \%$ of the time and between 1 and 5 another $16 \%$ of the time. Similar results were obtained for the South Pole clouds by Mahesh et al. [2001b] using a radiative transfer algorithm designed for FTIR data; they find that $65 \%$ of clouds sampled have optical depths 0 and 1 , and $24 \%$ have optical depths between 1 and 5. Aside from some basic sorting of clouds by first-order morphology or base height, there is little insight so far in these earlier studies from Palmer, McMurdo, and South Pole as to what types of meteorological conditions or microphysical processes give rise to different ranges of cloud optical depth.

\subsection{Regional Examples of Cloud Properties}

[89] In this section, the microphysical properties of Antarctic clouds described above are further discussed in four regional examples of observational programs. Some insight into the macrophysical properties of clouds (spatial distribution), presented in section 3, is also provided.

\subsubsection{Queen Maud Land}

[90] Monitoring programs including a combination of low-maintenance multiwavelength passive and active remote sensing instruments can provide comprehensive simultaneous data of cloud and precipitation macrophysical properties. One such program has recently started at the Belgian Antarctic station, Princess Elisabeth $\left(72^{\circ} \mathrm{S}, 23^{\circ} \mathrm{E}\right.$; $180 \mathrm{~km}$ inland, $1420 \mathrm{~m}$ asl), in Queen Maud Land (http:// ees.kuleuven.be/hydrant/) [Gorodetskaya et al., 2010]. The observatory consists of an automatic weather station (AWS) and a suite of ground-based cloud and precipitation remotesensing instruments. The AWS includes basic meteorological sensors (for temperature, humidity, pressure, and wind), four-component broadband radiometer containing both upward- and downward-facing pyranometers for shortwave 

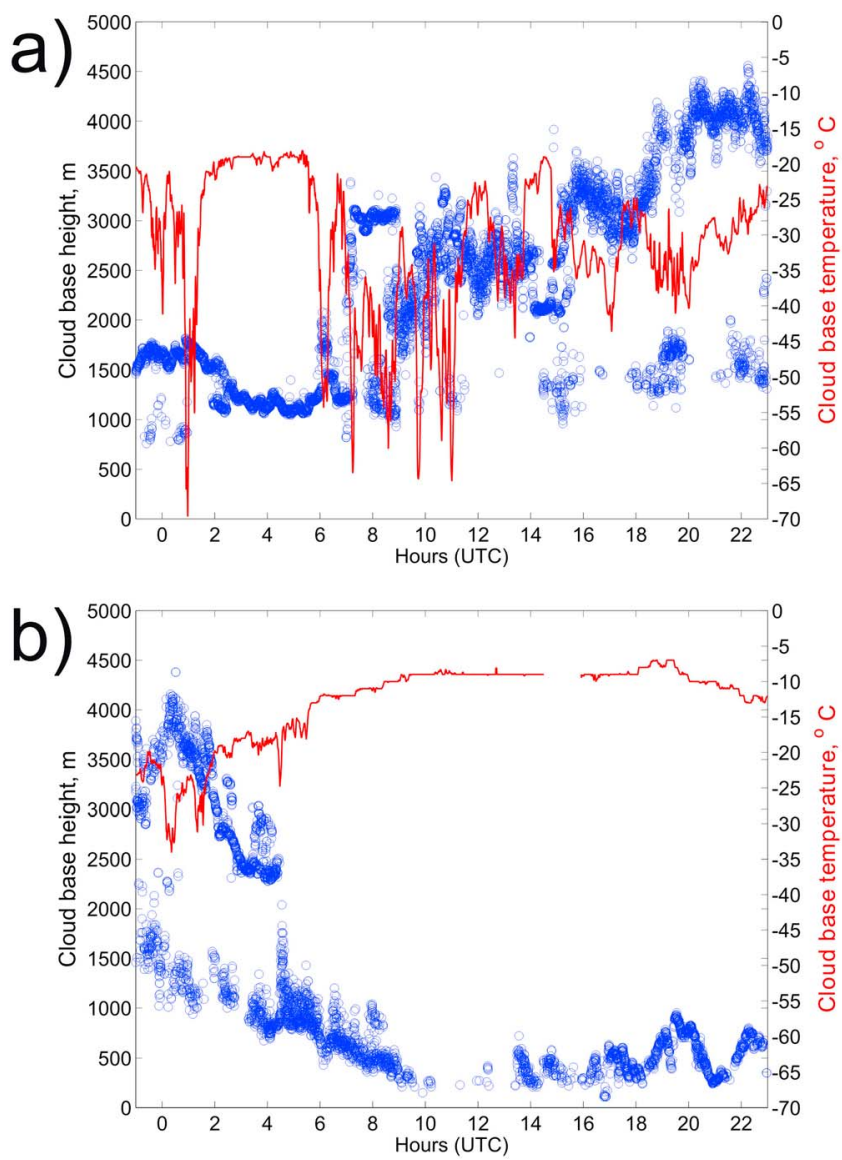

Figure 15. Cloud base heights in meters above surface (blue circles represent measurements every $15 \mathrm{~s}$ ) and effective cloud base temperature in degrees Celsius (red lines represent 2 min running mean based on original $15 \mathrm{~s}$ measurements) at Princess Elisabeth Station during (a) 6 February 2010 and (b) 7 February 2010. Cases when the ceilometer reported vertical visibility are excluded.

and pyrgeometers for longwave radiative fluxes, and ultrasonic snow height sensor. The remote sensing instruments include $910 \mathrm{~nm}$ pulsed laser ceilometer providing cloud vertical structure and height, infrared pyrometer providing equivalent blackbody cloud base temperature from the measured 8-14 $\mu \mathrm{m}$ radiance, and vertically pointing $24 \mathrm{GHz}$ precipitation radar providing snowfall depth and intensity.

[91] Currently, only short-term observational records are available, but the potential of this observatory can be illustrated by the analysis of a 2 day storm evolution during the austral summer 2010. On 6-7 February 2010, a synoptic event with snowfall at Princess Elisabeth was caused by a large depression centered to the northwest of the station, moving southeast and bringing a thick cloud deck over Queen Maud Land. Both low-level and midlevel clouds were observed at the station during the first day, forming multiple layers with short periods of light precipitation (Figure 15a). Cloud base temperatures ranged between $-20^{\circ} \mathrm{C}$ for low-level clouds $(1-1.5 \mathrm{~km})$ and $-35^{\circ} \mathrm{C}--40^{\circ} \mathrm{C}$ for midlevel clouds $(2-4 \mathrm{~km})$. During January through March 2010, the 1-3 km height range was found to have the highest cloud frequency (70\% of all cloud occurrences) at Princess Elisabeth (Figure 16). Strong ceilometer backscatter signal and cloud base temperatures higher than $-40^{\circ} \mathrm{C}$ suggest the presence of liquid in these clouds.

[92] During the second day, low clouds (with bases at $1-1.5 \mathrm{~km}$ ) started to dominate the sky (Figure 15b) with precipitation detected by the radar from 0500 UTC onward. Ceilometer observations showing cloud bases below $1 \mathrm{~km}$ above ground level must be treated with caution as in most cases they indicate precipitation and blowing snow near the surface. A significant increase in downwelling longwave flux (up to $20 \mathrm{~W} \mathrm{~m}^{-2}$ ) was recorded by the AWS pyrgeometer associated with the cloud base lowering and increase in cloud base temperature. Radar measurements indicated that the depth of precipitating layer ranged from 1 to at least $3 \mathrm{~km}$ above ground level (the limit of the radar vertical resolution) during the day. The height and temperature of precipitation formation plays an important role in snow particle size distribution and morphology and also has an important implication for the interpretation of the paleoclimate records from ice cores [Masson-Delmotte et al., 2008].

\subsubsection{Ross Island}

[93] One of the few genuine cloud microphysical experiments carried out in Antarctica was reported by Saxena and Ruggiero [1990b]. An LC-130 aircraft was instrumented with a CCN spectrometer, a FSSP, and a cloud water collection probe to measure $\mathrm{CCN}$ concentration, cloud droplet size distribution, and cloud water acidity. The aircraft made two flights, on 3 and 5 November 1980, successfully sampling liquid water clouds near Ross Island. Liquid water prevailed for cloud base temperatures in the range $-18.6^{\circ} \mathrm{C}-$ $-5.3^{\circ} \mathrm{C}$. Cloud droplet size distributions exhibited a bimodal distribution that is not readily explained by classical condensational growth. Four clouds sampled (base heights 500$700 \mathrm{~m}$ ) had mean droplet diameter between 9.2 and $9.9 \mu \mathrm{m}$, while another three (base heights 1400-1900 m) had mean droplet diameter between 11.9 and $13.5 \mu \mathrm{m}$. Two of these latter observations occurred for the coldest cloud layers. Liquid water content ranged from 0.06 to $0.18 \mathrm{~g} \mathrm{~m}^{-3}$. CCN spectra obtained on the first flight were fitted to the form $n=C S^{k}$, where $n$ is the number concentration per unit volume with critical supersaturations less than $S$. Throughout the flight, $k=1.03$, while the parameter $C$ varied between 121 and $242 \mathrm{~cm}^{-3}$. Sea salt and sulfate alternated as the primary source of $\mathrm{CCN}$, depending on cloud layer. Cloud acidity ( $\mathrm{pH}$ 5.7-6.2) was higher than expected for typical remote stratus clouds, and biogenic marine sulfate appeared responsible. Cloud supersaturations were between $0.34 \%$ and $0.76 \%$, which are large values for stratus clouds, and droplet concentrations were small $\left(33-101 \mathrm{~cm}^{-3}\right)$. Overall, cloud formation appeared to be characterized by limited competition for the available water vapor.

\subsubsection{The Antarctic Peninsula}

[94] In early 2010, 14 in-cloud research flights were operated from the British Antarctic Survey Rothera research base $\left(67.6^{\circ} \mathrm{S}, 68.1^{\circ} \mathrm{W}\right)$ on the Antarctic Peninsula. The Twin Otter aircraft was fitted with cloud probe instruments, making this the first set of extensive in situ cloud observations over 

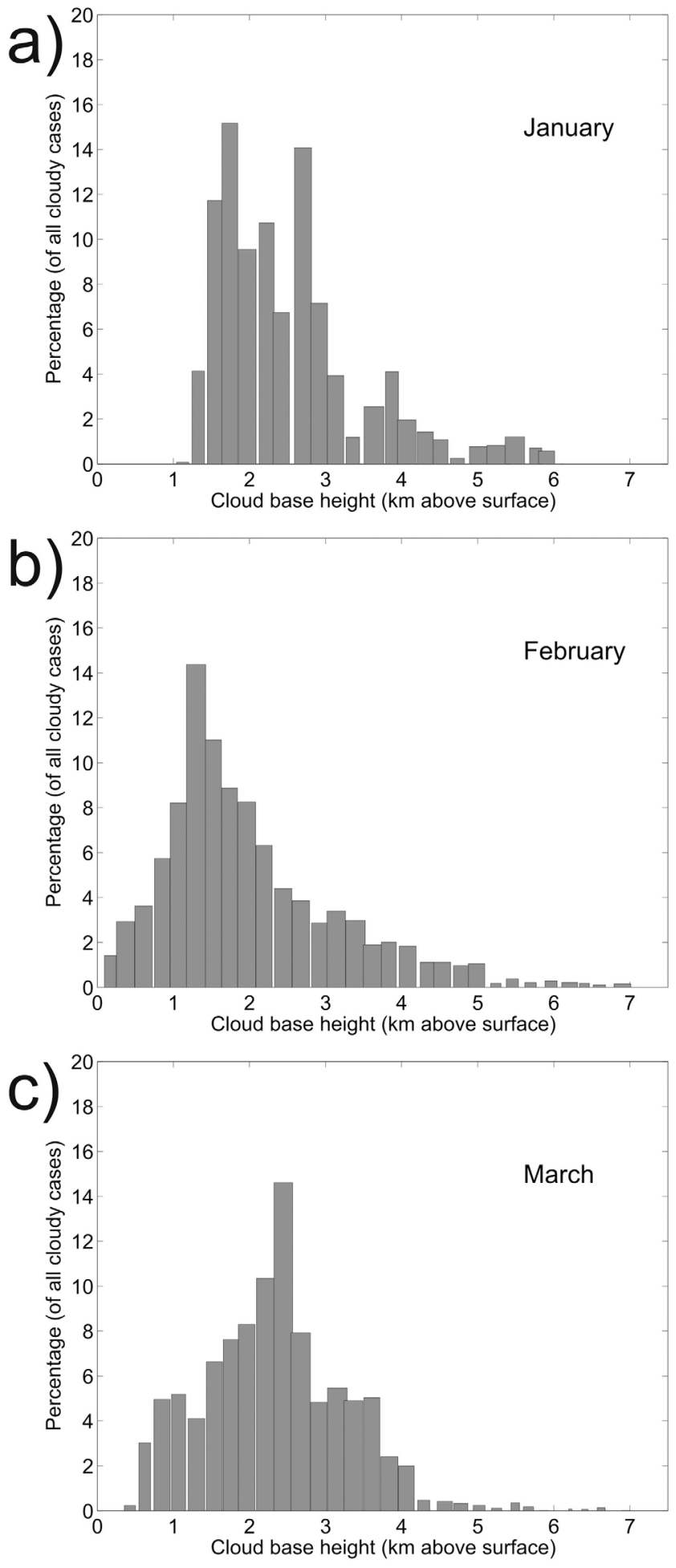

Figure 16. $(\mathrm{a}-\mathrm{c})$ Percentage of cloud base height occurrence within each cloud height bin (ranging from 0 to $7.5 \mathrm{~km}$ above ground level with bin interval of $250 \mathrm{~m}$ ) based on ceilometer measurements at Princess Elisabeth Station, Queen Maud Land, during 19 January through 30 March 2010. The percentages are calculated relative to the total number of cloudy profiles in each month. Bars are centered at the mean value within corresponding cloud height bin with the width equal to $\pm 2 \sigma$.
Antarctica since the two flights of Saxena and Ruggiero [1990b]. Three cloud instruments were fitted: the CAS (Cloud Aerosol and Spectrometer) probe, which measures size distributions of particles between 0.6 and $50 \mu \mathrm{m}$ in diameter and so mainly detects large aerosol, liquid water droplets, and small ice; the CIP (Cloud Imaging Probe), which images larger particles of between 12.5 and $1562.5 \mu \mathrm{m}$ in diameter and so mainly detects ice particles along with larger droplets and raindrops; and the King hotwire probe, which measures the liquid water content by evaporating droplets. Preliminary analysis of selected flights was presented by Grosvenor et al. [2010]. The first five flights have now been analyzed in detail and the results will be submitted to a peer reviewed journal shortly (D. Grosvenor, manuscript in preparation, 2011). The focus of this analysis has been on ice formation with ice concentrations calculated from CIP images using software developed at the University of Manchester, Manchester, United Kingdom.

[95] Clouds were sampled between temperatures of -0.5 and $-21^{\circ} \mathrm{C}$. The results highlight the likely importance of the Hallett-Mossop process [Hallett and Mossop, 1974, hereinafter $\mathrm{HM}]$, which operates over the narrow temperature range of $-3^{\circ} \mathrm{C}--8^{\circ} \mathrm{C}$, when considering the presence of ice in Antarctic clouds. Within this temperature range, droplets riming onto ice particles can shatter into many fragments. These ice particles can themselves then act as riming targets for smaller droplets. The fragments can also go on to freeze supercooled water droplets that they collide with, producing larger ice crystals that are likely to be more efficient riming targets. The process can continue at a greater rate, leading to concentrations of ice particles that are far higher than what would otherwise be expected from primary heterogeneous nucleation, especially at such warm temperatures. The presence of some ice is required in order to start off this process. It is possible that this initial ice is formed within the HM temperature zone through heterogeneous nucleation, although given the relatively warm temperatures it is also possible that the ice would have to come from that formed heterogeneously at colder temperatures where IN are thought to be more prevalent.

[96] The ice concentrations found within the HM temperatures zone in the Antarctic clouds were at least 2 orders of magnitude higher than those found in clouds where primary ice production through the activation of IN (heterogeneous nucleation) operates. Ice concentrations of up to $\sim 10 \mathrm{~L}^{-1}$ were observed near the HM zone with characteristic column-shaped ice being produced (Figure 17a). In stark contrast, ice concentrations outside of this temperature zone reached maximum concentrations of $\sim 0.15 \mathrm{~L}^{-1}$ in one small region, although values of $<0.1 \mathrm{~L}^{-1}$ were more typical (Figure 17b). Given that mixed phase cloud (i.e., cloud containing liquid and ice) was sampled down to temperatures of $-21^{\circ} \mathrm{C}$, the detection of such modest maximum ice concentrations suggests that low concentrations of IN were available. The presence of liquid is likely to be important when considering ice nucleation since deposition, condensation, and contact nucleation can occur. This suggests that the rapid increase in IN concentrations with decreasing 


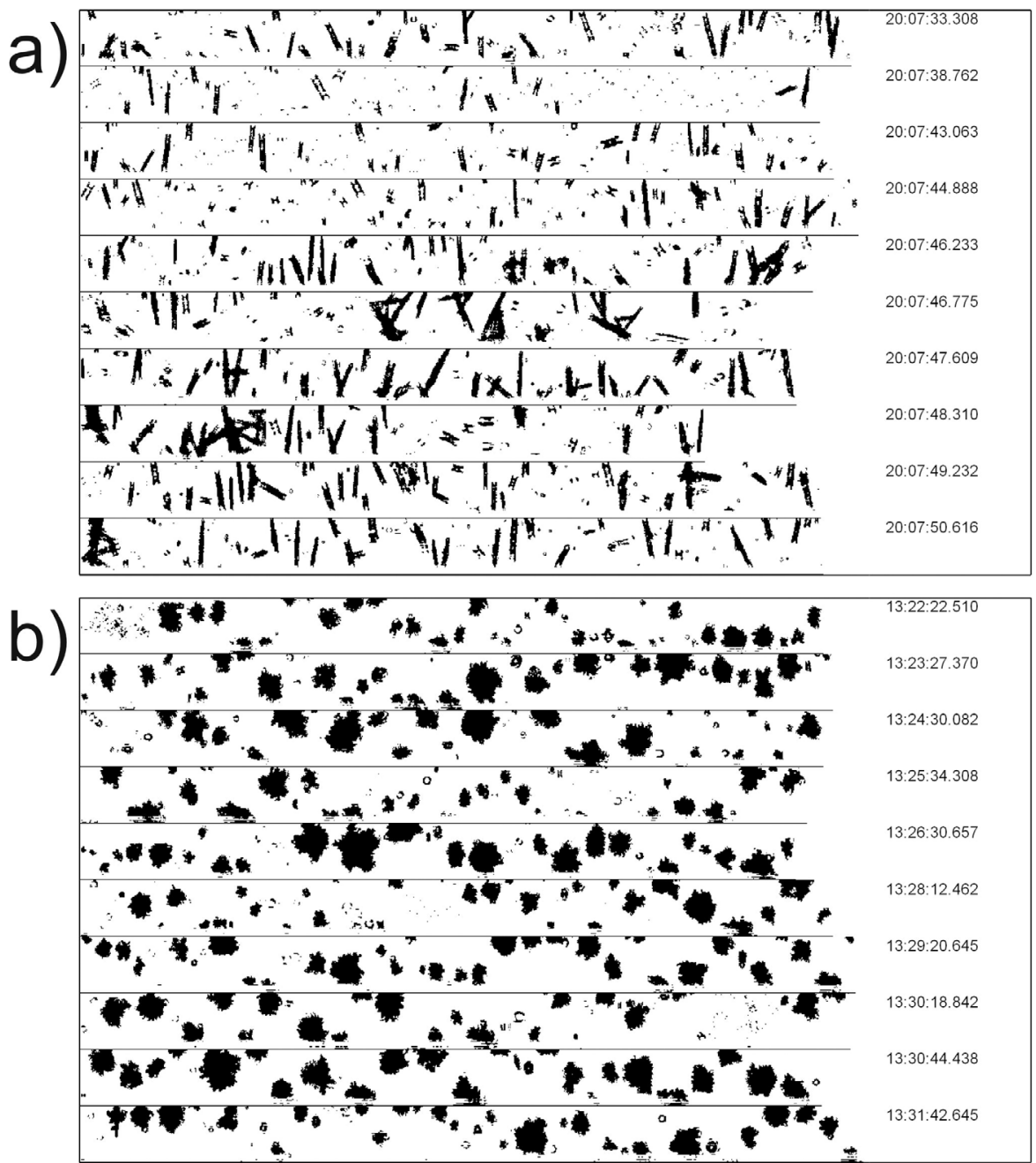

Figure 17. Example of CIP images taken (a) during a period when the aircraft was near to the HallettMossop temperature region and (b) in orographic cloud at temperatures between $-16^{\circ} \mathrm{C}$ and $-19^{\circ} \mathrm{C}$ when the ice was likely to have formed from heterogeneous nucleation.

temperatures observed at McMurdo [Bigg and Hopwood, 1963] (mean IN concentrations of $3 \mathrm{~L}^{-1}$ and $12 \mathrm{~L}^{-1}$ were reported at $-20.3^{\circ} \mathrm{C}$ and $-22.2^{\circ} \mathrm{C}$, respectively) was not occurring in these Antarctic Peninsula clouds. Such rapid IN increases with temperature reduction are also inherent in many heterogeneous ice parameterizations. For example, between $-18^{\circ} \mathrm{C}$ and $-22^{\circ} \mathrm{C}$ the Fletcher [1962] scheme predicts an increase of $0.5-5.4 \mathrm{~L}^{-1}$ and the Cooper [1986] scheme predicts an increase of $1.2-4 \mathrm{~L}^{-1}$. The latter scheme is used in the Morrison et al. [2009] double moment microphysics schemes, which is included in the Weather Research and Forecasting (WRF) model (version 3) and is probably the most sophisticated microphysics model available in that model.

[97] The more recent DeMott et al. [2010, hereinafter DM10] scheme predicts much less rapid increases in IN with temperature and thus appears to model the present data more closely. An aerosol concentration value for sizes $>0.5 \mu \mathrm{m}$ in diameter is required as a parameter for this scheme, which represents the fact that IN are aerosol particles and that increased aerosol concentrations are likely to mean increased IN concentrations at a given temperature. Using the typical out of cloud aerosol concentrations observed by the CAS instrument in the available size range of $>0.6 \mu \mathrm{m}$ gives values of $0.2-0.3$ and $0.3-0.46 \mathrm{~L}^{-1}$ (depending on the aerosol concentration chosen) at $-18^{\circ} \mathrm{C}$ and $-22^{\circ} \mathrm{C}$ from the scheme. Thus, the agreement with the maximum ice concentrations observed is reasonable. There is likely to be a strong marine influence on the aerosol composition in the Antarctic Peninsula region, and hence, a large component of the aerosol present is likely to be sea salt. Sea salt is prone to swelling with increased relative humidity, yet it does not nucleate ice and the DM10 parameterization was based on observations in regions that were thought to contain little sea salt aerosol. Given this, the aerosol concentrations based on the Antarctic Peninsula measurements here may represent an overestimate compared to the aerosol parameter that should be provided as input into the DM10 parameterization because of the counting of swollen sea salt aerosol. Thus, the parameterized IN values should perhaps be reduced a little from those quoted above. 


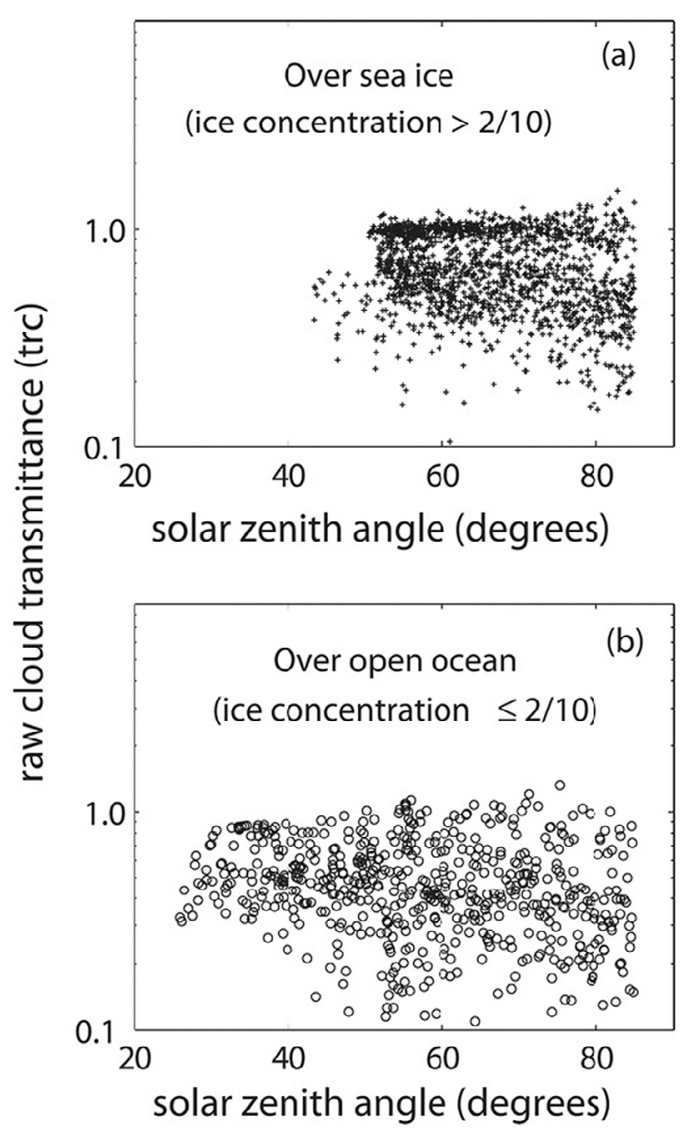

Figure 18. Cloud transmittance derived from pyranometers deployed on the 1996 springtime voyage of RSV Aurora and shown over (a) sea ice concentrations $>0.2$ and (b) open ocean (sea ice concentrations $<0.2$ ). The "Koehler gap" appears in the data over sea ice, in the relatively small number of data points between $0.8<\operatorname{trc}<1.0$ for all solar zenith angles. From Fitzpatrick and Warren [2005].

This might allow for a better match with the observed ice concentrations than the higher-than-observed values quoted.

[98] Despite the rapid production of large number concentrations of ice possible in the HM zone, there were many occasions when no ice was detected among liquid cloud located within the HM temperature range. This fits with the relatively low concentrations of ice seen in the heterogeneous ice nucleation regions. Ice particles are required to initiate the HM process, and these initial ice particles will need to come from heterogeneous nucleation. At the relatively warm temperatures of the HM zone the results here indicate that IN concentrations are likely to be very low, and the occurrence of the HM process in some places, but not in others, may indicate some variability in IN concentrations. Alternatively, the lack of HM multiplication in some regions may have been due to a lack of precipitating ice from above. Another possibility is that sufficient numbers of $<12 \mu \mathrm{m}$ and $>25 \mu \mathrm{m}$ diameter droplets were not present, as the presence of droplets of these sizes is thought to be a requirement for the HM process to occur. This highlights the fact that representation of the HM process in models is not straightfor- ward and is likely to require the inclusion of several linked microphysical processes.

[99] The results highlighted here suggest that IN concentrations in this region of Antarctica are likely to be lower than those that would be predicted by many older parameterizations. Thus, models based on these parameterizations, such as the WRF model when run with the popular Morrison et al. [2009] scheme and likely several global climate models, are likely to overestimate ice concentrations with subsequent impacts on the representation of cloud microphysics. The correct representation of the HM process is also likely to be of great importance since this can lead to ice numbers 2 or 3 orders of magnitude greater than the heterogeneous ice nucleation concentrations.

\subsubsection{Southern Ocean}

[100] Fitzpatrick and Warren [2005] obtained wellcharacterized broadband radiometric data from 18 voyages of the RSV Aurora Australis, when this vessel supported the Australian National Antarctic Research Expeditions (ANARE) on transects between Hobart and East Antarctica during the years 1991-2002. On the basis of the large volume of data collected, covering all four seasons, this observational program produced a viable climatology of Southern Ocean and coastal Antarctic cloud properties (in contrast to individual measurement campaigns described above). Gimbaled pyranometers were deployed on the port and starboard sides of the ship, and collocated all-sky photography was used to correct the data for field-of-view obstructions from the ship's superstructure. These cruises carried trained weather and ice observers, who provided valuable ancillary data. Surface albedo measurements of various sea ice types by Allison et al. [1993] and Brandt et al. [2005] were used to interpret the sea ice observations for input to the radiative transfer algorithm. Cloud cover records made every $3 \mathrm{~h}$ were used to distinguish clear from cloudy skies, which provided an empirical grounding for the radiative transfer retrieval method [Fitzpatrick and Warren, 2004].

[101] One insight appears in the data of Fitzpatrick and Warren [2005] even before cloud optical depth is estimated (Figure 18). In the raw cloud transmittance, $\operatorname{trc}$ (defined as the ratio of downwelling irradiance under cloud to the irradiance under clear sky with the same solar zenith angle), the range $0.8<\operatorname{trc}<1.0$ is sparsely populated, compared with smaller values (optically thicker clouds). This may represent a threshold in the transition from aerosol to cloud and would only appear if $\mathrm{CCN}$-active aerosols are primarily of one type (e.g., biogenic DMS). Fitzpatrick and Warren [2005] label this sparely populated trc distribution range the "Koehler gap." The presence of several types of $\mathrm{CCN}$-active aerosol would obscure this gap. The extensive pyranometer measurements from this program also provide a climatology of the cloud optical depth, $\tau$, over the East Antarctic maritime sector sampled by the Aurora (Figure 19). The frequency distributions of $\tau$ by latitude range show greater optical depths (up to 60) occurring over open water north of the seaice edge. The fitting of exponential decay functions to the histograms yields estimates of average optical depths (the decay constant, $\tau_{\mathrm{c}}$, in the fitting functions). The $55^{\circ} \mathrm{S}-60^{\circ} \mathrm{S}$ 


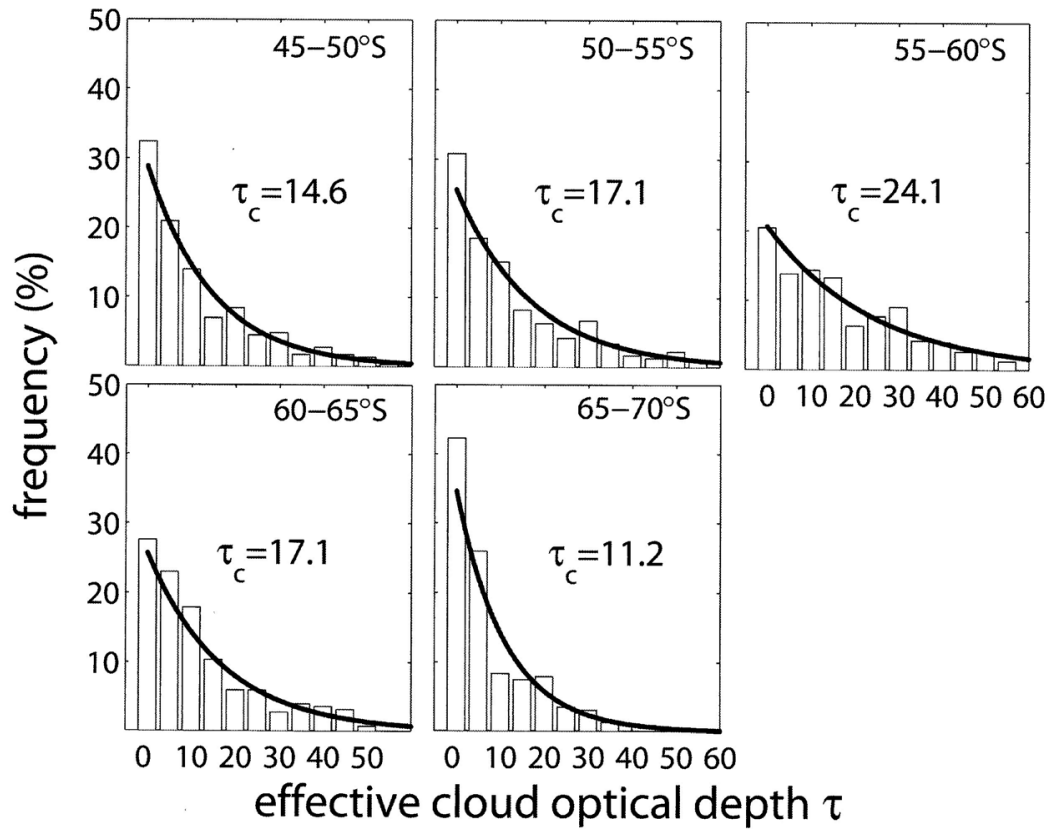

Figure 19. Cloud optical depth retrieved from pyranometer measurements deployed with ANARE support missions of RSV Aurora between 1991 and 2002. These retrievals encompass all seasons but with a bias toward spring and summer. The total number of observations is 797, 528, 380, 268, and 254 for latitude bands $45^{\circ} \mathrm{S}-50^{\circ} \mathrm{S}, 50^{\circ} \mathrm{S}-55^{\circ} \mathrm{S}, 55^{\circ} \mathrm{S}-60^{\circ} \mathrm{S}, 60^{\circ} \mathrm{S}-65^{\circ} \mathrm{S}$, and $65^{\circ} \mathrm{S}-70^{\circ} \mathrm{S}$, respectively. The histograms give percentages for bins of width $\Delta \tau=5$. The solid curves depict an exponential fit: $f(\tau)=$ $\left(1 / \tau_{\mathrm{c}}\right) \exp \left(-\tau / \tau_{\mathrm{c}}\right)$. From Fitzpatrick and Warren [2005].

latitude band exhibits the thickest clouds, consistent with the peak in cloud fractions seen in CloudSat-CALIPSO (Figure 8b) and MODIS (Figure 8f) over eastern longitudes, as discussed in section 3.1.1.

\section{MODELING OF ANTARCTIC CLOUDS}

[102] As noted by Lachlan-Cope [2010], the microphysical properties of cloud particles can have a major impact on the Earth's radiation budget. It is therefore important that they are correctly represented in climate models. Unfortunately, model cloud parameterizations are often empirically based upon measurements made in the Tropics and middle latitudes, so that their applicability for Antarctic clouds is questionable. For example, cloud physics schemes must provide for the radiative properties of thin clouds over Antarctica [Gallée and Gorodetskaya, 2010]. Furthermore, climate model simulations demonstrate the nonlocal as well as global impacts of changes in Antarctic cloud characteristics [Shibata and Chiba, 1990; Lubin et al., 1998; Gordon et al., 2000; Lachlan-Cope, 2010].

[103] This section discusses the modeling of Antarctic clouds with global and regional models, taking the opportunity to introduce important issues and technical details. Efforts with these models to represent Antarctic clouds within the hydrologic cycle have shown progress over the last two decades, but considerable work remains.

[104] Antarctic cloud modeling can be contrasted to that of the Arctic, where the clouds, especially the frequent summer mixed-phase clouds, are still not adequately represented in numerical models, but the challenges are well-recognized and concerted efforts have been organized to address the issues [e.g., Randall et al., 1998; Curry et al., 2000; Verlinde et al., 2007; Vavrus et al., 2009]. For the Antarctic region, there has been much less extensive research seeking to evaluate or improve the performance of cloud representations in numerical models. Nevertheless, the present cloud representations for Antarctica in current state-of-the-art numerical models appear to be far superior to those from the early systematic studies with global and regional models during the 1990s [e.g., Bromwich et al., 1995; Hines et al., 1997]. Much of that improvement is attributable to a general improvement in model cloud representations rather than a specific emphasis on Antarctic clouds.

\subsection{Global Models}

\subsubsection{Advances in Cloud Parameterization: The Example of NCAR's Climate Models}

[105] It is beyond the scope of this paper to present a comprehensive review of the cloud parameterizations and their Antarctic performances for all global climate models (GCMs) in use today. Instead, a historical perspective on cloud modeling in the generations of the widely used National Center for Atmospheric Research (NCAR) models is presented. Additional information about cloud parameterization in climate models can be found in the work by Stensrud [2009].

[106] It is common for GCMs to separate the cloud processes within the hydrologic cycle into (1) resolvable or "grid-scale" or "macrophysics" or "bulk microphysics" 
treatment that is applicable to the broad cloud systems within synoptic weather systems and (2) "sub-grid-scale" processes, especially for cumulus clouds. The latter is typically treated with cumulus parameterizations and will not be discussed further. The early representations of the large-scale processes within the hydrologic cycle by the NCAR climate models did not include prognostic treatment of cloud condensate. Rather, while water vapor was normally calculated as a prognostic variable, diagnostic formulas were applied to the clouds, precipitation, and the associated radiative properties [Williamson et al., 1987; Hack et al., 1993]. In particular, effective cloud particle radius is an important parameter for determining radiative characteristics from cloud variables [e.g., Lubin and Harper, 1996].

[107] Systematic evaluations of the representation of the Antarctic hydrologic cycle within NCAR climate models were initiated through a series of papers focusing on precipitation [e.g., Tzeng et al., 1993, 1994]. Their findings were summarized by Bromwich et al. [1995] and show that the standard version 2 of the NCAR Community Climate Model (CCM2) with improved horizontal resolution (T42) and the spectral transform method does not suffer from the huge positive polar biases in the polar hydrologic cycle of the lower resolution (R15) CCM1, which employed a positive moisture fixer scheme to remove negative values. The CCM2 more or less represented the arid climate of the continent.

[108] Additional efforts to evaluate and improve the representation of Antarctic clouds followed. Lubin et al. [1998] introduced the ice cloud optical properties of Ebert and Curry [1992] into the continental clouds over Antarctica, replacing the standard global water clouds in simulations with the NCAR CCM2. By substituting in the ice cloud optical properties over Antarctica they found that the simulation impact extended throughout the Southern Hemisphere well beyond the region of the $1{ }^{\circ} \mathrm{C}-2^{\circ} \mathrm{C}$ local warming that resulted directly from the change.

[109] Furthermore, Briegleb and Bromwich [1998a, 1998b] systematically evaluated the polar climate simulations of the following generation NCAR CCM3 developed during the late 1990s. Unfortunately, a plateau had been reached in the quality of the polar hydrologic cycle, perhaps because the diagnostic parameterization for cloud fraction was nearly identical to that of the earlier CCM2. Both versions determine cloud fraction following the widely used Slingo [1989] methodology, which is based upon relative humidity, with vertical velocity, static stability, and convective mass flux as additional inputs. The diagnosed cloud fraction is then fed into the radiation calculations. On the other hand, CCM3 did allow for ice clouds with a strict linear, temperature-based transition between liquid and ice clouds, with all-ice clouds for temperatures below $-30^{\circ} \mathrm{C}$ and all-water clouds for temperatures above $-10^{\circ} \mathrm{C}$. Over the oceans, cloud liquid water droplet effective radius was set at $10 \mu \mathrm{m}$. Over land, the liquid droplet size was variable, with radii as small as $5 \mu \mathrm{m}$. Briegleb and Bromwich [1998a] found CCM3's clouds, hydrologic cycle, and associated radiative fields over Antarctica were not superior to those of CCM2. Polar cloud water path was too large by about a factor of two, and the longwave and shortwave radiation were correspondingly biased.

[110] In an effort to improve the simulation of Antarctic clouds and climate, Hines et al. [2004] implemented changes into the NCAR CCM3. One change was to replace the standard diagnostic clouds with the Rasch and Kristjánsson [1998] single-moment prognostic cloud scheme with water and ice condensate. The new scheme is simpler than other prognostic bulk microphysics schemes in that it lacks a multivariate treatment of condensate found in more advanced schemes [e.g., Gallée, 1995; Girard and Curry, 2001]. The transformation of cloud ice to snow is known as "autoconversion" and is simply treated with a threshold cloud ice mixing ratio. The application of the new prognostic scheme resulted in increased (decreased) cloud emissivity in the upper (lower) troposphere, a qualitative improvement in the vertical distribution of cloud radiative properties over Antarctica. The optical thickness of Antarctic clouds, however, was excessive, resulting in errors in the longwave and shortwave radiative fields. The simple formula for autoconversion appeared to be at least partly responsible for the error. Excessive ice cloud amount was required for autoconversion, despite observations showing optically thin precipitating Antarctic clouds.

\subsubsection{Antarctic Cloud Cover in IPCC AR4 Models}

[111] Cloud radiative forcing represents the major source of discrepancies between GCMs [Dufresne and Bony, 2008]. Yet systematic reviews of the quality of cloud simulations by GCMs, especially in high southern latitudes, have been lacking, owing to a large extent to the absence of a reliable cloud climatology. Building upon the CloudSatCALIPSO cloud data set presented in section 3, the present section presents an evaluation of the cloud amounts from 12 GCMs used for the Intergovernmental Panel on Climate Change (IPCC) Fourth Assessment Report (AR4) [Solomon et al., 2007] over the Southern Ocean and Antarctica. The 12 models examined here and listed in Table 3 represent the state-of-the-art GCMs in the late 2000s decade. The 20 year model simulations (1980-1999) are taken from the Atmospheric Model Intercomparison Project (AMIP) experiment, in which the atmospheric component of the GCMs is constrained by observed sea surface temperature and sea ice concentrations. Thus, the assessment is not affected by the quality of the ocean model simulations. The model total cloud fraction (CF) fields are obtained from the World Climate Research Programs Coupled Model Intercomparison Project 3 data portal (https://esg.llnl.gov:8443/). Note that the evaluations of the AR4 models, globally and over Antarctica, have generally been done using their coupled ocean-atmosphere configuration [e.g., Chapman and Walsh, 2007; Connolley and Bracegirdle, 2007; Randall et al., 2007; Monaghan et al., 2008].

[112] Figure 20 shows maps of the mean annual $\mathrm{CF}$ from CloudSat-CALIPSO and the 12 IPCC AR4 model ensemble average. It also includes the results from three individual GCMs (Community Climate System Model, version 3 (CCSM3); Hadley Centre Global Environment Model, 
TABLE 3. List of the 12 IPCC AR4 Global Climate Models Evaluated in This Study ${ }^{\mathrm{a}}$

\begin{tabular}{lcc}
\hline \multicolumn{1}{c}{ Model } & Institute & Resolution $^{\mathrm{b}}$ \\
\hline HadGEM1 & Met Office, UK & $1.25^{\circ} \times 1.875^{\circ}$ \\
ECHAM5 & Max Planck Institute for Meteorology, Germany & $\sim 1.88^{\circ} \times 1.88^{\circ}$ \\
CCSM3 & National Center for Atmospheric Research, USA & $\sim 1.4^{\circ} \times 1.4^{\circ}$ \\
PCM1 & National Center for Atmospheric Research, USA & $\sim 2.8^{\circ} \times 2.8^{\circ}$ \\
CNRM-CM3 & Centre National de Recherches Météorologiques, France & $\sim 2.8^{\circ} \times 2.8^{\circ}$ \\
GFDL-CM2.0 & Geophysical Fluid Dynamics Laboratory, USA & $2.0^{\circ} \times 2.5^{\circ}$ \\
GISS-ER & Goddard Institute for Space Studies, USA & $4.0^{\circ} \times 5.0^{\circ}$ \\
FGOALS1 & Institute for Atmospheric Physics, China & $\sim 2.8^{\circ} \times 2.8^{\circ}$ \\
INM-CM3 & Institute for Numerical Mathematics, Russia & $4.0^{\circ} \times 5.0^{\circ}$ \\
IPSL-CM4 & Institut Pierre Simon Laplace, France & $2.5^{\circ} \times 3.75^{\circ}$ \\
MIROC3-medres & Center for Climate System Research, Japan & $\sim 2.8^{\circ} \times 2.8^{\circ}$ \\
MRI CGCM2 & Meteorological Research Institute, Japan & $\sim 2.8^{\circ} \times 2.8^{\circ}$ \\
\hline
\end{tabular}

${ }^{a}$ The study uses monthly data from the AR4 AMIP simulations (run 1). More details about the model configurations are available at http://www-pcmdi.llnl.gov/projects/amip/.

${ }^{\mathrm{b}}$ Latitude-longitude resolution of the atmospheric model.

version 1 (HadGEM1); and European Center/Hamburg, version 5 (ECHAM5)) as well as those from the ERAInterim reanalysis [Dee et al., 2011]. Unlike the AR4 GCMs, ERA-Interim is constrained by a wide variety of atmospheric observations, such as radiosoundings and satellite radiances.
Nonetheless, clouds are produced by the reanalysis model short-term forecasts and are thus strongly influenced by the model physics. ERA-Interim data were initially only available from 1989 onward. Therefore, a 20 year period spanning 1990-2009 is considered here (this data set has recently been a) ECHAM5

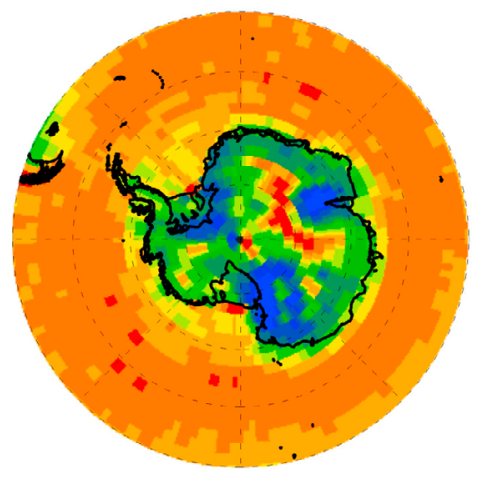

d) 12-model average

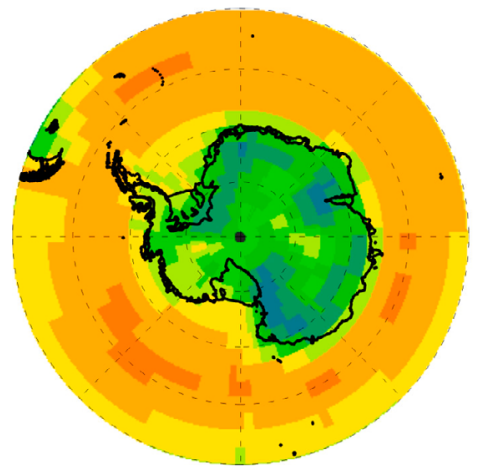

b) HADGEM1

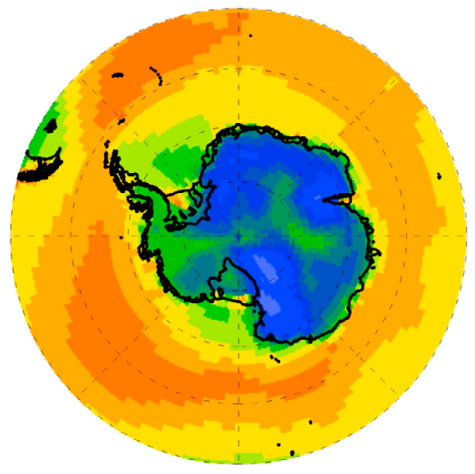

e) ERA-Interim

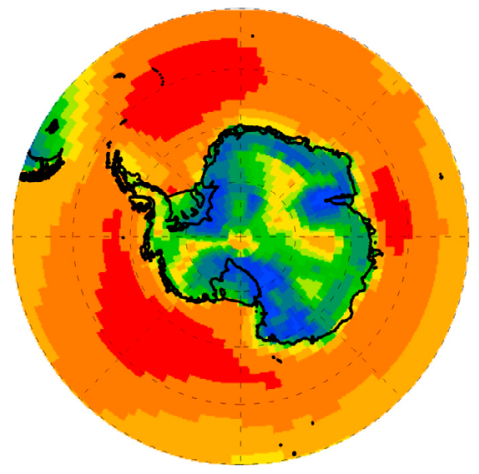

c) $\operatorname{CCSM3}$

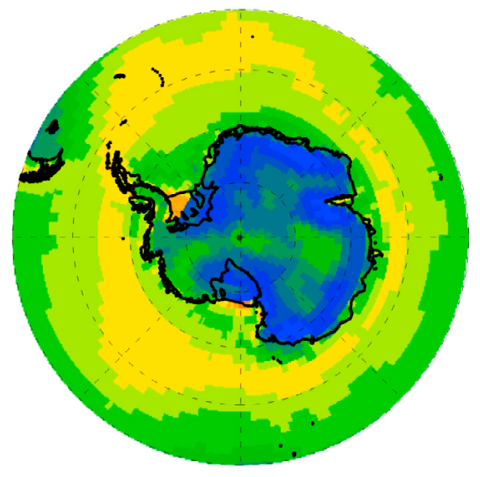

f) CloudSat/CALIPSO

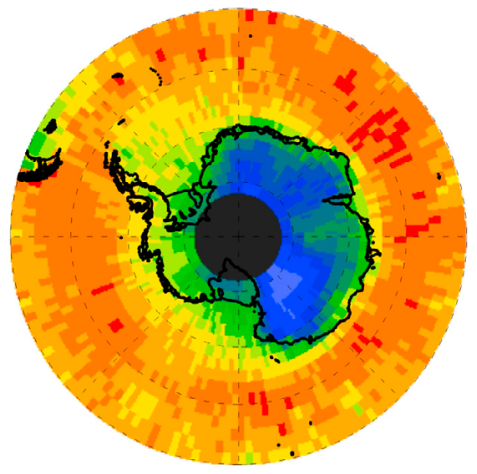

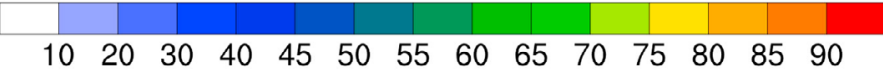

Figure 20. Annual average total cloud fraction in percent poleward of $50^{\circ} \mathrm{S}$ from $(\mathrm{a}-\mathrm{c})$ three individual IPCC AR4 AMIP model simulations (ECHAM5, HadGEM1, and CCSM3) spanning 1980-1999, (d) the ensemble average from the 12 IPCC AR4 AMIP model simulations listed in Table 3 and spanning 19801999, (e) the ERA-Interim reanalysis spanning 1990-2009, and (f) the CloudSat-CALIPSO cloud retrievals spanning September 2006 to August 2010. 
(a) DJF

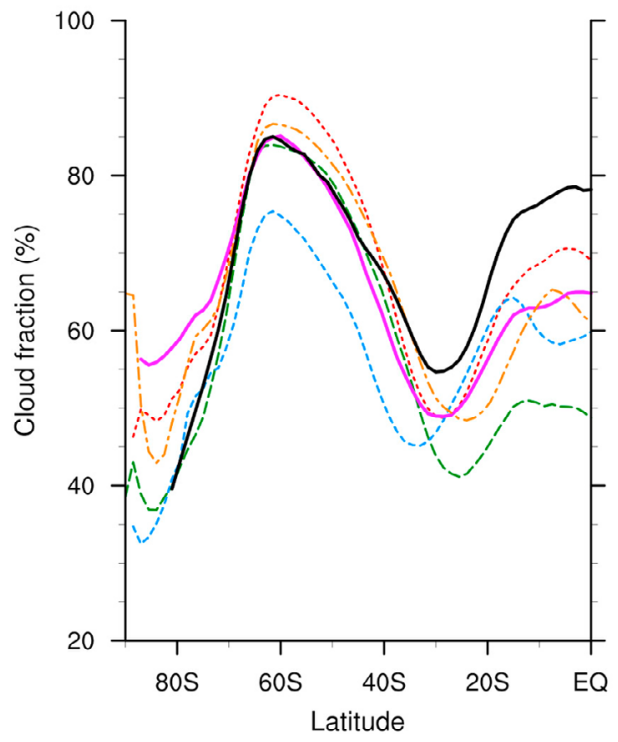

(b) JJA

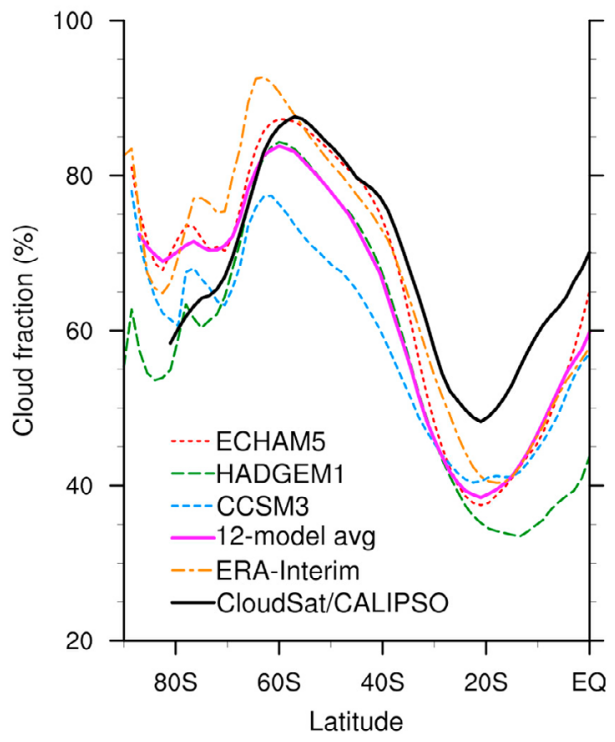

Figure 21. Zonal-average mean seasonal cloud fraction during (a) summer (DJF) and (b) winter (JJA) from three IPCC AR4 AMIP model simulations (ECHAM5, HadGEM1, and CCSM3) spanning 19801999, the ensemble average from the 12 IPCC AR4 AMIP model simulations listed in Table 3 and spanning 1980-1999, the ERA-Interim reanalysis spanning 1990-2009, and the CloudSat-CALIPSO cloud retrievals spanning September 2006 to August 2010.

extended back to 1979). In Figure 21, the zonal-average mean seasonal CF from the same data sets is plotted as a function of latitude for summer (December-January-February (DJF)) and winter (June-July-August (JJA)). The conclusions drawn from the comparison between CloudSat-CALIPSO cloud estimates and GCM data assume that the 4 year CloudSatCALIPSO data set is representative of the long-term average cloud cover. This assumption is supported by the fact that ERA-Interim exhibits very similar CF, on average, for the 4 year and 20 year periods.

[113] The annual average CF (Figure 20) shows that the ensemble average generally underestimates the cloud amounts over the Southern Ocean (by 5\%-10\%), whereas it overestimates the cloud amount over the Antarctic continent (by 10\%-15\%). Over the Southern Ocean, summer (Figure 21a) reveals fairly close agreement with CloudSat-CALIPSO. In contrast, the positive bias over the Antarctic continent is present both in summer and winter. The excess of clouds over Antarctica may be, in part, due to the coarse resolution of the atmospheric models (Table 3), resulting in a smoothing of the ice sheet's topography and an excessive influx of moisture inland. Figures 20 and 21 show that CCSM3 substantially underestimates the cloud amounts over the Southern Ocean but agrees relatively well with CloudSat-CALIPSO over Antarctica (equatorward of $82^{\circ} \mathrm{S}$ ).

[114] The relatively small bias displayed by the model ensemble masks large disparities. The cloud biases of the individual GCMs with respect to CloudSat-CALIPSO are shown in Table 4. Averaged over summer and winter and over latitudes $50^{\circ} \mathrm{S}-60^{\circ} \mathrm{S}$ and $70^{\circ} \mathrm{S}-80^{\circ} \mathrm{S}$, the lowest biases in absolute terms (average absolute difference column in Table 4) are found in HadGEM1; the Institute of Numerical Mathematics
Coupled Model, version 3 (INM-CM3); and ECHAM5. The quality of the HadGEM1 and ECHAM5 simulations is consistent with the conclusions from Connolley and Bracegirdle [2007]. These authors assessed the 20th century simulations from 19 AR4 GCMs over Antarctica on the basis of several variables. Over Antarctica, the highest "skill scores" were assigned to the HadGEM1 and ECHAM5 models. The performance of the INM-CM3 is more surprising as the model features the coarsest horizontal resolution among the 12 GCMs and uses a relatively simple diagnostic scheme to predict clouds (the stratiform cloud fraction is calculated as a linear function of the relative humidity), as opposed to prognostic equations of the cloud condensates in HadGEM1 and ECHAM5. The Centre National de Recherches Météorologiques Coupled Model, version 3 (CNRM-CM3); the Flexible Global Ocean-Atmosphere-Land System, version 1 (FGOALS1); and the Institut Pierre-Simon Laplace Coupled Model, version 4 (IPSL-CM4) are the models showing the greatest discrepancies from CloudSat-CALIPSO.

[115] Changes in near-surface temperature and precipitation are likely tied to changing cloud properties and their impact on the surface radiative budget and hydrological cycle. In this respect, one must emphasize the fact that the total cloud amount evaluated here is only one property of clouds among others (e.g., phase and radiative forcing) and does not tell how well these are represented in the GCMs.

\subsection{Regional Models}

[116] The 1990s saw the growth of regional modeling studies for Antarctica [e.g., Parish and Bromwich, 1991; Gallée, 1995; Hines et al., 1995, 1997; Bailey and Lynch, 2000a]. Cloud parameterizations within mesoscale models 
TABLE 4. Difference in Percentages Between the Mean Seasonal Cloud Amount From the AR4 GCMs Plus ERA-Interim and CloudSat-CALIPSO Estimates ${ }^{\text {a }}$

\begin{tabular}{|c|c|c|c|c|c|}
\hline \multirow[b]{2}{*}{ Model/Data Set } & \multicolumn{2}{|c|}{ DJF } & \multicolumn{2}{|c|}{ JJA } & \multirow{2}{*}{$\begin{array}{l}\text { Average Absolute } \\
\text { Difference }^{\mathrm{b}}\end{array}$} \\
\hline & $50^{\circ} \mathrm{S}-60^{\circ} \mathrm{S}$ & $70^{\circ} \mathrm{S}-80^{\circ} \mathrm{S}$ & $50^{\circ} \mathrm{S}-60^{\circ} \mathrm{S}$ & $70^{\circ} \mathrm{S}-80^{\circ} \mathrm{S}$ & \\
\hline CloudSat-CALIPSO $^{c}$ & 81.9 & 53.2 & 86.4 & 63.7 & \\
\hline ERA-Interim & 3.0 & 6.6 & 0.1 & 11.2 & 5.2 \\
\hline HadGEM1 & 0.5 & -3.3 & -4.2 & -2.6 & 2.7 \\
\hline INM-CM3 & 1.1 & 11.0 & -4.6 & -1.6 & 4.6 \\
\hline ECHAM5 & 6.8 & 5.2 & -0.4 & 7.9 & 5.1 \\
\hline MRI CGCM2 & 3.7 & 6.9 & -10.4 & -4.6 & 6.4 \\
\hline CCSM3 & -10.2 & -1.9 & -13.6 & 0.8 & 6.6 \\
\hline GFDL-CM2.0 & -1.8 & 20.8 & 3.6 & 14.3 & 10.1 \\
\hline MIROC3-medres & 8.3 & -5.2 & -0.3 & -27.7 & 10.4 \\
\hline GISS-ER & -4.1 & 29.7 & -4.1 & 4.1 & 10.5 \\
\hline PCM1 & -6.7 & 10.3 & -14.2 & 18.2 & 12.3 \\
\hline IPSL-CM4 & 10.1 & 12.4 & 5.7 & 29.7 & 14.5 \\
\hline FGOALS1 & -15.4 & 9.5 & -20.3 & 20.4 & 16.4 \\
\hline CNRM-CM3 & 14.6 & 22.6 & 8.5 & 24.5 & 17.6 \\
\hline
\end{tabular}

${ }^{\mathrm{a}}$ The difference is shown for summer (December-January-February (DJF)) and winter (June-July-August (JJA)) and for latitudes $50^{\circ} \mathrm{S}-60^{\circ} \mathrm{S}$ (Southern Ocean) and $70^{\circ} \mathrm{S}-80^{\circ} \mathrm{S}$ (Antarctic continent).

${ }^{\mathrm{b}}$ Average of the absolute values from each of the four measurements. The GCMs are ordered by increasing average absolute difference.

${ }^{\mathrm{c}}$ Shown are the estimates from CloudSat-CALIPSO used in the calculation.

tend to be more detailed and computationally expensive than those of global models. The microphysics equations are complicated and will not be repeated here. An excellent example of a detailed set of prognostic equations for large-scale precipitation is given in the Appendix of Gallée [1995]. Condensate is typically divided into cloud (suspended) and precipitation (falling) particles and further divided into liquid and ice components. The various processes treated are condensation/ evaporation/sublimation/deposition, melting/freezing, autoconversion (cloud to precipitation), accretion, and rain and snow fallout. Adequate representation of the clouds and hydrologic cycle in mesoscale models, however, has remained problematic, analogous to the global modeling studies. The overall advancement in model cloud parameterizations, regardless of climatic region, has offered hope for improved Antarctic representations. Early evaluations of performance of cloud representations for high southern latitudes demonstrate the inadequacy of parameterizations developed for other regions of the globe [e.g., Hines et al., 1997]. About the time of the Antarctic Weather Forecasting Workshop in May 2000 [Bromwich and Cassano, 2001], however, viable representations of Antarctic clouds began to more commonly appear in regional models.

[117] As an example, the fifth-generation Pennsylvania State University/NCAR Mesoscale Model (MM5) [Grell et al., 1994] contained the microphysics option of the singlemoment, prognostic explicit scheme from Reisner et al. [1998]. The model has a traditional bulk microphysics scheme with three-dimensional prognostic equations for the mixing ratios of water vapor, cloud water, cloud ice, rain, and snow. One issue is the use of the Fletcher [1962] IN formula that facilitates excessive number concentrations and unrealistically small particles at very low temperatures. An outcome can be a noticeable warm bias [e.g., Hines et al., 1997]. When the ice nuclei concentration of Meyers et al. [1992] replaced that of Fletcher [1962] in the polar-optimized version "Polar MM5," however, fewer IN are present at low temperature and realistic simulations are possible for Antarctica [Guo et al., 2003]. An additional update was adapting the radiation scheme away from a diagnostic cloud fraction calculation to one that input the predicted liquid and ice mixing ratios. Accordingly, Polar MM5 with the modified Reisner scheme tackled multiple Antarctic applications including real-time synoptic forecasting [e.g., Powers et al., 2003; Bromwich et al., 2003, 2005]. Concurrent to the Antarctic application of Polar MM5, several regional high-resolution models had cloud microphysics sufficiently advanced to allow synoptic and climatic studies for Antarctica, including studies of Antarctic hydrology [e.g., Pavolonis et al., 2004; Gallée et al., 2005; van de Berg et al., 2006].

[118] Looking forward, advances in cloud modeling that are available to mesoscale models provide opportunities to treat an increasing set of physical phenomena. Mixed-phase clouds, ice fog, polar cloud sensitivity to aerosols, and the frequent diamond dust/clear-sky precipitation over Antarctica are possibly treatable with advanced parameterizations including "double-moment" schemes discussed below [e.g., Girard and Curry, 2001]. Additionally, the impact of aerosols on cloud physics is gaining attention among modelers. From the Antarctic perspective, observations suggest that polar clouds are highly sensitive to the number concentration of IN, which are highly influenced by atmospheric aerosol concentrations [e.g., Prenni et al., 2007]. Not surprisingly, early attention has focused more on the Arctic [e.g., Girard and Blanchet, 2001; Girard and Curry, 2001; Morrison et al., 2008]. Yet there are good reasons to consider the aerosol impact for the relatively pristine Antarctic environment. Furthermore, the seasonal pattern of aerosols at the South Pole is opposite to that in the Arctic with minima in the winter an order of magnitude smaller than the summer values 
[Hogan and Barnard, 1978; Park et al., 2004]. Thus, Antarctica provides an opportunity to study and model clouds in a unique clean environment. However, little work has yet been done to explore detailed microphysics over Antarctica with the most advanced cloud schemes, coinciding with the lack of detailed observations for comparisons.

[119] One recent mesoscale study has been performed with an advanced microphysics scheme and compared to recent observations. Gallée and Gorodetskaya [2010] compared results of the Modèle Atmosphérique Régional to Dome $\mathrm{C}$ observations over the East Antarctic Plateau and achieved a representation of polar stratospheric clouds. Furthermore, they represented the impact of snow on the radiative fields by taking the effective radius of snow to be three times that of ice clouds.

[120] As to how cloud-aerosol issues might be addressed, it can be noted that the earlier generation of bulk microphysics schemes (known as "single-moment" schemes because they only carry cloud particle mass concentrations and not number concentrations) are poorly suited to the task of capturing aerosol sensitivities [Girard and Curry, 2001]. A more advanced set of schemes known as "double-moment" schemes seek to predict the number concentration for water and ice clouds in addition to predicting the mass of cloud condensate [Morrison and Grabowski, 2007; Philips et al., 2007; Morrison et al., 2008]. This allows for a more physical treatment of clouds and their aerosol interactions and also enables determination of key inputs to cloud radiative parameterizations such as effective particle radius [Girard and Curry, 2001; Morrison et al., 2008]. For example, the state-of-the-art Polar WRF mesoscale model [Hines and Bromwich, 2008; Bromwich et al., 2009; Hines et al., 2011], which has replaced Polar MM5, has the option for the Morrison two-moment microphysics scheme. It is plausible that these advanced schemes with appropriate revisions could treat ice fog and diamond dust/clear-sky precipitation [Girard and Blanchet, 2001; Girard and Curry, 2001]. Yet, to our knowledge, no studies have attempted to parameterize Antarctic clear-sky precipitation in this way, and only limited efforts have been attempted in the Arctic [Girard and Blanchet, 2001].

\subsection{Operational Forecasting of Clouds in Antarctica}

[121] Accurately forecasting clouds, especially low clouds, is critical to the support of Antarctic aviation operations. Both the Terminal Area Forecast and route forecast are required to provide estimates of low cloud cover (in octas) and base height (in feet) to ensure minimum safe altitudes and good visibility conditions at landing. Routine observations of cloud base and cover are only made at staffed Antarctic stations and many of the regular skiways and landing sites, with these observations traditionally provided by trained observers. Some landing sites now also rely on ceilometers to provide an estimate of the cloud base height (see section 2.1). The accuracy of the cloud base observations is dependent on the experience of the observer and the availability of reference markers to gauge the cloud height. These observations are also necessarily limited to staffed sites with large sections of the Antarctic continent devoid of any observations of cloud base or cover.

[122] This data void has led to a reliance on numerical weather prediction (NWP) output to provide information on cloud properties over the Antarctic region. Such NWP efforts include the Antarctic Mesoscale Prediction System (AMPS) [Powers et al., 2003; Bromwich et al., 2005], funded by the U.S. National Science Foundation, and an East Antarctic version of the Australian Bureau of Meteorology's Limited Area Prediction System, PolarLAPS [Adams, 2005; Adams and Powers, 2007].

[123] Since aviation forecasting is critical for Antarctic operations, accurate cloud representations are highly valued. However, verification of modeled prognostic clouds versus observations can be problematic. First, there are difficulties associated with obtaining objective cloud observations which are frequently reported in fractions or octas. Second, many modern cloud prediction schemes predict the mass of water substance but do not directly produce a cloud fraction that can be compared to observations. Diagnostic relationships, however, can be used to estimate cloud fraction from model results [e.g., Wyser and Jones, 2005; Fogt and Bromwich, 2008]. As an example, to generate its routine operational weather forecasts for Antarctica, the AMPS has successively used the mesoscale model Polar MM5 (until mid-2008) and the Polar WRF. A preexisting MM5 formula has been used to estimate the total $\mathrm{CF}$ from the forecast cloud liquid water (CLWP) and ice water (CIWP) paths within each model layer,

$$
\mathrm{CF}=C_{l} \sum_{\text {Surface }}^{\text {Top }} \mathrm{CLWP}+C_{i} \sum_{\text {Surface }}^{\text {Top }} \mathrm{CIWP},
$$

where the paths (in mass per unit area) are summed layer by layer from the surface to the top of the model. CLWP and CIWP are readily calculated from the cloud liquid water and cloud ice water mixing ratios, respectively (see details in the work by Fogt and Bromwich [2008]). The constants, $C_{l}$ and $C_{i}$, are longwave absorption coefficients that can be determined empirically or from cloud radiative properties. Fogt and Bromwich [2008] found, empirically, optimal matches between MM5 AMPS forecasts and cloud observations in the vicinity of McMurdo Station by setting $C_{l}$ and $C_{i}$ to $75 \mathrm{~m}^{2}$ $\mathrm{kg}^{-1}$ and $170 \mathrm{~m}^{2} \mathrm{~kg}^{-1}$, respectively.

[124] In theory, the empirically estimated cloud fraction should be consistent with the radiative properties of fractional clouds. Hines et al. [2011] found that the Fogt and Bromwich [2008] coefficients are also applicable in the Arctic at Barrow, Alaska. However, a recent study suggests that the cloud impact on radiation may not be well simulated by the Polar WRF (A. B. Wilson et al., Evaluation of polar WRF forecasts on the Arctic System Reanalysis domain. Part II. Atmospheric hydrologic cycle, submitted to Journal of Geophysical Research, 2011). A further limitation of the formula is that it only works for total cloud fraction and is highly sensitive to low clouds, which tend to have higher water substance contents. To estimate only the high cloud fraction, for example, the formula would require modifica- 
tions, as an overcast cirrus layer is typically denoted by small CIWP and no CLWP.

\section{CONCLUSIONS}

\subsection{Summary and Outstanding Questions}

[125] Despite indications that clouds from the troposphere to the mesosphere in the Antarctic have a major role in determining the ice sheet's radiative budget, surface mass balance, and ozone concentration, there are relatively few measurements of clouds in the Antarctic. Knowledge of cloud properties and the role of clouds in processes and feedbacks occurring in this region have been extrapolated from a combination of ground and satellite-based remote sensing retrievals, meteorological analyses, modeling studies, and a limited number of in situ aircraft and balloon-borne observations. However, because of the sparseness and limited duration of these observations, clouds in the extreme southern latitudes are still poorly understood. The complexity of Antarctic clouds and their importance to the climate system warrant increased study and an expanded observing network to support improved modeling and predictive efforts.

[126] Visual observations provide the longest direct observational record and suggest that cloud cover may be decreasing. However, such measurements are problematic after polar sunset when cloud cover tends to be underestimated. Further, the representativeness of observations from a small number of stations covering an extremely limited portion of the continent for a short time period is questionable. Coverage over the encircling Southern Ocean is even more uneven and limited, and what little data are available are often compromised by a lack of attention to the state of the instruments, a dearth of longwave and active data, or unidentified shadowing events by the ship's superstructure.

[127] Satellite remote sensing offers promise for enhancing the climatological database of Antarctic clouds by providing better temporal and spatial resolution and frequent overpass times in the polar regions. Standard techniques for passive remote sensing are limited by the lack of visible and thermal contrast between ice-covered surfaces and cloud tops and the relative transparency of thin ice clouds. Passive sensors measuring radiances at multiple viewing angles, such as the MultiAngle Imaging Spectroradiometer [Di Girolamo and Wilson, 2003] and the Polarization and Directionality of the Earth's Reflectances [Parol et al., 2004], provide possible pathways for improvements of daytime cloud detection over snow-covered surfaces. Atmospheric structure gleaned from hyperspectral instruments like the Atmospheric Infrared Sounder further support understanding of cloud formation and interaction with the surrounding environment [Stajner et al., 2007]. Limb-viewing sensors have started to provide long-term data on upper atmosphere properties [e.g., Saitoh et al., 2002] and have helped study the role of polar stratospheric clouds in ozone destruction.

[128] Active remote sensing techniques, such as airborne and spaceborne lidars, provide more detailed information needed for process studies. The comprehensive data sets generated by the CloudSat radar and CALIPSO lidar are also beginning to make possible investigations of the variation of cloud cover in different regimes (e.g., over West and East Antarctica and over coastal areas such as McMurdo), the influences of different factors on cloud cover (e.g., presence of open water and synoptic factors such as intrusion of marine air inland), and the dependence of PSC formation on the presence of deep tropospheric systems. Nevertheless, observations from spaceborne lidar and radar are limited in time and have infrequent orbital repeat, with no long-term plans for extending them to a decadal record. In this respect, it is unfortunate that the continuity of the joint CloudSatCALIPSO observations has been interrupted since April 2011 because of a battery anomaly on the CloudSat spacecraft (http://cloudsat.atmos.colostate.edu/). As of October 2011, it is uncertain whether CloudSat will return to its formation orbit with CALIPSO. Despite this uncertainty, the existence of the CloudSat-CALIPSO data set has undoubtedly started a new era in Antarctic cloud research.

[129] In addition to cloud macrophysical properties, knowledge of cloud microphysical properties is needed for understanding the role of clouds in Antarctic weather and climate. Only limited data on cloud particle shapes, sizes, and phase are currently available from retrievals of ground-based instruments, space-borne lidar, and infrequent tethered balloon and in situ observations. In situ measurements over the Avery Plateau showed larger concentrations of ice crystals and fewer droplets than expected so that agreement with model simulations could only be obtained by assuming additional surface sources of ice nuclei. On the other hand, heterogeneously nucleated ice crystal concentrations observed in situ in clouds of various types over the Antarctic Peninsula were low (generally $<0.1 \mathrm{~L}^{-1}$ ), especially compared to the predictions of older IN parameterizations. However, a new IN parameterization that takes into account aerosol concentrations adequately predicted low ice nuclei concentrations. Crystal concentrations near the narrow temperature band over which the Hallett-Mossop process is active were around 2 orders of magnitude higher, although such ice multiplication was not always observed in these regions in the presence of liquid. This suggests a complex process, which would be challenging to predict in models but which is likely to be very important in determining the degree of glaciation of these clouds given the low IN concentrations inferred.

[130] Surface and space-based observations of Antarctic clouds should complement and inform modeling studies encompassing a variety of spatial and temporal scales. For large-scale models, Antarctic snowfall and temperature records have been used to evaluate simulations because they have the longest spatial and temporal extent. Although nearsurface temperature trends have been overestimated by a factor of 2-3 by the IPCC AR4 GCMs, the sensitivity of snowfall to regional temperature changes has been consistent with $\mathrm{GCM}$ estimates within $5 \% \mathrm{~K}^{-1}$. However, it is still unclear whether the treatment of precipitation within Antarctic clouds is reliable enough to examine changes and variability in decadal trends [Monaghan et al., 2008].

[131] Process-oriented understanding gained from regional climate, mesoscale, and large eddy simulation (LES) modeling 
can be used to develop new representations for large-scale models. Recently developed sophisticated, multicategory parameterizations [e.g., Morrison et al., 2005; Thompson et al., 2008] for cloud-resolving and mesoscale models have the potential for improving modeled microphysical processes occurring in Antarctic clouds. However, since processes such as the sedimentation and single-scattering properties of nonspherical ice crystals are less understood than those for their liquid counterparts and because fundamental assumptions about the size and shape distributions of ice in pristine Antarctic conditions have not been evaluated against observations, there are uncertainties in these schemes that can only be addressed through collection of additional data that offer closure, that is, conducting constrained measurements of radiative properties with collocated in situ measurements oriented toward process understanding.

\subsection{Future Research Needs}

[132] Because limited observations are a major impediment to progress in Antarctic cloud research, it is critical to collect a focused set of observations to advance the understanding of dynamical, microphysical, and radiative processes in largely undersampled Antarctic clouds. Better and more frequent remote sensing and in situ observations are needed. Satellite and ground-based remote sensing provide broad characteristics of cloud structure and height at varying spatial and temporal resolution. However, they do not resolve the radiative field within the cloud and at the surface. Sites from the Baseline Surface Radiation Network (BSRN) provide point measurements of the incident, reflected and diffuse radiative field, needed for process studies and parameterization [Ohmura et al., 1998; Wild et al., 2009]. Currently, the BSRN sites are restricted to four locations (Neumayer and Syowa on the coast and South Pole and Concordia in the interior). No data are available over the sea ice or ocean. Equipping ships that routinely work within the Southern Ocean with more numerous and sophisticated radiation and cloud sensors could provide important data for determining how cloud properties vary according to the environment where they form and persist. Consistent cloud measurements over more varied surfaces coupled with (at a minimum) the complete radiative field would significantly contribute to modeling of the radiative budget, including potential cloud contributions to cryospheric melt.

[133] In addition to initiating process studies, in situ observations are critically needed to evaluate retrievals of cloud microphysical properties from remote sensors made in the pristine conditions of the Antarctic and adjacent Southern Ocean. Currently, used algorithms developed using data collected in more polluted environments may not be relevant. The in situ data are further needed to develop and evaluate cloud and precipitation parameterization schemes for GCM, LES, and NWP models and to evaluate the performance of said models.

[134] Several recent in situ aircraft field campaigns in the Arctic [e.g., Uttal et al., 2002; Verlinde et al., 2007; McFarquhar et al., 2011] can serve as models for future airborne campaigns in the Antarctic. Although Arctic cam- paigns have some relevance for studies of cloud processes occurring in cold boundary clouds over snow-covered surfaces, they do not negate the need for a focused campaign over Antarctica, where lower aerosol concentrations; different upper atmospheric chemistry; reduced ozone concentrations; drier, colder meteorological conditions; seasonal sea ice cover; and enhanced katabatic influences occur. An Antarctic campaign would be more complex and costly than those conducted in the Arctic because of its remote location, the presence of few suitable landing strips, and the seasonality of access to the continent.

[135] The instrumentation needed to measure cloud properties is almost as complex as the clouds themselves. At the same time, new and improved instruments are continuously being developed, such as those measuring the threedimensional distribution of radiative fluxes [Zinner et al., 2008]. Because of logistical and budgetary concerns associated with deploying instruments on and around Antarctica, prioritization of measurements, platforms, and sites will be necessary. Involving not only process modelers but also climate and forecast modelers into the planning may ensure that the sampling has added significance beyond the particular field season and location chosen.

[136] In addition to studies on the role of clouds in Antarctic climate change, the Antarctic environment offers a unique opportunity for investigations of cloud processes. Pristine conditions makes Antarctica an ideal test bed for examining hypotheses on primary and secondary ice nucleation mechanisms, an uncertainty that has plagued the cloud physics community for years [Cantrell and Heymsfield, 2005].

[137] The current range of uncertainty about Antarctic clouds is matched only by the variety of tools, sensors, and models poised to decipher the inner workings of these climatologically important clouds. The current understanding is the product of years of threading together data streams and parameterizations developed by researchers worldwide. One country's effort cannot solve all questions. The Antarctic is, after all, a continent of international cooperation. Much of the cloud-related data collection during the International Polar Year 2007-2009 and since has been the result of multinational teams who have optimized the use of platforms resident on and flying over the Antarctic. Such cooperation is crucial if further progress is to be made.

[138] ACKNOWLEDGMENTS. The International Workshop on Antarctic Clouds, from which the initiative of the present review originates, was sponsored by the Scientific Committee on Antarctic Research (SCAR), the International Union on Geodesy and Geophysics (IUGG), the International Commission on Polar Meteorology (ICPM), the Byrd Polar Research Center, and the British Antarctic Survey. The research of D.H.B., J.P.N., and K.M.H. was funded in part by NSF grant ATM-0751291 and grant ANT-0838967. Funding for J.E.K. to analyze CloudSat and CALIOP data was provided by NASA grant NNX10AM22G. The research of G.M.M. was supported by the Office of Science, Office of Biological and Environmental Research Science Division (BER), Department of Energy under grant DE-SC0001279. D.L. is supported in part by NASA under NNX08AF79G. M.A.L. thanks 
the NSF Office of Polar Program for supporting the Antarctic Meteorological Research Center via grant number ANT-0838834. I.G. and N.V.L. are grateful to the Belgian Science Policy for funding the cloud observatory at Princess Elisabeth station; to collaborators at the Institute for Marine and Atmospheric Research Utrecht, the University of Cologne, and the Belgian Royal Meteorological Institute for assistance in measurements and data processing; and to Maximilian Maahn (Bonn University) for help in radar data processing. The visual cloud observations from Antarctic stations were obtained from http://cdiac.ornl.gov/epubs/ndp/ndp026d/ndp026d. html. MODIS cloud data were obtained from the NASA/LAADS portal (http://modis.gsfc.nasa.gov/). ISCCP cloud data were obtained from: http://isccp.giss.nasa.gov/. ERA-Interim mean sea level pressure and cloud data were obtained from the ECMWF data server (http://data.ecmwf.int/data/). This review is Byrd Polar Research Center contribution 1414.

[139] The Editor responsible for this paper was Alan Robock. He thanks Von Walden and two anonymous reviewers.

\section{REFERENCES}

Abshire, J. B., X. Sun, H. Riris, J. M. Sirota, J. F. McGarry, S. Palm, D. Yi, and P. Liiva (2005), Geoscience Laser Altimeter System (GLAS) on the ICESat Mission: On-orbit measurement performance, Geophys. Res. Lett., 32, L21S02, doi:10.1029/ 2005 GL024028.

Ackerman, S. A., K. I. Strabala, W. P. Menzel, R. A. Frey, C. C. Moeller, and L. E. Gumley (1998), Discriminating clear sky from clouds with MODIS, J. Geophys. Res., 103, 32,141-32,157, doi:10.1029/1998JD200032.

Ackerman, S. A., R. E. Holz, R. Frey, E. W. Eloranta, B. C. Maddux, and M. McGill (2008), Cloud detection with MODIS. Part II: Validation, J. Atmos. Oceanic Technol., 25(7), 1073-1086, doi:10.1175/2007JTECHA1053.1.

Adams, N. (2005), Identifying the characteristics of strong southerly wind events at Casey Station in east Antarctica using a numerical weather prediction system, Mon. Weather Rev., 133(12), 3548-3561, doi:10.1175/MWR3050.1.

Adams, N., and J. Powers (2007), Advances in numerical weather prediction and weather forecasting systems in support of the Australian Antarctic Program, paper presented at the 2nd Antarctic Meteorological Observations, Modeling and Forecasting Workshop, Natl. Cent. for Atmos. Res., Rome, 26-28 June. [Available at http://www.mmm.ucar.edu/events/antarctic07/.]

Adhikari, L., Z. Wang, and D. Liu (2010), Microphysical properties of Antarctic polar stratospheric clouds and their dependence on tropospheric cloud systems, J. Geophys. Res., 115, D00H18, doi:10.1029/2009JD012125.

Alcenar, A. S., H. Evangelista, E. A. Dos Santos, S. M. Correa, M. Khodri, V. M. T. Garcia, C. A. E. Garcia, E. B. Pereira, A. R. Piola, and I. Felzenszwalb (2010), Potential source regions of biogenic aerosol number concentration apportioning at King George Island, Antarctic Peninsula, Antarct. Sci., 22, 580-588, doi:10.1017/S0954102010000398.

Allison, I., R. E. Brandt, and S. G. Warren (1993), East Antarctic sea ice: Albedo, thickness distribution, and snow cover, J. Geophys. Res., 98, 12,417-12,429, doi:10.1029/93JC00648.

Andreae, M. O., and P. J. Crutzen (1997), Atmospheric aerosols: Biogeochemical sources and the role in atmospheric chemistry, Science, 276, 1052-1058, doi:10.1126/science.276.5315.1052.

Arthern, R. J., D. P. Winebrenner, and D. G. Vaughan (2006), Antarctic snow accumulation mapped using polarization of 4.3-cm wavelength microwave emission, J. Geophys. Res., 111, D06107, doi:10.1029/2004JD005667.

Asmi, E., A. Frey, A. Virkkula, M. Ehn, H. E. Manninen, H. Timonen, O. Tolonen-Kivimäki, M. Aurela, R. Hillamo, and M. Kulmala (2010), Hygroscopicity and chemical composition of Antarctic sub-micrometre aerosol particles and observations of new particle formation, Atmos. Chem. Phys., 10, 4253-4271, doi:10.5194/ acp-10-4253-2010.

Bailey, D. A., and A. H. Lynch (2000a), Development of an Antarctic regional climate system model. Part I: Sea ice and large scale circulations, J. Clim., 13, 1337-1350, doi:10.1175/1520-0442(2000) 013<1337:DOAARC $>2.0 . C O ; 2$.

Bailey, D. A., and A. H. Lynch (2000b), Development of an Antarctic regional climate system model. Part II: Station validation and surface energy balance, J. Clim., 13, 1351-1361, doi:10.1175/1520-0442(2000)013<1351:DOAARC >2.0.CO;2.

Balsamo, E. P., M. Candidi, G. Consolini, and L. Morici (1997), The Italian all-sky camera for auroral observations at Terra Nova Bay (Antarctica), in Proceedings of the 8th GIFCO Conference, Cosmic Physics in the Year 2000: Scientific Perspectives and New Instrumentation, Conf. Proc. Ital. Phys. Soc., vol. 58, edited by S. Aiello et al., pp. 101-104, Soc. Ital. di Fis., Bologna, Italy. Barbante, C., C. Turetta, A. Gambaro, G. Capodaglio, and G. Scarponi (1998), Sources and origins of aerosols reaching Antarctica as revealed by lead concentration profiles in shallow snow, Ann. Glaciol., 27, 674-678.

Bernhard, G., C. R. Booth, and J. C. Ehramjian (2004), Version 2 data of the National Science Foundation's ultraviolet radiation monitoring network: South Pole, J. Geophys. Res., 109, D21207, doi:10.1029/2004JD004937.

Bernhard, G., C. R. Booth, J. C. Ehramjian, and S. E. Nichol (2006), UV climatology at McMurdo Station, Antarctica, based on version 2 data of the National Science Foundation's ultraviolet radiation monitoring network, J. Geophys. Res., 111, D11201, doi:10.1029/2005JD005857.

Berque, J., D. Lubin, and R. C. J. Somerville (2011), Transect method for Antarctic cloud property retrieval using AVHRR data, Int. J. Remote Sens., 32, 2887-2903.

Bigg, E. K., and S. C. Hopwood (1963), Ice nuclei in the Antarctic, J. Atmos. Sci., 20, 185-188, doi:10.1175/1520-0469(1963) 020<0185:INITA $>2.0$. CO;2.

Bodhaine, B. A., J. J. DeLuisi, J. M. Harris, P. Houmere, and S. Bauman (1986), Aerosol measurements at the South Pole, Tellus, Ser. B, 38, 223-235, doi:10.1111/j.1600-0889.1986. tb00189.x.

Boers, R., and P. B. Krummel (1998), Microphysical properties of boundary layer clouds over the Southern Ocean during ACE 1, J. Geophys. Res., 103, 16,651-16,663, doi:10.1029/97JD03280. Brandt, R. E., S. G. Warren, A. P. Worby, and T. C. Grenfell (2005), Surface albedo of the Antarctic sea ice zone, J. Clim., 18, 3606-3622, doi:10.1175/JCLI3489.1.

Briegleb, B. P., and D. H. Bromwich (1998a), Polar climate simulation of the NCAR CCM3, J. Clim., 11, 1270-1286, doi:10.1175/1520-0442(1998)011<1270:PCSOTN>2.0.CO;2.

Briegleb, B. P., and D. H. Bromwich (1998b), Polar radiation budgets of the NCAR CCM3, J. Clim., 11, 1246-1269, doi:10.1175/ 1520-0442(1998)011<1246:PRBOTN>2.0.CO;2.

Bromwich, D. H. (1988), Snowfall in high southern latitudes, Rev. Geophys., 26(1), 149-168, doi:10.1029/RG026i001p00149.

Bromwich, D. H., and J. J. Cassano (2001), Meeting summary: Antarctic Weather Forecasting Workshop, Bull. Am. Meteorol. Soc., 82, 1409-1413, doi:10.1175/1520-0477(2001)082<1409: MSAWFW $>2.3 . \mathrm{CO} ; 2$.

Bromwich, D. H., and S.-H. Wang (2008), A review of the temporal and spatial variability of Arctic and Antarctic atmospheric circulations based upon ERA-40, Dyn. Atmos. Oceans, 44, 213-243, doi:10.1016/j.dynatmoce.2007.09.001.

Bromwich, D. H., B. Chen, and R. Tzeng (1995), Arctic and Antarctic precipitation simulations produced by the NCAR Community Climate Models, Ann. Glaciol., 21, 117-122.

Bromwich, D. H., A. J. Monaghan, J. G. Powers, J. J. Cassano, H. Wei, Y.-H. Kuo, and A. Pellegrini (2003), Antarctic Mesoscale Prediction System (AMPS): A case study from the 2000/2001 
field season, Mon. Weather Rev., 131, 412-434, doi:10.1175/ 1520-0493(2003)131<0412:AMPSAA >2.0.CO;2.

Bromwich, D. H., Z. Guo, L. Bai, and Q.-S. Chen (2004), Modeled Antarctic precipitation. Part I: Spatial and temporal variability, J. Clim., 17, 427-447, doi:10.1175/1520-0442(2004)017<0427: MAPPIS $>2.0 . \mathrm{CO} ; 2$.

Bromwich, D. H., A. J. Monaghan, K. W. Manning, and J. G. Powers (2005), Real-time forecasting for the Antarctic: An evaluation of the Antarctic Mesoscale Prediction System (AMPS), Mon. Weather Rev., 133, 579-603, doi:10.1175/MWR-2881.1.

Bromwich, D. H., K. M. Hines, and L.-S. Bai (2009), Development and testing of Polar Weather Research and Forecasting model: 2. Arctic Ocean, J. Geophys. Res., 114, D08122, doi:10.1029/2008JD010300.

Cacciani, M., G. Fiocco, P. Colagrande, P. Di Girolamo, A. di Sarra, and D. Fua (1997), Lidar observations of polar stratospheric clouds at the South Pole: 1. Stratospheric unperturbed conditions, 1990, J. Geophys. Res., 102, 12,937-12,943, doi:10.1029/ 97JD00360.

Cantrell, W., and A. J. Heymsfield (2005), Production of ice in tropospheric clouds: A review, Bull. Am. Meteorol. Soc., 86, 795-807, doi:10.1175/BAMS-86-6-795.

Cariolle, D., S. Muller, F. Cayla, and M. P. McCormick (1989), Mountain waves, polar stratospheric clouds, and the ozone depletion over Antarctica, J. Geophys. Res., 94, 11,233-11,240, doi:10.1029/JD094iD09p11233.

Carrasco, J. F., D. H. Bromwich, and A. J. Monaghan (2003), Distribution and characteristics of mesoscale cyclones in the Antarctic: Ross Sea eastward to the Weddell Sea, Mon. Weather Rev., 131, 289-301, doi:10.1175/1520-0493(2003)131<0289:DACOMC $>2.0$. $\mathrm{CO} ; 2$.

Chapman, W. L., and J. E. Walsh (2007), A synthesis of Antarctic temperatures, J. Clim., 20, 4096-4117, doi:10.1175/JCLI4236.1.

Charlson, R. J., J. E. Lovelock, M. O. Andreae, and S. G. Warren (1987), Oceanic phytoplankton, atmospheric sulfur, cloud albedo and climate, Nature, 326, 655-661, doi:10.1038/326655a0.

Chaubey, J. P., K. K. Moorthy, S. S. Babu, and V. S. Nair (2011), The optical and physical properties of atmospheric aerosols over the Indian Antarctic stations during southern hemisphere summer of the International Polar Year 2007-2008, Ann. Geophys., 29, 109-121, doi:10.5194/angeo-29-109-2011.

Christner, B. C., C. E. Morris, C. M. Foreman, R. Cai, and D. C. Sands (2008), Ubiquity of biological ice nucleators in snowfall, Science, 319, 1214, doi:10.1126/science.1149757.

Comiso, J. C. (2000), Variability and trends in Antarctic surface temperatures from in situ and satellite infrared measurements, J. Clim., 13, 1674-1696, doi:10.1175/1520-0442(2000) $013<1674$ :VATIAS $>2.0 . \mathrm{CO} ; 2$.

Comiso, J., and L. Stock (2001), Studies of Antarctic cloud cover variability from 1982 through 1999, in IGARSS '01: IEEE 2001 International Geoscience and Remote Sensing Symposium, vol. 4, pp. 1782-1785, doi:10.1109/IGARSS.2001.977070.

Connolley, W. M., and T. J. Bracegirdle (2007), An Antarctic assessment of IPCC AR4 coupled models, Geophys. Res. Lett., 34, L22505, doi:10.1029/2007GL031648.

Cooper, W. A. (1986), Ice initiation in natural clouds, in Precipitation Enhancement: A Scientific Challenge, Meteorol. Monogr., vol. 21, edited by R. G. Braham Jr., pp. 29-32, Am. Meteorol. Soc., Boston, Mass.

Correia, A., P. Artaxo, and W. Maenhaut (1998), Monitoring of atmospheric aerosols on the Antarctic Peninsula, Ann. Glaciol., $27,560-564$.

Curry, J. A., et al. (2000), FIRE Arctic Clouds Experiment, Bull. Am. Meteorol. Soc., 81, 5-29, doi:10.1175/1520-0477(2000) 081<0005:FACE $>2.3 . \mathrm{CO} ; 2$.

Dai, A., T. R. Karl, B. Sun, and K. E. Trenberth (2006), Recent trends in cloudiness over the United States: A Tale of monitoring inadequacies, Bull. Am. Meteorol. Soc., 87(5), 597-606, doi:10.1175/ BAMS-87-5-597.
Dee, D. P., et al. (2011), The ERA-Interim reanalysis: Configuration and performance of the data assimilation system, $Q . J . R$. Meteorol. Soc., 137(656), 553-597, doi:10.1002/qj.828.

Del Guasta, M., M. Morandi, L. Stefanutti, J. Brechet, and J. Piquad (1993), One year of cloud lidar data from Dumont d'Urville (Antarctica): 1. General overview of geometrical and optical properties, J. Geophys. Res., 98, 18,575-18,587, doi:10.1029/93JD01476.

DeMott, P. J., A. J. Prenni, X. Liu, S. M. Kreidenweis, M. D. Petters, C. H. Twohy, M. S. Richardsona, T. Eidhammera, and D. C. Rogers (2010), Predicting global atmospheric ice nuclei distributions and their impacts on climate, Proc. Natl. Acad. Sci. U. S. A., 107(25), 11,217-11,222, doi:10.1073/pnas.0910818107.

Deshpande, C. G., and A. K. Kamra (2004), Physical properties of aerosols at Maitri, Antarctica, J. Earth Syst. Sci., 113, 1-25, doi:10.1007/BF02701995.

Dessler, A. E., S. P. Palm, W. D. Hart, and J. D. Spinhirne (2006), Tropopause-level thin cirrus coverage revealed by ICESat/ Geoscience Laser Altimeter System, J. Geophys. Res., 111, D08203, doi:10.1029/2005JD006586.

Di Girolamo, L., and M. J. Wilson (2003), A first look at banddifferenced angular signatures for cloud detection from MISR, IEEE Trans. Geosci. Remote Sens., 41, 1730-1734, doi:10.1109/ TGRS.2003.815659.

Dufresne, J.-L., and S. Bony (2008), An assessment of the primary sources of spread of global warming estimates from coupled atmosphere-ocean models, J. Clim., 21, 5135-5144, doi:10.1175/ 2008JCLI2239.1.

Ebert, E. E., and J. A. Curry (1992), A parameterization of ice cloud optical properties for climate models, J. Geophys. Res., 97, 3831-3836.

Eckermann, S. D., A. Drnbrack, H. Flentje, S. B. Vosper, M. J. Mahoney, T. P. Bui, and K. S. Carslaw (2006), Mountain wave-induced polar stratospheric cloud forecasts for aircraft science flights during SOLVE/THESEO 2000, Weather Forecast., 21, 42-68, doi:10.1175/WAF901.1.

Evan, A. T., A. K. Heidinger, and D. J. Vimont (2007), Arguments against a physical long-term trend in global ISCCP cloud amounts, Geophys. Res. Lett., 34, L04701, doi:10.1029/ 2006GL028083.

Fiebig, M., C. R. Lunder, and A. Stohl (2009), Tracing biomass burning aerosol from South America to Troll Research Station, Antarctica, Geophys. Res. Lett., 36, L14815, doi:10.1029/ 2009GL038531.

Fitzpatrick, M. F., and S. G. Warren (2004), Transmission of solar radiation by clouds over snow and ice surface. Part I: A parameterization in terms of optical depth, solar zenith angle, and surface albedo, J. Clim., 17, 266-275, doi:10.1175/1520-0442 (2004)017<0266:TOSRBC $>2.0$. CO;2.

Fitzpatrick, M. F., and S. G. Warren (2005), Transmission of solar radiation by clouds over snow and ice surface. Part II: Cloud optical depth and shortwave radiative forcing from pyranometer measurements in the Southern Ocean, J. Clim., 18, 4637-4648, doi:10.1175/JCLI3562.1.

Fletcher, N. H. (1962), Physics of Rain Clouds, Cambridge Univ. Press, Cambridge, U. K.

Fogt, R. L., and D. H. Bromwich (2008), Atmospheric moisture and cloud cover characteristics forecast by AMPS, Weather Forecast., 23, 914-930, doi:10.1175/2008WAF2006100.1.

Frey, R. A., S. A. Ackerman, Y. Liu, K. I. Strabala, H. Zhang, J. R. Key, and X. Wang (2008), Cloud detection with MODIS. Part I: Improvements in the MODIS cloud mask for Collection 5, J. Atmos. Oceanic Technol., 25(7), 1057-1072, doi:10.1175/ 2008JTECHA1052.1

Fromm, M. D., J. D. Lumpe, R. M. Bevilacqua, E. P. Shettle, J. Hornstein, S. T. Massie, and K. H. Fricke (1997), Observations of Antarctic polar stratospheric clouds by POAM II: 1994-1996, J. Geophys. Res., 102, 23,659-23,672, doi:10.1029/97JD00794. 
Fromm, M., J. Alfred, and M. Pitts (2003), A unified, long-term, high-latitude stratospheric aerosol and cloud database using SAM II, SAGE II, and POAM II/III data: Algorithm description, database definition, and climatology, J. Geophys. Res., 108(D12), 4366, doi:10.1029/2002JD002772.

Fujita, K., and O. Abe (2006), Stable isotopes in daily precipitation at Dome Fuji, East Antarctica, Geophys. Res. Lett., 33, L18503, doi:10.1029/2006GL026936.

Gallée, H. (1995), Simulation of the mesocyclonic activity in the Ross Sea, Antarctica, Mon. Weather Rev., 123, 2051-2069, doi:10.1175/1520-0493(1995)123<2051:SOTMAI>2.0.CO;2.

Gallée, H., and I. V. Gorodetskaya (2010), Validation of a limited area model over Dome C, Antarctic Plateau, during winter, Clim. Dyn., 34, 61-72, doi:10.1007/s00382-008-0499-y.

Gallée, H., V. Peyaud, and I. Goodwin (2005), Temporal and spatial variability of the Antarctic ice sheet surface mass balance assessed from a comparison between snow stakes measurements and regional climate modeling, Ann. Glaciol., 41, 17-22.

Garrett, T. J., and C. Zhao (2006), Increased Arctic cloud longwave emissivity associated with pollution from mid-latitudes, Nature, 440, 787-789, doi:10.1038/nature04636.

Genthon, C., and G. Krinner (1998), Convergence and disposal of energy and moisture on the Antarctic polar cap from ECMWF reanalyses and forecasts, J. Clim., 11, 1703-1716, doi:10.1175/ 1520-0442(1998)011<1703:CADOEA >2.0.CO;2.

Gettelman, A., P. Hoor, L. L. Pan, W. J. Randel, M. I. Hegglin, and T. Birner (2011), The extratropical upper troposphere and lower stratosphere, Rev. Geophys., 49, RG3003, doi:10.1029/ 2011RG000355.

Girard, E., and J.-P. Blanchet (2001), Simulation of Arctic diamond dust, ice fog and thin stratus using an explicit aerosolcloud-radiation model, J. Atmos. Sci., 58, 1181-1198, doi:10.1175/ 1520-0469(2001)058<1181:MPOADD>2.0.CO;2.

Girard, E., and J. A. Curry (2001), Simulation of Arctic low-level clouds observed during the FIRE Arctic Clouds Experiment using a new bulk microphysics scheme, J. Geophys. Res., 106, 15,139-15,154, doi:10.1029/2000JD900266.

Gordon, C. T., A. Rosati, and R. Gudgel (2000), Tropical sensitivity of a coupled model to specified ISCCP low clouds, J. Clim., 13, 2239-2260, doi:10.1175/1520-0442(2000)013<2239:TSOACM $>$ 2.0.CO;2.

Gorodetskaya, I., N. van Lipzig, M. van den Broeke, W. Boot, C. Reijmeer, A. Mangold, S. Kneifel, S. Crewell, and J. Schween (2010), Meteorological and cloud measurements at the Princess Elisabeth Belgian Antarctic Research Station, Dronning Maud Land, paper presented at the 5th Antarctic Meteorological Observation, Modeling and Forecasting Workshop, Byrd Polar Res. Cent., Ohio State Univ., Columbus, Ohio, 12-14 July. [Available at http://polarmet.osu.edu/workshops/amomfw_2010/.]

Grell, G. A., J. Dudhia, and D. R. Stauffer (1994), A description of the fifth-generation Penn State/NCAR mesoscale model (MM5), NCAR Tech. Note NCAR/TN-398+STR, 138 pp., Natl. Cent. for Atmos. Res., Boulder, Colo.

Grenier, P., J.-P. Blanchet, and R. Munoz-Alpizar (2009), Study of polar thin ice clouds and aerosols seen by CloudSat and CALIPSO during mid-winter 2007, J. Geophys. Res., 114, D09201, doi:10.1029/2008JD010927.

Grosvenor, D. P., T. W. Choularton, M. W. Gallagher, T. LachlanCope, and R. Ladkin (2010), In-situ aircraft observations of Antarctic Peninsula clouds, paper presented at the 5th Antarctic Meteorological Observation, Modeling and Forecasting Workshop, Byrd Polar Res. Cent., Ohio State Univ., Columbus, Ohio, 12-14 July. [Available at http://polarmet.osu.edu/workshops/ amomfw_2010/.]

Guo, Z., D. H. Bromwich, and J. J. Cassano (2003), Evaluation of Polar MM5 simulations of Antarctic atmospheric circulation, Mon. Weather Rev., 131, 384-411, doi:10.1175/1520-0493(2003) $131<0384$ :EOPMSO $>2.0 . \mathrm{CO} ; 2$.
Hack, J. J., B. A. Boville, B. P. Briegleb, J. T. Kiehl, P. J. Rasch, and D. L. Williamson (1993), Description of the NCAR Community Climate Model (CCM2), NCAR Tech. Note NCAR/TN-382+STR, 108 pp., Natl. Cent. for Atmos. Res., Boulder, Colo.

Hagihara, Y., H. Okamoto, and R. Yoshida (2010), Development of a combined CloudSat-CALIPSO cloud mask to show global cloud distribution, J. Geophys. Res., 115, D00H33, doi:10.1029/ 2009JD012344.

Hahn, C. J., and S. G. Warren (2003), Cloud climatology for land stations worldwide, 1971-1996, Tech. Rep. NDP-026D, Carbon Dioxide Inf. Anal. Cent., Oak Ridge, Tenn.

Hahn, C. J., S. G. Warren, and J. London (1995), The effect of moonlight on observation of cloud cover at night, and application to cloud climatology, J. Clim., 8, 1429-1446, doi:10.1175/15200442(1995)008<1429:TEOMOO > 2.0.CO;2.

Hallett, J., and S. C. Mossop (1974), Production of secondary ice particles during the riming process, Nature, 249, 26-28, doi:10.1038/249026a0.

Hara, K., T. Kikuchi, K. Furuya, M. Hayashi, and Y. Fujii (1996), Characterization of Antarctic aerosol particles using laser microprobe mass spectrometry, Environ. Sci. Technol., 30, 385-391, doi:10.1021/es9407305.

Hara, K., K. Osada, M. Yabuki, G. Hashida, T. Yamanouchi, M. Hayashi, M. Shiobara, C. Nishita, and M. Wada (2010), Haze episodes at Syowa Station, coastal Antarctica: Where did they come from?, J. Geophys. Res., 115, D14205, doi:10.1029/2009JD012582.

Harder, S., S. G. Warren, and R. J. Charlson (2000), Sulfate in air and snow at the South Pole: Implications for transport and deposition at sites with low snow accumulation, J. Geophys. Res., 105, 22,825-22,832, doi:10.1029/2000JD900351.

Hatzianastassiou, N., N. Cleridou, and I. Vardavas (2001), Polar cloud climatologies from ISCCP C2 and D2 datasets, J. Clim., 14, 3851-3862, doi:10.1175/1520-0442(2001)014<3851:PCCFIC $>$ 2.0.CO;2.

Herman, J. R., P. K. Bhartia, O. Torres, C. Hsu, C. Seftor, and E. Celarier (1997), Global distributions of UV-absorbing aerosols from Nimbus 7 TOMS data, J. Geophys. Res., 102, 16,911-16,922, doi:10.1029/96JD03680.

Hines, K. M., and D. H. Bromwich (2008), Development and testing of Polar WRF. Part I. Greenland ice sheet meteorology, Mon. Weather Rev., 136, 1971-1989, doi:10.1175/2007MWR2112.1.

Hines, K. M., D. H. Bromwich, and T. R. Parish (1995), A mesoscale modeling study of the atmospheric circulation of high southern latitudes, Mon. Weather Rev., 123, 1146-1165, doi:10.1175/1520-0493(1995)123<1146:AMMSOT>2.0.CO;2.

Hines, K. M., D. H. Bromwich, and R. I. Cullather (1997), Evaluating moist physics for Antarctic mesoscale simulations, Ann. Glaciol., 25, 282-286.

Hines, K. M., D. H. Bromwich, P. J. Rasch, and M. J. Iacono (2004), Antarctic clouds and radiation within the NCAR climate models, J. Clim., 17, 1198-1212, doi:10.1175/1520-0442(2004) 017<1198:ACARWT>2.0.CO;2.

Hines, K. M., D. H. Bromwich, L.-S. Bai, M. Barlage, and A. G. Slater (2011), Development and testing of Polar WRF. Part III. Arctic land, J. Clim., 24, 26-48, doi:10.1175/2010JCLI3460.1.

Hogan, A. W. (1986), Aerosol exchange in the remote troposphere, Tellus, Ser. B, 38, 197-213, doi:10.1111/j.1600-0889.1986. tb00187.x.

Hogan, A. W., and S. Barnard (1978), Seasonal and frontal variations in Antarctic aerosol concentrations, J. Appl. Meteorol., 17, 1458-1465, doi:10.1175/1520-0450(1978)017<1458:SAFVIA $>2.0$. $\mathrm{CO} ; 2$.

Hu, Y. (2007), Depolarization ratio-effective lidar ratio relation: Theoretical basis for space lidar cloud phase discrimination, Geophys. Res. Lett., 34, L11812, doi:10.1029/2007GL029584.

$\mathrm{Hu}$, Y., et al. (2007), The depolarizationatten-uated backscatter relation: CALIPSO lidar measurements vs. theory, Opt. Express, 15, 5327-5332, doi:10.1364/OE.15.005327. 
$\mathrm{Hu}$, Y., et al. (2009), CALIPSO/CALIOP cloud phase discrimination algorithm, J. Atmos. Oceanic Technol., 26, 2293-2309, doi:10.1175/2009JTECHA1280.1.

Hubanks, P. A., M. D. King, S. A. Platnick, and R. A. Pincus (2008), MODIS Atmosphere L3 Gridded Product, Algorithm Theor. Basis Doc. ATBD-MOD-30, NASA Goddard Space Flight Cent., Greenbelt, Md. [Available at http://modis.gsfc. nasa.gov/data/atbd/atbd_mod30.pdf.]

Ito, T. (1989), Antarctic submicron aerosols and long-range transport of pollutants, Ambio, 18, 34-41.

James, I. N. (1989), The Antarctic drainage flow: Implications for hemispheric flow on the Southern Hemisphere, Antarct. Sci., 1, 279-290, doi:10.1017/S0954102089000404.

Junge, K., and B. D. Swanson (2008), High-resolution ice nucleation spectra of sea-ice bacteria: Implications for cloud formation and life in frozen environments, Biogeosciences, 5, 865-873, doi:10.5194/bg-5-865-2008.

Kay, J. E., and A. Gettelman (2009), Cloud influence on and response to seasonal Arctic sea ice loss, J. Geophys. Res., 114, D18204, doi:10.1029/2009JD011773.

Kay, J. E., T. L'Ecuyer, A. Gettelman, G. Stephens, and C. O'Dell (2008), The contribution of cloud and radiation anomalies to the 2007 Arctic sea ice extent minimum, Geophys. Res. Lett., 35, L08503, doi:10.1029/2008GL033451.

Key, J. (2002), The Cloud and Surface Parameter Retrieval (CASPR) System for Polar AVHRR data, user's guide, technical report, Space Sci. and Eng. Cent., Madison, Wis.

Key, J., D. Santek, C. S. Velden, N. Bormann, J.-N. Thepaut, L. P. Riishojgaard, Y. Zhu, and W. P. Menzel (2003), Cloud-drift and water vapor winds in the polar regions from MODIS, IEEE Trans. Geosci. Remote Sens., 41(2), 482-492, doi:10.1109/ TGRS.2002.808238.

King, J. C., and J. Turner (1997), Antarctic Meteorology and Climatology, 409 pp., Cambridge Univ. Press, New York, doi:10.1017 CBO9780511524967.

Kirchgäßner, A. (2010), An analysis of cloud observations from Vernadsky, Antarctica, Int. J. Climatol., 30(10), 1431-1439, doi:10.1002/joc. 1998.

Klein, S. A., and D. L. Hartmann (1993), Spurious changes in the ISCCP dataset, Geophys. Res. Lett., 20(6), 455-458, doi:10.1029/93GL00211.

Kneifel, S., U. Löhnert, A. Battaglia, S. Crewell, and D. Siebler (2011), Snow scattering signals in ground-based passive microwave radiometer measurements, J. Geophys. Res., 115, D16214, doi:10.1029/2010JD013856.

Kokhanovsky, A. A., S. Planick, and M. D. King (2011), Remote sensing of terrestrial clouds from space using backscattering and thermal emission techniques, in The Remote Sensing of Tropospheric Composition from Space, edited by J. P. Burrows et al., pp. 231-257, Springer, Berlin, doi:10.1007/978-3-642-14791-3_5.

Lachlan-Cope, T. (2010), Antarctic clouds, Polar Res., 29(2), 150-158, doi:10.1111/j.1751-8369.2010.00148.x.

Lachlan-Cope, T., R. Ladkin, J. Turner, and P. Davison (2001), Observations of cloud and precipitation particles on the Avery Plateau, Antarctic Peninsula, Antarct. Sci., 13, 339-348, doi:10.1017/S0954102001000475.

Lachlan-Cope, T., W. M. Connolley, J. Turner, H. Roscoe, G. J. Marshall, S. R. Colwell, M. Hassner, and W. Ingram (2009), Antarctic winter tropospheric warming-The potential role of polar stratospheric clouds, a sensitivity study, Atmos. Sci. Lett., 10(4), 262-266, doi:10.1002/asl.237.

Lazzara, M. A., L. M. Keller, C. R. Stearns, J. E. Thom, and G. A. Weidner (2003), Antarctic satellite meteorology: Applications for weather forecasting, Mon. Weather Rev., 131, 371-383, doi:10.1175/1520-0493(2003)131<0371:ASMAFW>2.0.CO;2.

Lazzara, M. A., R. Dworak, D. Santek, C. Velden, and J. Key (2010), High latitude atmospheric motion vectors: Applications for Antarctic and Arctic composite satellite imagery, paper pre- sented at the 10th International Winds Workshop, Jpn. Meteorol. Agency, Tokyo, 22-26 Feb.

Liu, Y. H., J. R. Key, R. A. Frey, S. A. Ackerman, and W. P. Menzel (2004), Nighttime polar cloud detection with MODIS, Remote Sens. Environ., 92(2), 181-194, doi:10.1016/j.rse.2004.06.004.

Lubin, D. (1994), Infrared radiative properties of the maritime Antarctic atmosphere, J. Clim., 7, 121-140, doi:10.1175/15200442(1994)007<0121:IRPOTM>2.0.CO;2.

Lubin, D. (2004), Thermodynamic phase of maritime Antarctic clouds from FTIR and supplementary radiometric data, J. Geophys. Res., 109, D04204, doi:10.1029/2003JD003979.

Lubin, D., and J. E. Frederick (1991), The ultraviolet radiation environment of the Antarctic Peninsula: The roles of ozone and cloud cover, J. Appl. Meteorol., 30, 478-493, doi:10.1175/ 1520-0450(1991)030<0478:TUREOT $>2.0 . C O ; 2$.

Lubin, D., and D. A. Harper (1996), Cloud radiative properties over the South Pole from AVHRR infrared data, J. Clim., 9, 3405-3418, doi:10.1175/1520-0442(1996)009<3405:CRPOTS $>2.0$. $\mathrm{CO} ; 2$.

Lubin, D., and R. Massom (2006), Polar Remote Sensing, vol. 1, Atmosphere and Oceans, 756 pp., Springer, Chichester, U. K.

Lubin, D., and A. M. Vogelmann (2006), A climatologically significant aerosol longwave indirect effect in the Arctic, Nature, 439, 453-456, doi:10.1038/nature04449.

Lubin, D., B. Chen, D. H. Bromwich, R. C. J. Somerville, W.-H. Lee, and K. M. Hines (1998), The impact of Antarctic cloud radiative properties on a GCM climate simulation, J. Clim., 11(3), 447-462, doi:10.1175/1520-0442(1998)011<0447:TIOACR>2.0.CO;2.

Lubin, D., P. Ricchiazzi, A. Payton, and C. Gautier (2002), Significance of multidimensional radiative transfer effects measured in surface fluxes at an Antarctic coastline, J. Geophys. Res., 107(D19), 4387, doi:10.1029/2001JD002030.

Mace, G. G., Q. Zhang, M. Vaughan, R. Marchand, G. Stephens, C. Trepte, and D. Winker (2009), A description of hydrometeor layer occurrence statistics derived from the first year of merged Cloudsat and CALIPSO data, J. Geophys. Res., 114, D00A26, doi:10.1029/2007JD009755.

Mahesh, A., V. P. Walden, and S. G. Warren (2001a), Ground-based infrared remote sensing of cloud properties over the Antarctic Plateau. Part I: Cloud-base heights, J. Appl. Meteorol., 40(7), 1265-1278, doi:10.1175/1520-0450(2001)040<1265: GBIRSO $>2.0 . \mathrm{CO} ; 2$.

Mahesh, A., V. P. Walden, and S. G. Warren (2001b), Groundbased infrared remote sensing of cloud properties over the Antarctic Plateau. Part II: Cloud optical depths and particle sizes, J. Appl. Meteorol., 40(7), 1279-1294, doi:10.1175/1520-0450 (2001)040<1279:GBIRSO $>2.0$. CO 2 .

Mahesh, A., M. A. Gray, S. P. Palm, W. D. Hart, and J. D. Spinhirne (2004), Passive and active detection of clouds: Comparisons between MODIS and GLAS observations, Geophys. Res. Lett., 31, L04108, doi:10.1029/2003GL018859.

Mahesh, A., J. R. Campbell, and J. D. Spinhirne (2005), Multiyear measurements of cloud base heights at South Pole by lidar, Geophys. Res. Lett., 32, L09812, doi:10.1029/2004GL021983.

Massom, R. A., and D. Lubin (2006), Polar Remote Sensing, vol. 2, Ice Sheets, 426 pp., Springer, Chichester, U. K.

Massom, R. A., M. J. Pook, J. C. Comiso, N. Adams, J. Turner, T. Lachlan-Cope, and T. T. Gibson (2004), Precipitation over the interior East Antarctic Ice Sheet related to midlatitude blocking-high activity, J. Clim., 17, 1914-1928, doi:10.1175/ 1520-0442(2004)017<1914:POTIEA>2.0.CO;2.

Masson-Delmotte, V., et al. (2008), A review of antarctic surface snow isotopic composition: Observations, atmospheric circulation, and isotopic modeling, J. Clim., 21, 3359-3387, doi:10.1175/ 2007JCLI2139.1.

McCarthy, M. P., G. Hernandez, A. Mactutis, and J. A. Moore (2007), Validation of an 8-14 $\mu$ m cloud monitor using visual observations of Antarctic cloud cover, Appl. Opt., 46, 2091-2098, doi:10.1364/AO.46.002091. 
McConnell, J. R., A. J. Aristarain, J. R. Banta, P. R. Edwards, and J. C. Simões (2007), 20th-century doubling in dust archived in an Antarctic Peninsula ice core parallels climate change and desertification in South America, Proc. Natl. Acad. Sci. U. S. A., 104, 5743-5748, doi:10.1073/pnas.0607657104.

McFarquhar, G. M., et al. (2011), Indirect and Semi-Direct Aerosol Campaign (ISDAC): The impact of arctic aerosols on clouds, Bull. Am. Meteorol. Soc., 92, 183-201, doi:10.1175/ 2010BAMS2935.1.

McInnes, L., D. Covert, and D. Baker (1997), The number of seasalt, sulfate, and carbonaceous particles in the marine atmosphere: EM measurements consistent with ambient size distribution, Tellus, Ser. B, 49, 300-313, doi:10.1034/j.1600-0889.49. issue3.6.x.

Meier, W. N., J. A. Maslanik, C. W. Fowler, and J. R. Key (1997), Multiparameter AVHRR-derived products for Arctic climate studies, Earth Interact., 1(5), 1-29, doi:10.1175/1087-3562 (1997)001<0001:MADPFA>2.3.CO;2.

Meyers, M. P., P. J. DeMott, and W. R. Cotton (1992), New primary ice-nucleation parameterizations in an explicit cloud model, J. Appl. Meteorol., 31, 708-721, doi:10.1175/15200450(1992)031<0708:NPINPI >2.0.CO;2.

Monaghan, A. J., et al. (2006), Insignificant change in Antarctic snowfall since the International Geophysical Year, Science, 313, 827-831, doi:10.1126/science.1128243.

Monaghan, A. J., D. H. Bromwich, and D. P. Schneider (2008), 20th Century Antarctic air temperature and snowfall simulations by IPCC climate models, Geophys. Res. Lett., 35, L07502, doi:10.1029/2007GL032630.

Morley, B. M., E. E. Uthe, and W. Viezee (1989), Airborne lidar observations of clouds in the Antarctic troposphere, Geophys. Res. Lett., 16(6), 491-494, doi:10.1029/GL016i006p00491.

Morrison, H., and W. W. Grabowski (2007), Comparison of bulk and bin warm-rain microphysics models using a kinematic framework, J. Atmos. Sci., 64, 2839-2861, doi:10.1175/ JAS3980.

Morrison, H., J. A. Curry, and V. I. Khvorostyanov (2005), A new double-moment microphysics parameterization for application in cloud and climate models. Part I: Description, J. Atmos. Sci., 62, 1665-1677, doi:10.1175/JAS3446.1.

Morrison, H., J. O. Pinto, J. A. Curry, and G. M. McFarquhar (2008), Sensitivity of arctic mixed-phase stratocumulus to cloud condensation and ice nuclei over regionally varying surface conditions, J. Geophys. Res., 113, D05203, doi:10.1029/ 2007JD008729.

Morrison, H., G. Thompson, and V. Tatarskii (2009), Impact of cloud microphysics on the development of trailing stratiform precipitation in a simulated squall line: Comparison of one- and two-moment schemes, Mon. Weather Rev., 137, 991-1007, doi:10.1175/2008MWR2556.1.

Naithani, J., H. Gallee, and G. Schayes (2002), Marine air intrusion into the Adelie Land sector of East Antarctica: A study using the regional climate model (MAR), J. Geophys. Res., 107(D11), 4124, doi:10.1029/2000JD000274.

Nardino, M., and T. Georgiadis (2003), Cloud type and cloud cover effects on the surface radiative balance at several Polar sites, Theor. Appl. Climatol., 74, 203-215, doi:10.1007/ s00704-002-0708-2.

Naud, C., J. P. Muller, and P. de Valk (2005), On the use of ICESAT-GLAS measurements for MODIS and SEVIRI cloudtop height accuracy assessment, Geophys. Res. Lett., 32, L19815, doi:10.1029/2005GL023275.

Nichol, S. E., G. Pfister, G. E. Bodeker, R. L. McKenzie, and S. W. Wood (2003), Moderation of cloud reduction of UV in the Antarctic due to high surface albedo, J. Appl. Meteorol., 42, 1174-1183, doi:10.1175/1520-0450(2003)042<1174: MOCROU $>2.0 . C O ; 2$.
Nicolas, J. P., and D. H. Bromwich (2011), Climate of West Antarctica and influence of marine air intrusions, J. Clim., 24, 49-67, doi:10.1175/2010JCLI3522.1.

Noel, V., A. Hertzog, H. Chepfer, and D. M. Winker (2008), Polar stratospheric clouds over Antarctica from the CALIPSO spaceborne lidar, J. Geophys. Res., 113, D02205, doi:10.1029/ 2007JD008616.

Ohmura, A., et al. (1998), Baseline Surface Radiation Network: New precision radiometry for climate research, Bull. Am. Meteorol. Soc., 79, 2115-2136, doi:10.1175/1520-0477(1998) $079<2115$ :BSRNBW $>2.0$. CO 2 .

Palm, S. P., M. Fromm, and J. Spinhirne (2005), Observations of antarctic polar stratospheric clouds by the Geoscience Laser Altimeter System (GLAS), Geophys. Res. Lett., 32, L22S04, doi:10.1029/2005GL023524.

Pant, V., D. Siingh, and A. K. Kamra (2010), Concentrations and size distributions of aerosol particles at Maitri during the passage of cyclonic storms revolving around the continent of Antarctica, J. Geophys. Res., 115, D17202, doi:10.1029/2009JD013481.

Parish, T. R., and D. H. Bromwich (1991), Continental-scale simulation of the Antarctic katabatic wind regime, J. Clim., 4, 135-146, doi:10.1175/1520-0442(1991)004<0135:CSSOTA >2.0.CO;2.

Parish, T. R., and D. H. Bromwich (2007), Re-examination of the near-surface air flow over the Antarctic continent and implications on atmospheric circulations at high southern latitudes, Mon. Weather Rev., 135, 1961-1973, doi:10.1175/MWR3374.1.

Park, J., H. Sakurai, K. Vollmers, and P. H. McMurry (2004), Aerosol size distributions measured at the South Pole during ISCAT, Atmos. Environ., 38, 5493-5500, doi:10.1016/j.atmosenv. 2002.12.001.

Parol, F., et al. (2004), Review of capabilities of multi-angle and polarization cloud measurements from POLDER, Adv. Space Res., 33, 1080-1088, doi:10.1016/S0273-1177(03)00734-8.

Pavolonis, M. J., and J. R. Key (2003), Antarctic cloud radiative forcing at the surface estimated from the AVHRR Polar Pathfinder and ISCCP D1 datasets, 1985-1993, J. Appl. Meteorol., 42, 827-840, doi:10.1175/1520-0450(2003)042<0827: ACRFAT $>2.0 . \mathrm{CO} ; 2$.

Pavolonis, M. J., J. R. Key, and J. J. Cassano (2004), A study of the Antarctic surface energy budget using a polar regional atmospheric model forced with satellite-derived cloud properties, Mon. Weather Rev., 132, 654-661, doi:10.1175/1520-0493 (2004) $132<0654$ :ASOTAS $>2.0 . C O ; 2$.

Philips, V. T. J., L. J. Donner, and S. T. Garner (2007), Nucleation processes in deep convection simulated by a cloud-systemresolving model with double moment bulk microphysics, J. Atmos. Sci., 64, 738-761, doi:10.1175/JAS3869.1.

Pitts, M. C., L. W. Thomason, L. R. Poole, and D. M. Winker (2007), Characterization of polar stratospheric clouds with space-borne lidar: CALIPSO and the 2006 Antarctic season, Atmos. Chem. Phys. Discuss., 7(3), 7933-7985, doi:10.5194/ acpd-7-7933-2007.

Pook, M., and L. Cowled (1999), On the detection of weather systems over the Antarctic interior in the FROST analyses, Weather Forecast., 14, 920-929, doi:10.1175/1520-0434(1999) 014<0920:OTDOWS $>2.0 . \mathrm{CO} ; 2$.

Poole, L. R., and M. C. Pitts (1994), Polar stratospheric cloud climatology based on Stratospheric Aerosol Measurement II observations from 1978 to 1989, J. Geophys. Res., 99, 13,083-13,089, doi:10.1029/94JD00411.

Powers, J. G., A. J. Monaghan, A. M. Cayette, D. H. Bromwich, Y.-H. Kuo, and K. W. Manning (2003), Real-time mesoscale modeling over Antarctica: The Antarctic Mesoscale Prediction System (AMPS), Bull. Am. Meteorol. Soc., 84, 1533-1545, doi:10.1175/BAMS-84-11-1533.

Prenni, A. J., J. Y. Harrington, M. Tjernström, P. J. DeMott, A. Avramov, C. N. Long, S. M. Kreidenweis, P. Q. Olsson, 
and J. Verlinde (2007), Can ice-nucleating aerosols affect Arctic seasonal climate?, Bull. Am. Meteorol. Soc., 88, 541-550, doi:10.1175/BAMS-88-4-541.

Randall, D. A., J. Curry, D. Battisti, G. Flato, R. Grumbine, S. Hakkinen, D. Martinson, R. Preller, J. Walsh, and J. Weatherly (1998), Status of and outlook for large-scale modeling of atmosphere-ice-ocean interactions in the Arctic, Bull. Am. Meteorol. Soc., 79, 197-219, doi:10.1175/1520-0477(1998)079<0197: SOAOFL $>2.0 . \mathrm{CO} ; 2$.

Randall, D. A., et al. (2007), Climate models and their evaluation, in Climate Change 2007: The Physical Science Basis. Contribution of the Working Group I to the Fourth Assessment of the Intergovernmental Panel on Climate Change, edited by S. Solomon et al., pp. 589-662, Cambridge Univ. Press, Cambridge, U. K.

Rankin, A. M., and E. W. Wolff (2002), Aerosol profiling using a tethered balloon in coastal Antarctica, J. Atmos. Oceanic Technol., 19, 1978-1985, doi:10.1175/1520-0426(2002)019<1978: APUATB $>2.0 . \mathrm{CO} ; 2$.

Rasch, P. J., and J. E. Kristiansson (1998), A comparison of the CCM3 model climate using diagnosed and predicted condensate parameterizations, J. Clim., 11, 1587-1614, doi:10.1175/15200442(1998)011<1587:ACOTCM >2.0.CO;2.

Reisner, J., J. R. Rasmussen, and R. T. Bruintjes (1998), Explicit forecasting of supercooled liquid water in winter storms using the MM5 mesoscale model, Q. J. R. Meteorol. Soc., 124, 1071-1107, doi:10.1002/qj.49712454804.

Ricchiazzi, P., C. Gautier, and D. Lubin (1995), Cloud scattering optical depth and local surface albedo in the Antarctic: Simultaneous retrieval using ground-based radiometry, J. Geophys. Res., 100, 21,091-21,104, doi:10.1029/95JD01461.

Rossow, W. B., and E. N. Duenas (2004), The International Satellite Cloud Climatology Project (ISCCP) web site: An online resource for research, Bull. Am. Meteorol. Soc., 85(2), 167-172, doi:10.1175/BAMS-85-2-167.

Rossow, W. B., and L. C. Garder (1993), Cloud detection using satellite measurements of infrared and visible radiances for ISCCP, J. Clim., 6, 2341-2369, doi:10.1175/1520-0442(1993) 006<2341:CDUSMO $>2.0$. CO $;$.

Rossow, W. B., and R. A. Schiffer (1999), Advances in understanding clouds from ISCCP, Bull. Am. Meteorol. Soc., 64, 779-784.

Saitoh, N., S. Hayashida, Y. Sasano, and L. L. Pan (2002), Characteristics of Arctic polar stratospheric clouds in the winter of 1996/1997 inferred from ILAS measurements, J. Geophys. Res., 107(D24), 8205, doi:10.1029/2001JD000595.

Sassen, K. (1991), The polarization lidar technique for cloud research: A review and current assessment, Bull. Am. Meteorol. Soc., 72, 1848-1866, doi:10.1175/1520-0477(1991)072<1848: TPLTFC $>2.0 . \mathrm{CO} ; 2$

Savoie, D. L., J. M. Prospero, R. J. Larsen, F. Huang, M. A. Izaguirre, T. Huang, T. H. Snowdon, L. Custals, and C. G. Sanderson (1993), Nitrogen and sulfur species in Antarctic aerosols at Mawson, Palmer Station and Marsh (King George Island), J. Atmos. Chem., 17, 95-122, doi:10.1007/BF00702821.

Saxena, V. K. (1983), Evidence of the biological nuclei involvement in Antarctic coastal clouds, J. Phys. Chem., 87, 4130-4134, doi:10.1021/j100244a029.

Saxena, V. K. (1996), Bursts of cloud condensation nuclei (CCN) by dissipating clouds at Palmer Station, Antarctica, Geophys. Res. Lett., 23, 69-72, doi:10.1029/95GL03588.

Saxena, V. K., and F. H. Ruggiero (1990a), Aerosol measurements at Palmer Station, Antarctica, in Contributions to Antarctic Research I, Antarct. Res. Ser., vol. 50, edited by D. H. Elliot, pp. 1-5, AGU, Washington, D. C.

Saxena, V. K., and F. H. Ruggiero (1990b), Antarctic coastal stratus clouds: Microstructure and acidity, in Contributions to Antarctic Research, Antarct. Res. Ser., vol. 50, edited by D. H. Elliot, pp. 7-18, AGU, Washington, D. C.
Saxena, V. K., and D. C. Weintraub (1988), Ice forming nuclei concentrations at Palmer Station, Antarctica, in Atmospheric Aerosols and Nucleation, edited by P. E. Wagner and G. Vali, Lect. Notes Phys., 309, 679-682, doi:10.1007/3-540-50108-8 1158.

Schiffer, R. A., and W. Rossow (1983), The International Satellite Cloud Climatology Project (ISCCP): The first project of the World Climate Research Programme, Bull. Am. Meteorol. Soc., 64, 779-784.

Schiffer, R. A., and W. B. Rossow (1985), ISCCP global radiance data set: A new resource for climate research, Bull. Am. Meteorol. Soc., 66, 1498-1505, doi:10.1175/1520-0477(1985) 066<1498:IGRDSA $>2.0$. CO; 2 .

Schwerdtfeger, W. (1970), The climate of the Antarctic, in Climates of the Polar Regions, World Surv. Climatol., vol. 14 edited by S. Orvig, pp. 253-355, Elsevier, New York.

Shaw, G. E. (1988), Antarctic aerosols: A review, Rev. Geophys., 26, 89-112, doi:10.1029/RG026i001p00089.

Shibata, K., and M. Chiba (1990), Effects of radiation scheme on the surface temperature and wind over the Antarctic and on circumpolar lows, Proc. NIPR Symp. Polar Meteorol. Glaciol., 3, 58-78.

Shiobara, M., M. Yabuki, and H. Kobayasi (2003), A polar cloud analysis based on Micro-pulse Lidar measurements at NyAlesund, Svalbard and Syowa, Antarctica, Phys. Chem. Earth, $28,1205-1212$.

Simmonds, I., K. Keay, and E. Lim (2003), Synoptic activity in the seas around Antarctica, Mon. Weather Rev., 131, 272-288, doi:10.1175/1520-0493(2003)131<0272:SAITSA>2.0.CO;2.

Slingo, A. (1989), A GCM parameterization for the shortwave radiative properties of water clouds, J. Atmos. Sci., 46, 1419-1427, doi:10.1175/1520-0469(1989)046<1419: AGPFTS $>2.0 . \mathrm{CO} ; 2$.

Smiley, V. N., and B. M. Morley (1981), Lidar depolarization studies of the atmosphere at the South Pole, Appl. Opt., 20, 2189-2195, doi:10.1364/AO.20.002189.

Solomon, S., D. Qin, M. Manning, Z. Chen, M. Marquis, K. B. Averyt, M. Tignor, and H. L. Miller (Eds.) (2007), Climate Change 2007: The Physical Science Basis. Contribution of Working Group I to the Fourth Assessment Report on the Intergovernmental Panel on Climate Change, Cambridge Univ. Press, Cambridge, U. K.

Souza-Echer, M. P., E. G. Pereira, L. S. Bins, and M. A. R. Andrade (2006), A simple method for the assessment of the cloud cover state in high-latitude regions by a ground-based digital camera, J. Atmos. Oceanic Technol., 23, 437-447, doi:10.1175/JTECH1833.1.

Spinhirne, J. D., S. P. Palm, W. D. Hart, D. L. Hlavka, and E. J. Welton (2005a), Cloud and aerosol measurements from GLAS: Overview and initial results, Geophys. Res. Lett., 32, L22S03, doi:10.1029/2005GL023507.

Spinhirne, J. D., S. P. Palm, and W. D. Hart (2005b), Antarctica cloud cover for October 2003 from GLAS satellite lidar profiling, Geophys. Res. Lett., 32, L22S05, doi:10.1029/ 2005GL023782.

Stajner, I., C. Benson, H.-C. Liu, S. Pawson, N. Brubaker, L.-P. Chang, L. P. Riishojgaard, and R. Todling (2007), Ice polar stratospheric clouds detected from assimilation of Atmospheric Infrared Sounder data, Geophys. Res. Lett., 34, L16802, doi:10.1029/2007GL029415.

Stammerjohn, S. E., D. G. Martinson, R. C. Smith, X. Yuan, and D. Rind (2008), Trends in Antarctic annual sea ice retreat and advance and their relation to El Nino-Southern Oscillation and Southern Annular Mode variability, J. Geophys. Res., 113, C03S90, doi:10.1029/2007JC004269.

Stamnes, K., J. Slusser, M. Bowen, C. Booth, and T. Lucas (1990), Biologically effective ultraviolet radiation, total ozone abundance and cloud optical depth at McMurdo Station, Antarctica, 
September 15, 1988 through April 15, 1989, Geophys. Res. Lett., 17, 2181-2184, doi:10.1029/GL017i012p02181.

Stensrud, D. J. (2009), Parameterization Schemes: Keys to Understanding Numerical Weather Prediction Models, Cambridge Univ. Press, Cambridge, U. K.

Stephens, G. L. (2005), Cloud feedbacks in the climate system: A critical review, J. Clim., 18, 237-273, doi:10.1175/JCLI-3243.1.

Stephens, G. L., and C. D. Kummerow (2007), The remote sensing of clouds and precipitation from space: A review, J. Atmos. Sci., 64, 3742-3765, doi:10.1175/2006JAS2375.1.

Stephens, G. L., et al. (2002), The CloudSat mission and the A-TRAIN: A new dimension to space-based observations of clouds and precipitation, Bull. Am. Meteorol. Soc., 83, 1771-1790, doi:10.1175/BAMS-83-12-1771.

Stone, R. S. (1993), Properties of austral winter clouds derived from radiometric profiles at the South Pole, J. Geophys. Res., 98, 12,961-12,971, doi:10.1029/92JD02213.

Szyrmer, W., and I. Zawadzki (1997), Biogenic and anthropogenic sources of ice-forming nuclei: A review, Bull. Am. Meteorol. Soc., 78, 209-228, doi:10.1175/1520-0477(1997)078<0209: BAASOI $>2.0 . \mathrm{CO} ; 2$.

Thomas, S. M., A. K. Heidinger, and M. J. Pavolonis (2004), Comparison of NOAA's operational AVHRR-derived cloud amount to other satellite-derived cloud climatologies, J. Clim., 17, 4805-4822, doi:10.1175/JCLI-3242.1.

Thompson, G., P. R. Field, R. M. Rasmussen, and W. D. Hall (2008), Explicit forecasts of winter precipitation using an improved bulk microphysics scheme. Part II: Implementation of a new snow parameterization, Mon. Weather Rev., 136, 5095-5115, doi:10.1175/2008MWR2387.1.

Tietäväinen, H., and T. Vihma (2008), Atmospheric moisture budget over Antarctica and the Southern Ocean based on the ERA-40 reanalysis, Int. J. Climatol., 28, 1977-1995, doi:10.1002/joc. 1684 .

Town, M. S., V. P. Walden, and S. G. Warren (2005), Spectral and broadband longwave downwelling radiative fluxes, cloud radiative forcing, and fractional cloud cover over the South Pole, J. Clim., 18, 4235-4252, doi:10.1175/JCLI3525.1.

Town, M. S., V. P. Walden, and S. G. Warren (2007), Cloud cover over the South Pole from visual observations, satellite retrievals, and surface-based infrared radiation measurements, J. Clim., 20, 544-559, doi:10.1175/JCLI4005.1.

Turner, J., and S. Pendlebury (Eds.) (2004), The International Antarctic Weather Forecasting Handbook, Br. Antarc. Surv., Cambridge, U. K.

Turner, J., G. J. Marshall, and R. S. Ladkin (2001), An operational, real-time cloud detection scheme for use in the Antarctic based on AVHRR data, Int. J. Remote Sens., 22, 3027-3046.

Turner, J., T. A. Lachlan-Cope, S. Colwell, G. J. Marshall, and W. M. Connolley (2006), Significant warming of the Antarctic winter troposphere, Science, 311, 1914-1917, doi:10.1126/science. 1121652.

Tzeng, R.-Y., D. H. Bromwich, and T. R. Parish (1993), Presentday Antarctic climatology of the NCAR Community Climate Model Version 1, J. Clim., 6, 205-226, doi:10.1175/1520-0442 (1993)006<0205:PDACOT $>2.0 . C O ; 2$.

Tzeng, R.-Y., D. H. Bromwich, T. R. Parish, and B. Chen (1994), NCAR CCM2 simulation of the modern Antarctic climate, J. Geophys. Res., 99, 23,131-23,148, doi:10.1029/94JD02156.

Uttal, T., et al. (2002), Surface heat budget of the Arctic Ocean, Bull. Am. Meteorol. Soc., 83, 255-275, doi:10.1175/1520-0477 (2002) $083<0255$ :SHBOTA $>2.3 . C O ; 2$.

Vallina, S. M., R. Simó, and S. Gassó (2006), What controls CCN seasonality in the Southern Ocean? A statistical analysis based on satellite-derived chlorophyll and CCN and model-estimated $\mathrm{OH}$ radical and rainfall, Global Biogeochem. Cycles, 20, GB1014, doi:10.1029/2005GB002597.

van de Berg, W. J., M. R. van den Broeke, C. H. Reijmer, and E. van Meijgaard (2006), Reassessment of the Antarctic surface mass balance using calibrated output of a regional atmospheric climate model, J. Geophys. Res., 111, D11104, doi:10.1029/ 2005JD006495.

van den Broeke, M. R. (2000), The semi-annual oscillation and Antarctic climate. Part 3: The role of near-surface wind speed and cloudiness, Int. J. Climatol., 20, 117-130, doi:10.1002/ (SICI)1097-0088(200002)20:2<117::AID-JOC481>3.0.CO;2-B.

Vavrus, S., D. Waliser, A. Schweiger, and J. Francis (2009), Simulations of 20th and 21 st century Arctic cloud amount in the global climate models assessed in the IPCC AR4, Clim. Dyn., 33, 1099-1115, doi:10.1007/s00382-008-0475-6.

Verlinde, J., et al. (2007), The Mixed-Phase Arctic Cloud Experiment (M-PACE), Bull. Am. Meteorol. Soc., 88, 205-221, doi:10.1175/BAMS-88-2-205.

Verlinden, K. L., D. W. J. Thompson, and G. L. Stephens (2011), The three-dimensional distribution of clouds over the Southern Hemisphere high latitudes, J. Clim., 24, 5799-5811, doi:10.1175/2011JCLI3922.1.

Wagenbach, D., U. Görlach, K. Moser, and K. O. Münnich (1988), Coastal Antarctic aerosol: The seasonal pattern of its chemical composition and radionuclide content, Tellus, Ser. B, 40, 426-436, doi:10.1111/j.1600-0889.1988.tb00114.x.

Walden, V. P., et al. (2001), The South Pole atmospheric radiation and cloud lidar experiment (SPARCLE), paper presented at Sixth Conference on Polar Meteorology and Oceanography, Am. Meteorol. Soc., San Diego, Calif.

Walden, V. P., S. G. Warren, and E. Tuttle (2003), Atmospheric ice crystals over the Antarctic Plateau in winter, J. Appl. Meteorol., 42(10), 1391-1405, doi:10.1175/1520-0450(2003) 042<1391:AICOTA $>2.0 . \mathrm{CO} ; 2$.

Wang, X., and J. R. Key (2005), Arctic surface, cloud, and radiation properties based on the AVHRR Polar Pathfinder dataset. Part I: Spatial and temporal characteristics, J. Clim., 18, 2558-2574, doi:10.1175/JCLI3438.1.

Wang, Z., G. Stephens, T. Deshler, C. Trepte, T. Parish, D. Vane, D. Winker, D. Liu, and L. Adhikari (2008), Association of Antarctic polar stratospheric cloud formation on tropospheric cloud systems, Geophys. Res. Lett., 35, L13806, doi:10.1029/ 2008 GL034209.

Warren, S., C. J. Hahn, J. London, R. M. Chervin, and R. L. Jenne (1986), Global distribution of total cloud cover and cloud type amounts over land, NCAR Tech. Note TN-273+STR, Natl. Cent. for Atmos. Res., Boulder, Colo.

Warren, S., C. J. Hahn, J. London, R. M. Chervin, and R. L. Jenne (1988), Global distribution of total cloud cover and cloud type amounts over the ocean, NCAR Tech. Note TN-317+STR, Natl. Cent. for Atmos. Res., Boulder, Colo., doi:10.2172/5415329.

Wild, M., B. Trüssel, A. Ohmura, C. N. Long, G. König-Langlo, E. G. Dutton, and A. Tsvetkov (2009), Global dimming and brightening: An update beyond 2000, J. Geophys. Res., 114, D00D13, doi:10.1029/2008JD011382.

Williams, R. N., K. J. Michael, S. Pendlebury, and P. Crowther (2002), An automated image analysis system for determining sea-ice concentration and cloud cover from AVHRR images of the Antarctic, Int. J. Remote Sens., 23, 611-625, doi:10.1080/ 01431160010025989.

Williamson, D. L., J. T. Kiehl, V. Ramanathan, R. E. Dickinson, and J. J. Hack (1987), Description of NCAR Community Climate Model (CCM1), NCAR Tech. Note NCAR/TN-285+STR, 112 pp., Natl. Cent. for Atmos. Res., Boulder, Colo.

Winker, D. M., W. H. Hunt, and M. J. McGill (2007), Initial performance assessment of CALIOP, Geophys. Res. Lett., 34, L19803, doi:10.1029/2007GL030135.

Winker, D. M., M. A. Vaughan, A. Omar, Y. Hu, K. A. Powell, Z. Liu, W. H. Hunt, and S. A. Young (2009), Overview of the CALIPSO mission and CALIOP data processing algorithms, J. Atmos. Oceanic Technol., 26(11), 2310-2323, doi:10.1175/ 2009JTECHA1281.1. 
Winker, D. M., et al. (2010), The CALIPSO mission: A global $3 \mathrm{D}$ view of aerosols and clouds, Bull. Am. Meteorol. Soc., 91, 1211-1229, doi:10.1175/2010BAMS3009.1.

World Meteorological Organization (1995), Manual on codes: International codes, vol. I.1, WMO 306, Geneva, Switzerland.

Wylie, D., D. L. Jackson, W. P. Menzel, and J. J. Bates (2005), Trends in global cloud cover in two decades of HIRS observations, J. Clim., 18, 3021-3031, doi:10.1175/JCLI3461.1.

Wyser, K., and C. G. Jones (2005), Modeled and observed clouds during Surface Heat Budget of the Arctic Ocean (SHEBA), J. Geophys. Res., 110, D09207, doi:10.1029/2004JD004751.

Yamanouchi, T., and Y. Shudou (2007), Trends in cloud amount and radiative fluxes at Syowa Station, Antarctica, Polar Sci., 1(1), 17-23, doi:10.1016/j.polar.2007.04.001.

Yamanouchi, T., K. Suzuki, and S. Kawaguchi (1987), Detection of clouds in Antarctica from infrared multispectral data of AVHRR, J. Meteorol. Soc. Jpn., 65, 949-962.

Yamanouchi, T., N. Hirasawa, G. Kadosaki, and M. Hayashi (2000), Evaluation of AVHRR cloud detection at Dome Fuji Station, Antarctica, Polar Meteorol. Glaciol., 14, 100-116.

Yoshida, R., H. Okamoto, Y. Hagihara, and H. Ishimoto (2010), Global analysis of cloud phase and ice crystal orientation from Cloud-Aerosol Lidar and Infrared Pathfinder Satellite Observation (CALIPSO) data using attenuated backscattering and depolarization ratio, J. Geophys. Res., 115, D00H32, doi:10.1029/ 2009JD012334.

Zinner, T., A. Marshak, S. Lang, J. V. Martins, and B. Mayor (2008), Remote sensing of cloud sides of deep convection: Towards a three-dimensional retrieval of cloud particle size pro- files, Atmos. Chem. Phys. Discuss., 8, 4267-4308, doi:10.5194/ acpd-8-4267-2008.

Zwally, H. J., et al. (2002), ICESat's laser measurements of polar ice, atmosphere, ocean and land, J. Geodyn., 34, 405-445, doi:10.1016/S0264-3707(02)00042-X.

D. H. Bromwich, K. M. Hines, and J. P. Nicolas, Polar Meteorology Group, Byrd Polar Research Center, Ohio State University, 1090 Carmack Rd., 108 Scott Hall, Columbus, OH 43210, USA. (bromwich.1@osu.edu)

I. V. Gorodetskaya and N. P. M. van Lipzig, Department of Earth and Environmental Sciences, K.U. Leuven, Celestijnenlaan 200E, Heverlee B-3001, Belgium.

D. P. Grosvenor, Centre for Atmospheric Science, SEAES, University of Manchester, Oxford Road, Manchester M13 9PL, UK.

J. E. Kay, Climate and Global Dynamics Division, National Center for Atmospheric Research, PO Box 3000, Boulder, CO 80307-3000, USA.

E. L. Key, Arctic Division, Office of Polar Programs, National Science Foundation, 4201 Wilson Blvd., Arlington, VA 22230, USA

T. Lachlan-Cope, British Antarctic Survey, High Cross, Madingley Road, Cambridge CB3 OET, UK.

M. A. Lazzara, Antarctic Meteorological Research Center, Space Science and Engineering Center, University of Wisconsin-Madison, 1225 W. Dayton St., Madison, WI 53706, USA.

D. Lubin, Scripps Institution of Oceanography, University of California, San Diego, 9500 Gilman Dr., La Jolla, CA 92093-0221, USA.

G. M. McFarquhar, Department of Atmospheric Sciences, University of Illinois at Urbana-Champaign, 105 S. Gregory St., Urbana, IL 61801-3070, USA. 